Cálculo de reputação em redes sociais a partir de dados da colaboração entre os participantes

Edith Zaida Sonco Mamani

\author{
DisSERTAÇÃO APRESENTADA \\ $\mathrm{AO}$ \\ Instituto DE MATEMÁticA E EstatísticA \\ DA \\ Universidade DE SÃo PaUlo \\ PARA \\ OBTENÇÃO DO TÍTULO \\ DE \\ Mestre EM CiÊnCIAS \\ Programa: Ciência da Computação \\ Orientador: Prof. Dr. Marco Aurélio Gerosa
}

São Paulo, fevereiro de 2013 


\section{Cálculo de reputação em redes sociais a partir de dados da colaboração entre os participantes}

Esta versão da dissertação contém as correções e alterações sugeridas pela Comissão Julgadora durante a defesa da versão original do trabalho, realizada em 03/12/2012. Uma cópia da versão original está disponível no

Instituto de Matemática e Estatística da Universidade de São Paulo.

Comissão Julgadora:

- Prof. Dr. Marco Aurélio Gerosa (orientador) - IME-USP

- Prof. Dr. Alfredo Goldman Vel Lejbman - IME-USP

- Prof. Dr. Celso Massaki Hirata - ITA 
Dedico este trabalho a meus queridos pais Andres e Guillermina. Muito obrigada pelo amor e por sua companhia durante toda minha vida. 


\section{Agradecimentos}

Agradeço a todos que participaram dessa minha trajetória no IME. Tenho certeza que esse trabalho não teria sido possível sem o apoio desses amigos, da minha família e de todos aqueles que ao longo do caminho, ajudaram na realização dos meus objetivos. Quero deixar os meus sinceros agradecimentos a essas pessoas.

Um profundo agradecimento ao meu orientador Marco Gerosa. Ele me deu a grande oportunidade de estudar no estrangeiro, muito obrigada orientador por compreender os meus momentos de fraqueza e por dar-me a liberdade intelectual para prosseguir com os meus interesses e por fornecer o incentivo e orientação ao longo da vida deste trabalho. Agradeço aos meus parceiros de trabalho da equipe GW pelo apoio: Straus, Lucas, Carlos H. e Alfonso. Muito obrigada pelo incentivo e pela confiança. Muito obrigada ao Prof. Alfredo, quem ainda sem ser meu orientador sempre estava ali.

Muito obrigada aos meus amigos e colegas do IME: Edwin T., Edwin D., Erika, Glaucus, Carlos A. e Ana Paula, que fora de casa eles foram como minha família.

A Jesus Mena pela orientação antes e durante o mestrado, seus conselhos e dicas me ajudaram muito, especialmente para conseguir superar cada problema que se presentava. Nunca esquecerei a sua ajuda e generosidade no natal do meu primeiro ano no Brasil, elas trouxeram tranquilidade, felicidade e alegria nessas férias.

A toda minha família, que fora da tristeza de ficar longe de casa, eles me deram a força e coragem para seguir com os meus sonhos. Este trabalho não seria possível sem o carinho de aqueles que sempre me apoiaram. Aos meus queridos irmãos Gilbert, Edgar, Yanet e Jhonny por compreender-me a vida toda. Aos meus sobrinhos Rebeka, Samuel, Steve, Belen, Alexandra, Patricia e Camila, por ser a alegria da família. A minhas cunhadas Estela e Melissa, por ficar sempre pendentes dos meus queridos pais na minha ausência.

Um agradecimento muito especial ao meu querido Alvarito, sem ele as longas horas de estudo no IME ficariam ainda mais longas, obrigada pelo carinho e apoio nos meus momentos de saudade e pelos momentos mas felizes da minha vida.

Com muito amor, muito obrigada aos meus queridos pais, Andres Sonco Ochochoque e Guillermina Mamani de Sonco, por dar-me o presente mais valioso, uma vida em companhia deles, que na simplicidade e na limitação investiram na minha educação e na de meus irmãos e nos ensinaram o valor de cada coisa, material e espiritual. Sem vocês nada seria. 
A Deus, que sempre esteve com a gente em cada viagem e em cada momento de nossa vida. Muito obrigada Deus por dar fortaleza especialmente nos momentos de solidão. 


\title{
Resumo
}

\author{
MAMANI, E. Z. S. Cálculo de reputação em redes sociais a partir da colaboração entre \\ os participantes. 2013. 93 f. Dissertação de Mestrado - Instituto de Matemática e Estatística, \\ Universidade de São Paulo, São Paulo, 2013.
}

Na Web 2.0 são encontrados sistemas com alto volume de interação social. Alguns desses sistemas oferecem cálculo de reputação ou alguma forma de classificação de usuários ou do conteúdo compartilhado. Contudo, em muitos casos, esse valor de reputação resultante é obtido somente a partir de dados quantitativos ou qualitativos.

O objetivo deste trabalho é elaborar um modelo para o cálculo de reputação em comunidades on-line, baseando-se em dados qualitativos e quantitativos provenientes da interação dos próprios participantes da rede, a fim de potencializar a colaboração entre os membros e fornecer um meio de cálculo resistente a algumas das vulnerabilidades comuns em sistemas de reputação, como tolerância a ruídos e ataques Sybil. Para atingir esse objetivo é realizada uma adaptação do algoritmo PageRank, definida como CR (Collaborative Reputation) para obter uma ordenação dos usuários a partir de suas interações.

Para avaliação, adotamos um conjunto de dados do sítio Epinions.com, com o qual foi realizada uma análise comparativa dos resultados obtidos a partir do modelo proposto com outros três algoritmos correlatos ao trabalho apresentado. Dentre as técnicas usadas na análise estão: diversidade de valores, comparação da ordenação, estudo comparativo de cenários, tolerância a ruídos e robustez contra ataques tipo Sybil. Os algoritmos usados na avaliação são: o PageRank original e o algoritmo ReCop, usados para a identificação de usuários relevantes, e o algoritmo LeaderRank usado para a identificação dos usuários com maior prestígio na rede. Os resultados indicam que o modelo proposto é mais sensível às interações dos usuários em comparação aos outros modelos usados na avaliação, mas é mais eficiente a ataques Sybil.

Palavras-chave: reputação, confiança, interação, PageRank, sistemas colaborativos, redes sociais. 


\section{Abstract}

\section{MAMANI, E. Z. S. Computation of reputation in social networks from the collaboration}

between participants. 2013. 93 f. Dissertação de Mestrado - Instituto de Matemática e Estatística, Universidade de São Paulo, São Paulo, 2013.

In the Web 2.0, there are systems with high volume of social interaction. Some of these systems offer reputation calculation or some form of classification of users or shared content,. However, in many cases, this reputation value is obtained solely from quantitative or qualitative data.

The objective of this work is to develop a model for the reputation calculation in online communities, based on qualitative and quantitative data from the interaction of the participants of a social network, in order to potentiate the collaboration between users, and to provide a resistant environment for some of the vulnerabilities present in reputation systems. To achieve this goal we defined an adaptation of the PageRank algorithm, defined as CR (Collaborative Reputation), to obtain a rank of users based on their interactions in the network.

For evaluation, we used a dataset from the site Epinions.com. With that database, we executed a comparative analysis of the results of the proposed algorithm and of three other algorithms related to the presented work. The procedures used in the analysis were: diversity of values, comparison of ordination, comparative study of scenarios, noise tolerance and robustness against Sybil attacks. The algorithms used in the comparison were: the original PageRank algorithm and ReCop, used to identify relevant users, and the algorithm LeaderRank, which is used for identification of the most prestigious users in the network. The results showed that the proposed model is more sensitive to the interactions of users, but its performance on Sybil attacks is better than the others.

Keywords: reputation, trust, interaction, PageRank, collaborative systems, social networks. 


\section{Sumário}

Lista de Figuras $\quad$ Xv

$\begin{array}{ll}\text { Lista de Tabelas } & \text { xvii }\end{array}$

1 Introdução $\quad 1$

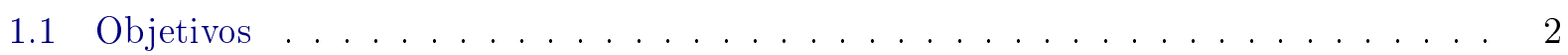

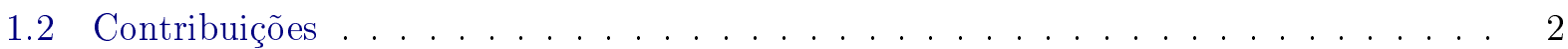

1.3 Organização do trabalho . . . . . . . . . . . . . . . . . . . 3

2 Confiança e reputação em comunidades online $\quad 5$

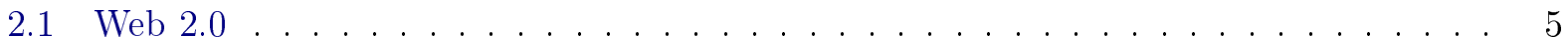

2.1.1 Redes sociais baseadas na Web . . . . . . . . . . . . . 5

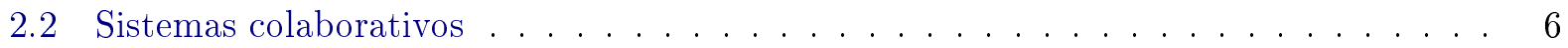

2.2 .1 Modelo $3 \mathrm{C}$ de colaboração . . . . . . . . . . . . . . . . . 6

2.3 Confiança . . . . . . . . . . . . . . . . . . . . . 7

2.3 .1 Definição de confiança . . . . . . . . . . . . . . . . . 8

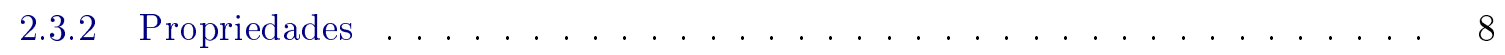

2.4 Reputação . . . . . . . . . . . . . . . . . . . . 10

2.4.1 Classificação dos sistemas de confiança e reputação . . . . . . . . . . . . . . 11

2.4 .2 Vulnerabilidades em sistemas de confiança e reputação . . . . . . . . . . . 13

2.4 .3 Mecanismos de imunidade . . . . . . . . . . . . . . . . . . . . 15

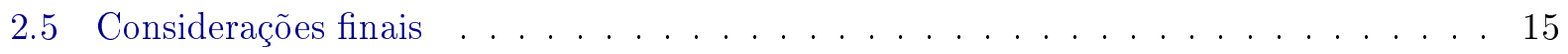

3 Trabalhos relacionados $\quad 17$

3.1 Trabalhos relacionados ao cálculo de confiança e reputação . . . . . . . . . . . 17

3.1.1 TidalTrust: Confiança em redes sociais baseadas na web . . . . . . . . . . 17

3.1.2 T-SWEETS: Inferência de confiança em redes sociais . . . . . . . . . . . . 18

3.1.3 O modelo ReCoP e a reputação em comunidades de prática . . . . . . . . . . 19

3.1.4 Modelo de reputação híbrido: Cálculo de reputação de agentes de software baseado em testemunhos . . . . . . . . . . . . . . . . 20

3.1.5 LeaderRank: Identificação de líderes em redes . . . . . . . . . . . . . . . . . 21

3.1.6 Algoritmos baseados em PageRank . . . . . . . . . . . . . . . . . . 21

3.1.7 TrustExpert: Sistema de reputação em subcomunidades . . . . . . . . . . . . 24

3.2 Considerações finais . . . . . . . . . . . . . . . . . . . . . . 24 
4 Análise de domínio: Cálculo de reputação em sistemas Web $2.0 \quad 27$

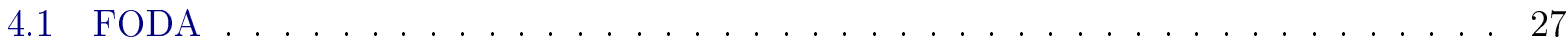

4.2 Estudo: Avaliação e cálculo de reputação em sistemas web $2.0 \quad \ldots$. . . . . . . . 28

4.3 Análise das características . . . . . . . . . . . . . . . . . . 30

4.4 Considerações finais . . . . . . . . . . . . . . . . . . . . . . 32

5 Modelo proposto para o cálculo de reputação de participantes 33

5.1 Descrição . . . . . . . . . . . . . . . . . . . . . . . . . 33

5.2 Cálculo de reputação . . . . . . . . . . . . . . . . . . . . . 34

5.2 .1 Fontes de Dados . . . . . . . . . . . . . . . . . . . . . 35

5.2 .2 Reputação dos usuários . . . . . . . . . . . . . . . . . . . 38

5.2 .3 Mecanismos de imunidade . . . . . . . . . . . . . . . . . . . . . . . 40

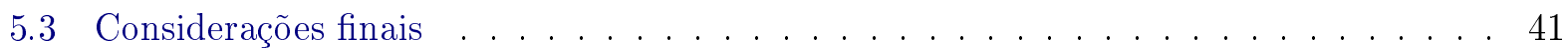

6 Cenário de avaliação $\quad 43$

6.1 Ambiente de avaliação . . . . . . . . . . . . . . . . . . . . 43

6.2 Resumo dos dados usados no estudo . . . . . . . . . . . . . . . . . . 44

6.3 Descrição dos algoritmos . . . . . . . . . . . . . . . . . . 46

6.3.1 Proposta: Collaborative Reputation _ . . . . . . . . . . . . . 46

6.3 .2 Algoritmo: PageRank . . . . . . . . . . . . . . . . . . 47

6.3.3 ReCop: Cálculo de reputação em comunidades de prática . . . . . . . . . . . 48

6.3 .4 LeaderRank . . . . . . . . . . . . . . . . . . . . . . 49

6.4 Considerações finais . . . . . . . . . . . . . . . . . . . . 49

7 Avaliação da abordagem: Resultados $\quad 51$

7.1 Diversidade de valores . . . . . . . . . . . . . . . . . . . . . 51

7.2 Comparação da ordenação . . . . . . . . . . . . . . . . . . . . 5 52

7.3 Estudo comparativo de cenários . . . . . . . . . . . . . . . . . . 53

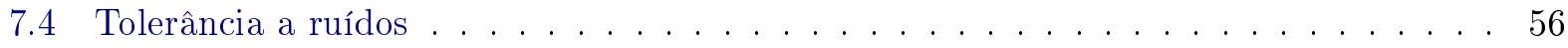

7.4.1 Estudos com avaliações de conteúdo . . . . . . . . . . . . . . . . . . 57

7.4 .2 Estudos com avaliações de confiança . . . . . . . . . . . . . . 58

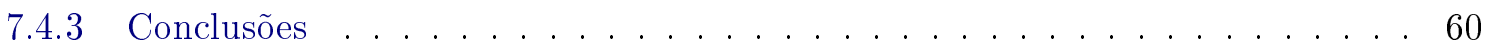

7.5 Robustez contra ataques Sybil . . . . . . . . . . . . . . . . 61

7.6 Ameaças à validade . . . . . . . . . . . . . . . . . . . . . . . 62

7.6 .1 Validade de construção . . . . . . . . . . . . . . . . . . 62

7.6 .2 Validade interna . . . . . . . . . . . . . . . . . . 63

7.6 .3 Validade externa . . . . . . . . . . . . . . . . . . . 63

7.6.4 Validade de conclusão . . . . . . . . . . . . . . . . . . . . 63

8 Conclusões $\quad 65$

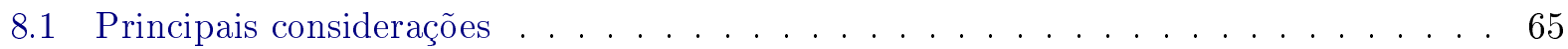

8.2 Limitações e pesquisas futuras . . . . . . . . . . . . . . . . . 66

$\begin{array}{ll}\text { Referências Bibliográficas } & 69\end{array}$ 
Índice Remissivo 


\section{Lista de Abreviaturas}

CSCW Computer Supported Cooperative Work

FODA Feature-Oriented Domain Analysis

$I_{S} \quad$ Impacto na pontuação

$I_{R} \quad$ Impacto na classificação

$\kappa(X, Y) \quad$ Correlação de Kendall

GW Groupware Workbench

NP Node Position

PR PageRank

CR Collaborative Reputation

WBSN Web-based Social Network 


\section{Lista de Figuras}

1.1 Organização dos capítulos da dissertação. . . . . . . . . . . . . . . . . 4

2.1 Mapa visual de conceitos da Web 2.0 [Budd, 2005] . . . . . . . . . . . . . . 6

2.2 Modelo 3C de colaboração [Fuks et al., 2005]. . . . . . . . . . . . . . . . 7

2.3 Exemplo da propriedade de transitividade de confiança. Adaptação de Golbeck [2005]. 9

2.4 Exemplo da propriedade de composição de confiança. Adaptação de Golbeck [2005]. . 10

2.5 Esquema de um sistema de reputação centralizado. Adaptação de Jøsang et al. [2007]. 12

2.6 Esquema de um sistema de reputação distribuído. Adaptação de Jøsang et al. [2007]. 12

3.1 Inferência de confiança do nó A até o nó G. Adaptação de Golbeck [2005] . . . . . . . 18

3.2 Exemplo de uma rede social de mensagens com os valores das funções de compromisso. Adaptação de Kazienko et al. [2009]. . . . . . . . . . . . . . . . . . . . . 23

4.1 Representação da reputação dos usuários nos sítios web Stackoverflow e Reddit. . . . 29

4.2 Distintivos nos sítios web Kekanto e Stackoverflow. . . . . . . . . . . . . . . . . 30

5.1 Esquema do modelo proposto que combina abordagens dos sistemas de interação e

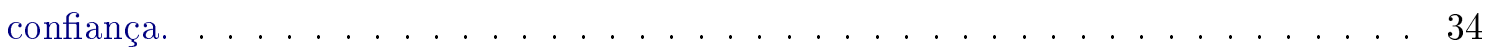

5.2 Representação de rede de confiança. . . . . . . . . . . . . . . . 36

5.3 Informação da contribuição. A informação das contribuições de cada nó está armazenada no próprio nó. . . . . . . . . . . . . . . 37

5.4 Rede de interação de avaliação. As setas representam a designação de avaliações a conteúdo que foi compartilhado. . . . . . . . . . . . . . . 37

6.1 Quadro resumo de divisão em meses do conjunto de dados Epinions.com. . . . . . . . 45

6.2 Quadro resumo dos subconjuntos com os valores acumulados para as fontes de contribuição e avaliação. . . . . . . . . . . . . . . . . . . . . . 45

6.3 Representação gráfica dos nós considerados na estimativa de reputação no algoritmo

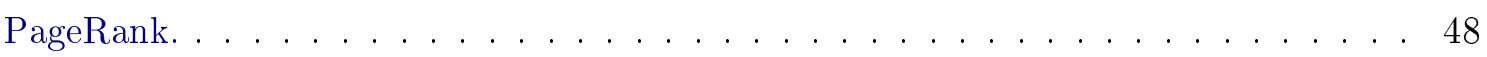

7.1 Porcentagem de diversidade na pontuação dos usuários dos subconjuntos de dados

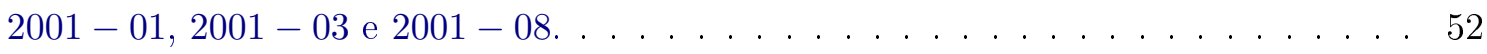

7.2 Resultados do estudo comparativo de cenários na classificação dos usuários teste: muito bom, médio e muito ruim. Cenários a) 2001 - 01, b) 2001 - 03, c) 2001 - 08 . 56

7.3 Impacto na pontuação por adição/exclusão de avaliações ao conteúdo. Cenários a) $2001-01$, b) $2001-03$, c) $2001-08 \ldots \ldots \ldots \ldots \ldots$ 
7.4 Impacto na classificação por adição/exclusão de avaliações ao conteúdo. Cenários a) $2001-01$ b) $2001-03$, c) $2001-08 \ldots \ldots \ldots \ldots \ldots$. . . . . . . . 58

7.5 Impacto na pontuação por adição/exclusão de avaliações de confiança. Cenários a) $2001-01$, b) $2001-03$, c) $2001-08 \ldots \ldots \ldots \ldots \ldots$

7.6 Impacto na classificação por adição/exclusão de avaliações de confiança. Cenários a) $2001-01$, b) $2001-03$, c) $2001-08 \ldots \ldots \ldots$. . . . . . . . . . . 60 


\section{Lista de Tabelas}

3.1 Quadro resumo da classificação de modelos para o cálculo de reputação/confiança. 24

4.1 Lista de sítios web avaliados na análise de domínio. . . . . . . . . . . . . . . 28

4.2 Padrão de descrição de características colaborativas. . . . . . . . . . . . . . . . 29

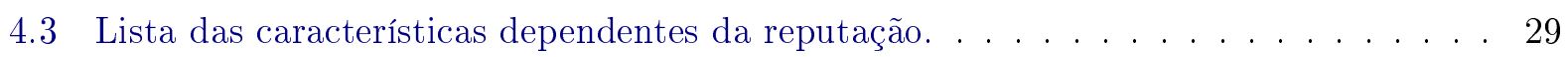

4.4 Avaliação das características. . . . . . . . . . . . . . . . . . 31

5.1 Tabela resumo dos tipos de dados. . . . . . . . . . . . . . . . 35

5.2 Possível estratificação de valores de confiança. Adaptação de Marsh [1994]. . . . . . . 36

5.3 Comparação de critérios da função de compromisso definida em Kazienko et al. [2009] e o modelo proposto. . . . . . . . . . . . . . . . . . 39

6.1 Informação estatística do conjunto de dados Epinions.com. . . . . . . . . . . . . . 43

6.2 Conjunto de dados Epinions.com divididos em meses. . . . . . . . . . . . . . . . . . 44

6.3 Faixa de valores pelo tipo de contribuição. . . . . . . . . . . . . . . . . . 47

6.4 Conversão de valores usados no conjunto de dados para valores usados no modelo

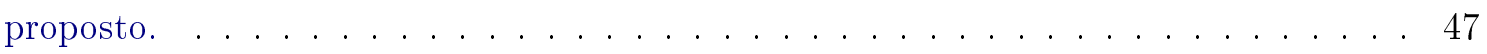

7.1 Valor de correlação de Kendall com os subconjuntos de dados 2001 - 01, 2001 - 03 e $2001-08 \ldots \ldots \ldots \ldots \ldots \ldots \ldots \ldots$

7.2 Índices dos documentos falsos criados de acordo ao tipo de usuário teste. . . . . . . 54

7.3 Avaliações falsas criadas para os usuários: Bom, mau e médio. . . . . . . . . . . . . . 54

7.4 Avaliações de confiança falsas criadas para os usuários: Bom, mau e médio. . . . . . . 55

7.5 Resultados obtidos com a simulação do ataque Sybil no subconjunto 2001 - 01. . . . 62

7.6 Resultados obtidos com a simulação do ataque Sybil no subconjunto 2001 - 03 . . . . 62

7.7 Resultados obtidos com a simulação do ataque Sybil no subconjunto 2001 - 08. . . . 62 


\section{Capítulo 1}

\section{Introdução}

"Todas as flores do futuro estão nas sementes de hoje."

Provérbio Chinês

Pessoas investem tempo, compartilham seus conhecimentos e ideias para que um produto colaborativo seja bom, mas como saber se essas contribuições são de boa qualidade? Como saber se as pessoas não são mal-intencionadas, compartilhando informação com erro ou mesmo falsa? [Cheng e Friedman, 2005]. Cerca de $67 \%$ da população mundial usa redes sociais e blogs [Nielsen, 2009]. Toda a interação produzida por esses usuários gera dados de algum tipo; dados que são valiosos e que podem ser aproveitados na geração de mais informações. A interação em um grupo de pessoas com interesses comuns e que pertencem e interagem em uma rede social específica favorece o surgimento de novo conhecimento por meio da colaboração, mas tal como é no mundo real, a confiança na competência de pessoas desconhecidas envolve riscos [Gomes, 2009].

Segundo Cruz et al. [2007], é fundamental em sistemas baseados na web a participação dos usuários no processo de estabelecimento de confiança, sendo os principais obstáculos o ceticismo dos participantes, o isolamento e a demora em responder às exigências do grupo. Para Cruz et al. [2007], é difícil confiar na competência das pessoas que não são conhecidas, especialmente em um cenário como o da internet, em que há uma grande quantidade de informações disponíveis por meio de fontes de informação não confiáveis.

Na Web 2.0 são encontrados sistemas com alto volume de interação social, alguns desses sistemas oferecem cálculo de reputação, mas o valor resultante é obtido somente a partir de dados quantitativos ou qualitativos. O objetivo principal deste trabalho é a elaboração de um modelo para o cálculo de reputação centralizado, baseado em dados qualitativos e quantitativos provenientes da interação dos participantes em uma rede social. O modelo proposto utiliza uma adaptação do algoritmo PageRank [Brin e Page, 1998] a fim de obter a reputação dos usuários a partir da qualidade e quantidade de suas interações e avaliações.

Nessa abordagem, são propostos dois fluxos de entrada de dados. No primeiro, os dados são fornecidos explicitamente pelos participantes. Os usuários indicam um valor de confiança sobre outros usuários que pertencem à sua rede de conexões na comunidade. No segundo, os dados são obtidos por meio de mecanismos de interação, caracterizados por meio de uma análise de domínio 
em sistemas de reputação de sítios da Web 2.0 e classificados utilizando o modelo 3C de colaboração (comunicação, coordenação e cooperação)[Pimentel e Fuks, 2011, Capítulo 2].

Para a avaliação, adotamos um conjunto de dados ou dataset ${ }^{1}$ do sítio Epinions.com, sobre o qual foi analisado o modelo proposto neste trabalho. Esse conjunto de dados foi coletado por Massa e Avesani [2009] e dispõe de avaliações de conteúdo e de usuários, assim como a informação do conteúdo compartilhado por cada usuário (documentos). Essa informação representa as interações dos usuários na comunidade e possibilita a realização de estudos experimentais para avaliar a proposta deste estudo e comparar os resultados obtidos com outros algoritmos relacionados ao cálculo de reputação em redes sociais.

\section{$1.1 \quad$ Objetivos}

O objetivo geral deste trabalho é:

- Propor uma abordagem resistente a algumas das vulnerabilidade de sistemas de reputação (como tolerância a ruídos ou ataques Sybil) baseada em dados quantitativos e qualitativos provenientes da interação em uma rede social para poder classificar os indivíduos da comunidade tendo em vista a sua reputação.

Dentre os objetivos específicos podemos indicar:

- Realizar uma análise do domínio para mecanismos de interação social e de cálculo de reputação em sistemas Web 2.0, a fim de identificar os principais mecanismos utilizáveis no cálculo de reputação.

- Propor um modelo para a utilização dos dados provenientes dos mecanismos de interação para calcular o grau de reputação dos usuários em una comunidade.

- Comparar os resultados do modelo proposto com resultados de outros algoritmos e analisar os resultados obtidos com base em um conjunto de dados que represente uma comunidade.

\subsection{Contribuições}

As principais contribuições do trabalho são:

- Uma abordagem resistente a algumas das vulnerabilidades atuais de sistemas de reputação, levando em consideração dados quantitativos e qualitativos.

- Uma análise de domínio para mecanismos de interação social e reputação em sistemas Web 2.0 .

- Uma análise comparativa da abordagem proposta com outras abordagens existentes na literatura.

\footnotetext{
${ }^{1}$ Disponível em http://www.trustlet.org/wiki/Epinions_dataset. Último acesso: 04 julho 2012
} 


\subsection{Organização do trabalho}

O Capítulo 2 define o que são comunidades online; mais especificamente, são fornecidos os conceitos básicos de redes sociais e sistemas colaborativos, assim como uma breve explicação do modelo 3C de colaboração. Introduzimos também os conceitos principais deste trabalho, tais como confiança e reputação, e alguns algoritmos usados para seu cálculo. São apresentados alguns trabalhos correlatos no Capítulo 3. No capítulo seguinte, é apresentada uma análise de domínio em sistemas de reputação na Web 2.0 (Capítulo 4). No Capítulo 5 é definida a abordagem proposta no nosso trabalho. A avaliação da abordagem proposta é realizada em uma comparação de resultados com outros algoritmos relacionados ao cálculo de reputação em redes sociais em um conjunto de dados ou dataset. A apresentação dos algoritmos usados na comparação é realizada no Capítulo 6, assim como a especificação do conjunto de dados usado nos procedimentos. No Capítulo 7 são especificados os estudos realizados para a avaliação do modelo proposto e os resultados obtidos nas comparações. O Capítulo 8 apresenta as conclusões do trabalho e especifica os passos seguintes a serem realizados. Na Figura 1.1 é apresentado um resumo gráfico da organização do trabalho e o fluxo dos conceitos, no qual cada seta indica a sequência seguida nos capítulos. Por exemplo, para a definição do Modelo do Capítulo 5 foi necessário conhecer os Trabalhos Correlatos ao tema de pesquisa (Capítulo 3) e a especificação da Análise de Domínio (Capítulo 4). 


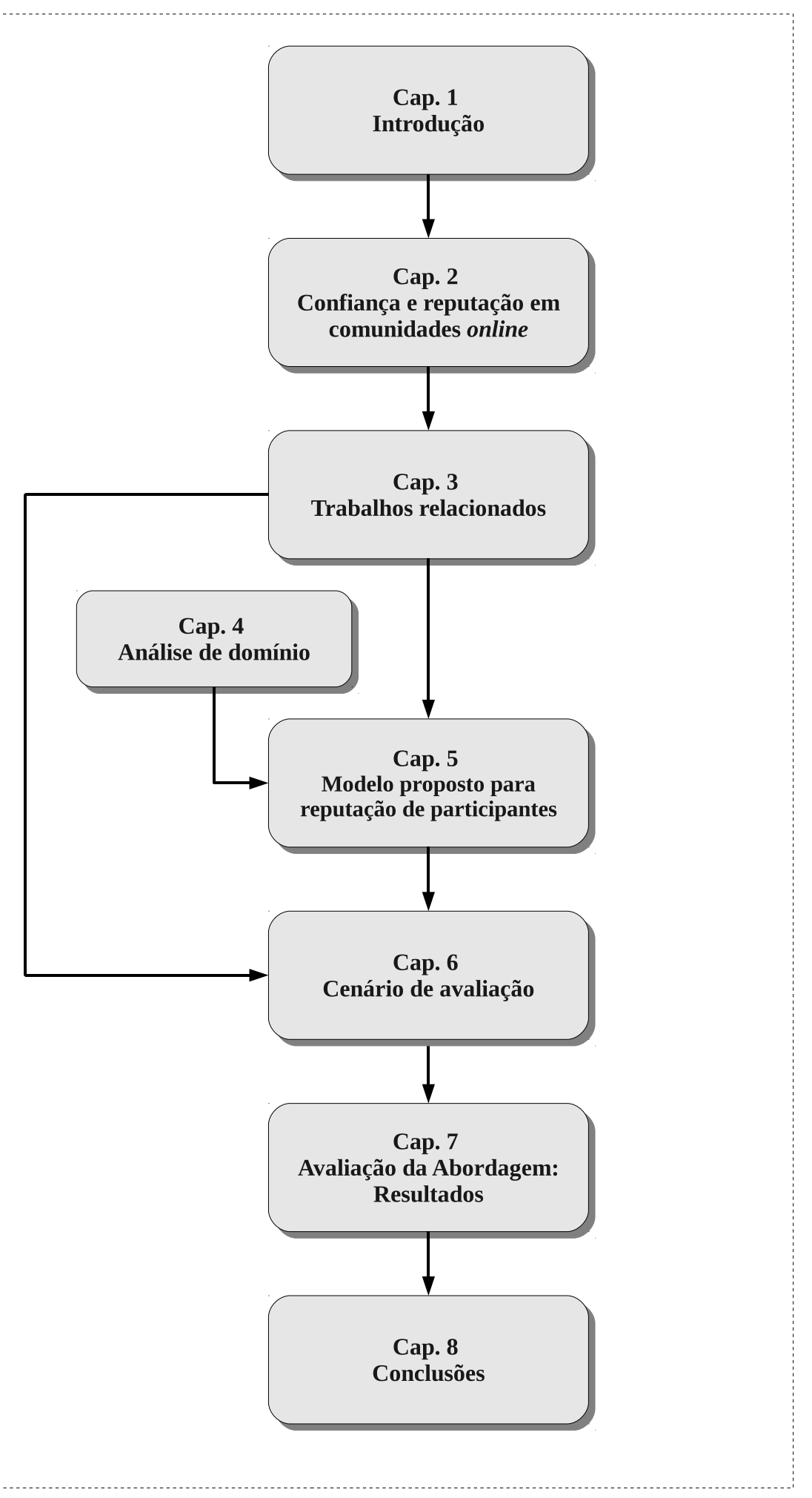

Figura 1.1: Organização dos capítulos da dissertação. 


\section{Capítulo 2}

\section{Confiança e reputação em comunidades online}

"A dúvida é o princípio da sabedoria."

Aristóteles

Neste capítulo são apresentados os conceitos relacionados ao contexto em que este trabalho se insere. Esses conceitos são: Web 2.0, redes sociais na web, sistemas colaborativos, confiança e reputação.

\section{$2.1 \quad$ Web 2.0}

O termo "Web 2.0" começou a ser usado em uma conferência no MediaLive International por Tim O'Reilly em outubro do 2004; um ano e meio depois, foi consagrado com mais de 9,5 milhões de citações no mecanismo de busca do Google [O’Reilly, 2005]. A Web 2.0 é a segunda geração de serviços online, em que os sítios web se caracterizam por potencializar a publicação, compartilhamento e organização da informação, além de incentivar a interação entre os participantes. As pessoas geram conteúdos e os disponibilizam na rede, potencializando o trabalho coletivo, o compartilhamento de informação e a construção do conhecimento social apoiada pela computação. Surge assim uma nova inteligência, gerada coletivamente a partir das interações entre os participantes [Primo, 2006][Segaran, 2007][Alag, 2008].

A Web 2.0 é uma combinação de tecnologias, novas estratégias mercadológicas e processos de comunicação mediados pela computação. Na Figura 2.1 é apresentada uma nuvem de termos (chamada de tag cloud) gerada a partir de conceitos importantes na Web 2.0 [Primo, 2006][Budd, 2005]. De acordo com O’Reilly [2005], não há como demarcar as fronteiras da Web 2.0.

\subsubsection{Redes sociais baseadas na Web}

As redes sociais baseadas na Web (WBSN - Web-based Social Network) tiveram um crescimento muito rápido em número e âmbito de aplicação desde os anos da década de 90 [Golbeck, 2005]. Com esse crescimento, muitas pessoas começaram a ser parte de alguma rede que lhes possibilitam compartilhar ideias e interagir com outros. 


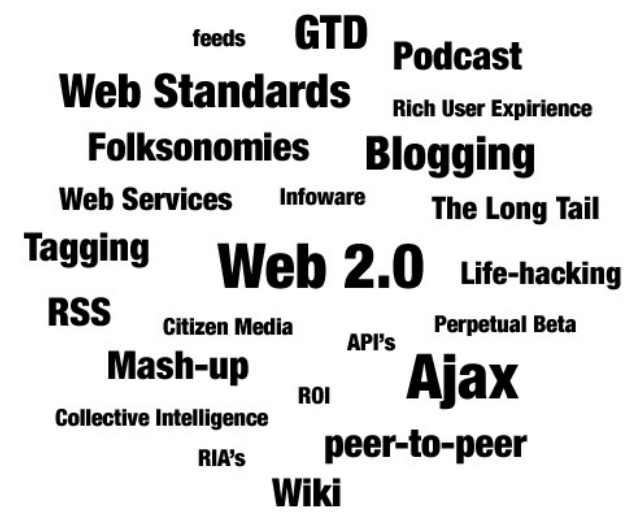

Figura 2.1: Mapa visual de conceitos da Web 2.0 [Budd, 2005].

Segundo Recuero [2005], uma rede social é a partir de atores (usuários ou entidades) e conexões entre esses atores. Os atores são representados pelos nós em uma estrutura de grafo. Para Recuero, uma interação social tem um aspecto comunicativo, assim uma relação social é constituída por esse tipo de interação; por sua vez, os denominados laços sociais são constituídos por relações sociais. No final, um laço social é uma conexão entre dois atores.

Uma rede social é uma estrutura de relacionamentos entre atores com propósitos comuns (pessoais, acadêmicos, profissionais etc.) [Gomes, 2009]. O uso de uma rede social possibilita compartilhar informação, música, conceitos e conhecimento; debater o conteúdo que é compartilhado e interagir com outros atores e compor grupos e comunidades com interesses afins. As redes sociais conectam pessoas e possibilitam a colaboração.

\subsection{Sistemas colaborativos}

Os sistemas colaborativos possibilitam o trabalho em equipe, tanto de forma síncrona (ao mesmo tempo) quanto assíncrona (em tempos diferentes) e em lugares geograficamente distantes [Pimentel e Fuks, 2011]. Esse tipo de sistema fornece serviços de suporte para um grupo de pessoas comprometidas com um objetivo em comum em alguma atividade.

Há diversos termos para designar o conceito de sistemas colaborativos. Em meados dos anos 80, os termos Groupware e CSCW (Computer Supported Cooperative Work) foram introduzidos [Grudin, 1994]. O termo Groupware vem da junção das palavras group = grupo e software = programa de computação. Alguns exemplos de aplicações groupware são: reuniões eletrônicas, correio eletrônico, sistemas de gerenciamentos de documentos, videoconferências, correio eletrônico entre outros.

\subsubsection{Modelo 3C de colaboração}

Foram identificados três classes conceituais sobre as quais está embasado um sistema groupware, a fim de fornecer as funcionalidades necessárias para o trabalho em equipe: comunicação, coordenação e cooperação [Ellis et al., 1991]. Essa maneira de analisar a colaboração é conhecida como modelo 3C [Fuks et al., 2005] e é apresentada na Figura 2.2. 


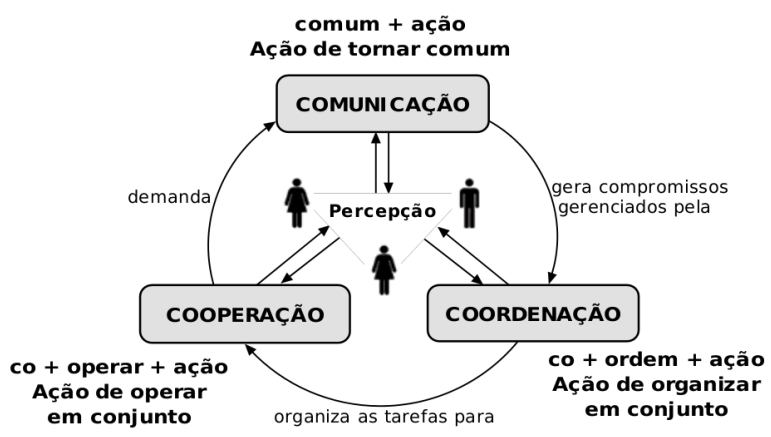

Figura 2.2: Modelo 3C de colaboração [Fuks et al., 2005].

Um groupware oferece suporte e flexibilidade para prover e exercer simultaneamente a comunicação, a coordenação e a cooperação.

- Comunicação: A comunicação está relacionada com a troca de mensagens e informações assim como a negociação de compromissos entre pessoas.

- Coordenação: A coordenação é relacionada ao gerenciamento de pessoas, suas atividades e recursos para lidar com conflitos e evitar a perda dos esforços de comunicação e de cooperação.

- Cooperação: A cooperação é a produção que acontece em um espaço compartilhado, gerando objetos de cooperação na realização de tarefas [Gerosa, 2006].

Essas atividades não são realizadas isoladamente, as tarefas originam compromissos gerados durante a comunicação, depois são gerenciadas pela coordenação e realizadas durante a cooperação [Fuks et al., 2005].

\subsection{Confiança}

Segundo Costa [2005], um dos aspectos essenciais que deve existir para a consolidação de comunidades é o sentimento de confiança entre as pessoas. A formação dessa confiança depende da capacidade de uma pessoa de se relacionar com outras, e de incluí-las em sua rede de referência. Esse tipo de inclusão está ligado ao reconhecimento das habilidades dos outros, suas competências e conhecimentos. Quando um indivíduo interage com os outros tem oportunidade de reconhecer os comportamentos, intenções e valores do seu meio.

As sociedades dependem fortemente da confiança entre seus membros [Fukuyama, 1995]. A confiança e reputação na web tem sido estudada desde seus primórdios. O sistema de avaliação do eBay usa as avaliações positivas e negativas dos clientes como uma medida de reputação do vendedor. O algoritmo PageRank, usado pelo motor de busca do Google, também é baseado em uma métrica de confiança para a ordenação dos sítios web, por meio do número de ligações/hiperlinks a uma página específica.

Para Golbeck [2005], a confiança depende de uma série de fatores que não podem ser facilmente modelados num sistema computacional: a experiência do passado com uma pessoa e com seus 
amigos, os fatores psicológicos impactados por uma vida de história e acontecimentos, a influência das opiniões dos outros e os motivos para ganhar algo adicional são apenas alguns desses fatores.

\subsubsection{Definição de confiança}

Na literatura, confiança é um termo usado em muitas áreas, incluindo sociologia, psicologia, economia, ciência política, história, filosofia e ciência da computação, portanto, cada área de trabalho define de algum modo o conceito de confiança [Shapiro, 1987][Golbeck, 2005]. As redes sociais são ferramentas para usuários comuns da web. Logo, a definição de confiança deve ser o suficientemente simples para que tais usuários entendam o que estão expressando e o façam com precisão [Golbeck, 2005]. No campo da sociologia e psicologia, a definição de confiança é mais simples e clara.

Para Deutsch [1962], o comportamento de confiança ocorre quando uma pessoa $A$, encontra-se em uma situação em que percebe um caminho ambíguo. O resultado de seguir um caminho ou outro pode ser bom ou ruim e essa decisão depende da experiência de outra pessoa, $B$, que tem conhecimento do caminho. O impacto do resultado da escolha do caminho ruim é maior do que o impacto do resultado da escolha do caminho bom, essa situação motiva $A$ a tomar a escolha correta. $A$ conhece $B$ e confia que $B$ fará o necessário para garantir o resultado bom da escolha. Se $A$ escolhe ir por um caminho, segundo a informação de $B$, pode-se dizer que fez uma escolha de confiança, senão, $A$ desconfia do resultado a partir da informação de $B$.

Uma observação importante sobre o termo confiança é que ele não assume um valor único. Por exemplo, a partir de um tema específico, que seria "gostar de música", os usuários são capazes de formar uma opinião geral de quanto eles confiam em outros sobre o gosto musical. Contudo, um usuário pode confiar em um amigo sobre canções românticas, mas não sobre rock. O gênero romântico pode ser quebrado em músicas em inglês ou em português, ou, inclusive, dividido pelo tempo, música romântica dos anos 1980 ou atual [Jøsang e Golbeck, 2009].

Ha muitas maneiras de considerar a confiança. Neste trabalho será usada a definição de confiança adotada por Golbeck e Hendler [2006]: "confiar em uma pessoa é um compromisso a realizar uma ação baseada na crença de que as futuras ações dessa pessoa levarão a um bom resultado", pois estamos focados em interações sociais colaborativas. A ação e o compromisso por parte da pessoa que confia pode ser algo simples como considerar a recomendação de uma música, por exemplo.

\subsubsection{Propriedades}

A seguir são apresentadas propriedades do termo confiança.

\section{Transitividade}

A confiança não é perfeitamente transitiva no sentido matemático. Se Ana confia fortemente em Bruno e este confia fortemente em Caio não significa que Ana vai confiar fortemente em Caio. Há, no entanto, uma noção de que a confiança é transmitida entre pessoas. Quando pedimos a um amigo de confiança por uma opinião sobre um encanador, estamos considerando a opinião do amigo e a incorporamos para ajudar a formar uma opinião preliminar sobre o assunto. Geralmente, quando 
uma pessoa se encontra com alguma pessoa desconhecida, é comum perguntar a seus amigos de confiança por opiniões sobre o quanto confiar nessa nova pessoa [Golbeck, 2005].

Há dois tipos de confiança que uma pessoa expressa: a confiança em alguém e a confiança nas recomendações de terceiros acerca de outras pessoas. Ana pode confiar em Bruno para recomendar um encanador, mas pode não confiar completamente em Bruno se ele recomendar a opinião de outras pessoas sobre encanadores. Segundo Golbeck [2005], apesar dessa dicotomia, nas redes sociais é preferível deixar que um único valor represente essas duas ideias, porque um sistema de classificação único é também mais compatível com a maneira tradicional de participação dos usuários nas redes sociais. O seguinte exemplo mostra como ambas ideias são representadas como um único conceito.

A definição de confiança apoia a ideia de transitividade, a confiança envolve a crença de que a pessoa de confiança terá uma ação que irá produzir um bom resultado. Seguindo com o exemplo do encanador, se Ana pergunta a Bruno se Caio é um bom encanador, Ana vai usar a resposta de Bruno para apoiar a sua ação de contratar ou não o trabalho de Caio, pois Ana acredita que Bruno vai dar informações que conduzirão a um bom resultado. Assim, se Bruno diz para Ana que deve confiar em Caio, Ana conta com a confiança que tem em Bruno para desenvolver um pouco de confiança em Caio. A recomendação de Bruno se torna a base para o começo da confiança em Caio. Ana terá um pouco de confiança em Caio, pois acredita em Bruno e sabe que ele irá tomar as medidas necessárias para que a escolha dela produza um bom resultado.

A mesma argumentação pode ser estendida para criar cadeias maiores. A transitividade pode ser representada na Figura 2.3, em que Ana tem uma opinião sobre Caio baseada na informação que Denise compartilha com Bruno e que Bruno passa a Ana. No caso de Bruno, este confia que as ações futuras de Denise terão um bom resultado, por isso, pode informar a Ana sobre quão bom encanador é Caio, pois Denise conhece diretamente Caio e ela pode lhe dar uma informação verdadeira. Assim há uma cadeia de confiança de pessoas. Essa lógica suporta o uso de um único valor para representar a confiança nas pessoas e nas recomendações acerca de terceiros. No entanto, o valor de confiança é degradado ao longo da cadeia de conhecidos.

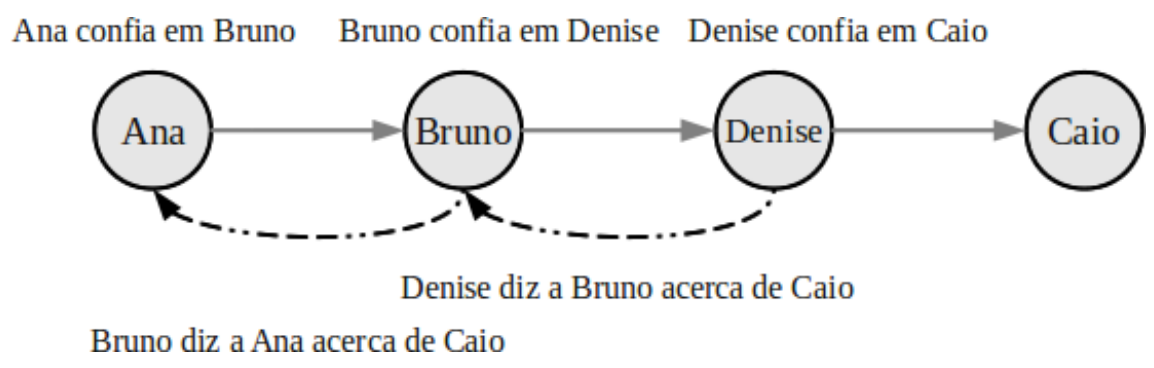

Figura 2.3: Exemplo da propriedade de transitividade de confiança. Adaptação de Golbeck [2005].

\section{Composição}

As recomendações acerca da integridade de uma pessoa desconhecida são usadas para gerar um valor de confiança. Na Figura 2.4, várias pessoas conhecem Caio e fornecem recomendações por meio da rede de confiança. Nesse caso, Ana tem de realizar uma composição de toda a informação 
que recebe, e decidir se confia ou não em Caio. Essa composição de confiança é outra importante característica para realizar o cálculo de confiança.

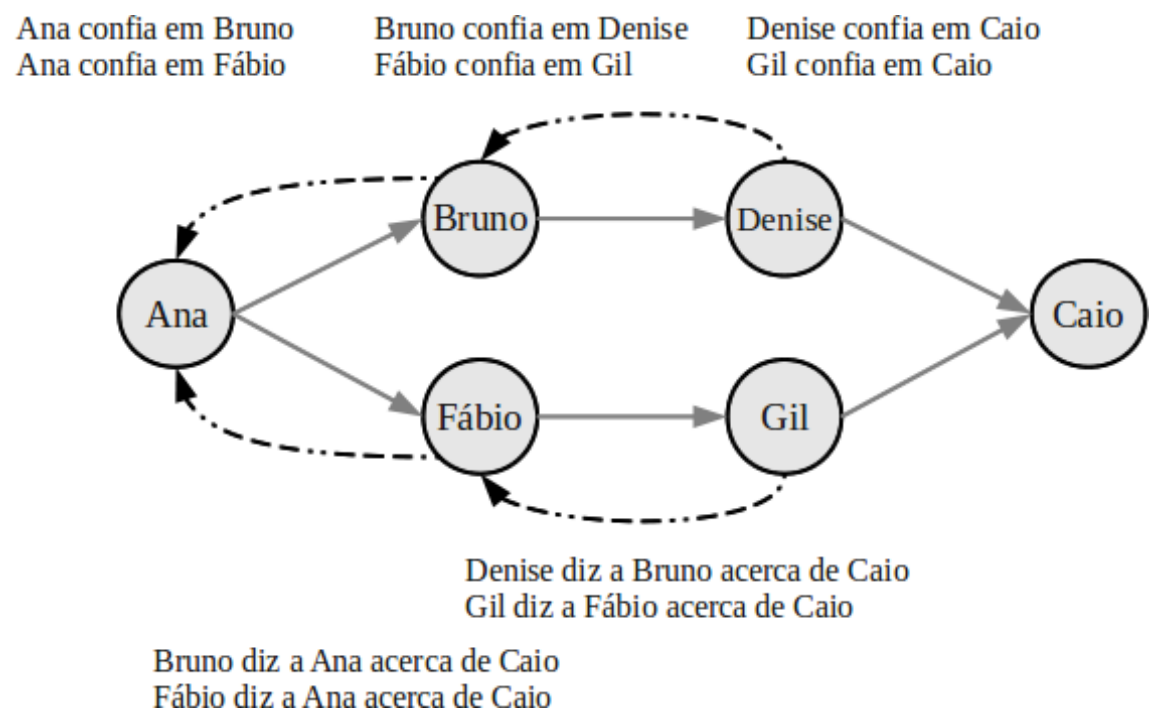

Figura 2.4: Exemplo da propriedade de composição de confiança. Adaptação de Golbeck [2005].

\section{Personalização}

Confiança é uma opinião subjetiva, por isso, diferentes pessoas podem ter opiniões distintas sobre a integridade de um mesmo indivíduo. A definição de confiança inclui a crença de que as ações das pessoas de confiança conduzirão a um bom resultado. O significado de bom resultado muda de pessoa para pessoa. Por exemplo, uma recomendação de uma mulher romântica sobre um filme romântico vai ser diferente de uma mulher que gosta de filmes de terror. Uma vez que todos têm interesses, prioridades e opiniões e que podem entrar em conflito com os interesses, as prioridades e opiniões dos outros, quando e quanto confiar em uma pessoa varia de pessoa a pessoa. Raramente existe uma absoluta confiança em alguma pessoa. Porém, a confiança deve ser calculada a partir da perspectiva de cada indivíduo e a partir de seus próprios interesses.

\section{Assimetria}

A confiança também tem assimetria, e reflete um tipo específico de personalização. Para duas pessoas envolvidas em um relacionamento, a confiança não é necessariamente idêntica em ambos os sentidos. Por exemplo, pais e filhos confiam claramente um no outro, mas em níveis diferentes. Assimetria pode surgir em qualquer relacionamento, e representações de relações de confiança em modelos de redes sociais devem possibilitar essas diferenças.

\subsection{Reputação}

A reputação de uma entidade usualmente é estimada com base em um histórico de relacionamentos com outras entidades [Gomes, 2009][Cruz et al., 2007]. A reputação representa a opinião geral de um grupo sobre alguém. Normalmente, uma entidade com boa reputação tem influência em outras entidades, e induz a ter uma alta confiança nas interações com essa entidade. Não há uma 
regra específica para relacionar confiança com reputação, às vezes existem interesses particulares que podem influenciar esses conceitos, por exemplo, um indivíduo pode confiar em uma má pessoa, além de ter uma má reputação, esse tipo de cenário existe pela propriedade de personalização em termos de confiança. Como no contexto anterior, a confiança é definida como um fator pessoal e subjetivo. A confiança de um indivíduo é derivada de uma combinação de referências recebidas e experiência pessoal, enquanto a reputação é uma medida de confiança coletiva, calculada com base nas referências ou qualificações dos membros de uma comunidade.

A diferença entre confiança e reputação é ilustrada nas seguintes sentenças:

1. Eu confio em você pela sua boa reputação.

2. Eu confio em você apesar de sua má reputação.

Essa observação indica que confiança é um fenômeno pessoal e subjetivo e que se baseia em vários fatores ou evidências, e que uns têm mais peso do que outros. A experiência pessoal normalmente tem mais peso do que as referências de confiança de segunda mão (como amigos, parentes, entre outros) ou a reputação, mas, na falta de experiência pessoal, muitas vezes a confiança tem que ser baseada em referências de terceiros.

Os sistemas de reputação, segundo Resnick et al. [2000], devem coletar, distribuir e adicionar diversas avaliações que os participantes realizam sobre o uso de algum serviço. Baseado nessas avaliações, pode ser calculado um valor de reputação sobre uma entidade (artefato ou item) em questão. Esse tipo de sistema ajuda a pessoas a decidirem em quem confiar, encorajam um comportamento de interação e sugerem impedir uma interação com quem é considerado desonesto. Os sistemas de reputação são chamados de sistemas de sanções colaborativas para refletir o seu caráter colaborativo, e estão relacionados a sistemas de filtragem colaborativos ou sistemas de recomendação, considerados como os antecessores dos sistemas de reputação[Cruz, 2008].

Segundo Jøsang e Golbeck [2009], a finalidade dos sistemas de confiança e reputação é de fortalecer a qualidade nas comunidades, fornecendo incentivos pelo bom comportamento e punindo serviços de baixa qualidade. Os sistemas de reputação são usados em aplicações comerciais bemsucedidas online [Jøsang et al., 2007], em que, a confiança que gera um usuário com boa reputação é importante. Nesse cenário, a reputação tem uma grande influência nos preços dos serviços oferecidos, especialmente com entidades de alto valor (reputação)[Mui e Mohtashemi, 2002].

\subsubsection{Classificação dos sistemas de confiança e reputação}

Segundo Jøsang et al. [2007], a arquitetura dos sistemas de reputação determina como as avaliações e os valores de reputação são comunicados entre os participantes em sistemas de reputação. Na literatura são encontradas diversas abordagens para classificação de sistemas de confiança e reputação. Dentre as principais estão: Jøsang et al. [2007], Mui et al. [2002], Wang e Vassileva [2007]. Neste trabalho, é adotada a classificação de Wang e Vassileva por ser um compêndio das outras abordagens. Segundo Wang e Vassileva, os sistemas de confiança e reputação estão classificados de acordo com três propriedades: centralizado vs. descentralizado, usuário vs. recurso e global vs. local (pessoal). 


\section{Centralizado vs. descentralizado}

Nos modelos de reputação centralizada, em inglês Centralised Reputation Systems, o desempenho de cada membro é determinado mediante as avaliações de outros membros da comunidade que tiveram experiência direta como o membro [Jøsang et al., 2007]. Há uma autoridade central (reputation centre) ou coordenador que coleta as avaliações e calcula um valor de reputação (podemos chamar de pontuação) de cada membro. Com essas pontuações, os participantes usam os resultados para decidir se devem realizar uma interação com outro.

A Figura 2.5 mostra um quadro típico de reputação centralizada. Os participantes A e B não tiveram interações no passado, mas existem interações dos parceiros de A e B no passado. Depois da interação, os participantes avaliam o desempenho do outro participante. A autoridade central coleta novamente os dados e atualiza a reputação de cada participante, retroalimentando o sistema.

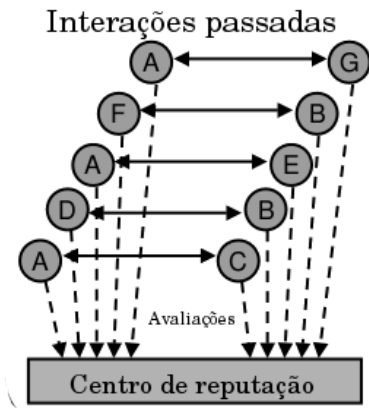

a) Passado

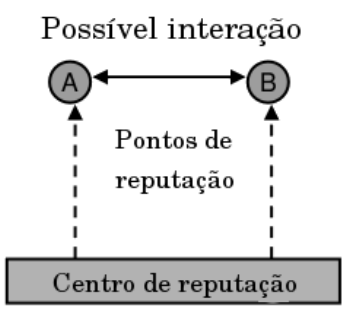

b) Presente

Figura 2.5: Esquema de um sistema de reputação centralizado. Adaptação de Jøsang et al. [2007].

Nos modelos distribuídos ou descentralizados não existe um coordenador que centralize as decisões ou informações de reputação. Os dados de reputação são distribuídos e armazenados pelos membros da comunidade. Cada um deles é responsável por calcular uma reputação com base nas interações diretas ou mediante alguma consulta a outros membros. Para que se possa avaliar a reputação dos outros participantes é preciso obter informação sobre eles, portanto é necessário que sua informação seja alcançável. Esse cenário pode ser representado como na Figura 2.6 em que são calculados os graus de reputação dos membros A e B com base nas interações passadas dos outros membros alcançáveis.

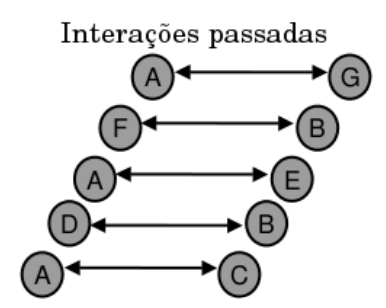

a) Passado

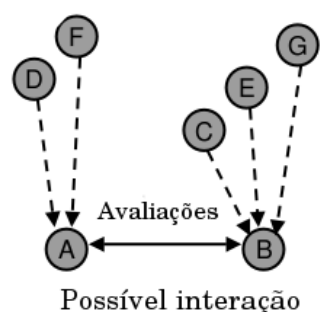

b) Presente

Figura 2.6: Esquema de um sistema de reputação distribuído. Adaptação de Jøsang et al. [2007]. 
Guedes [2007] padronizou as diversas denominações utilizadas nesse modelo como: Modelo Descentralizado Simples, Modelo Descentralizado Baseado em Testemunhas e Modelo Descentralizado Baseado em Reputação Certificada. O modelo centralizado é adotado em sítios web bem sucedidos como eBay, Amazon e outros leilões, e o modelo descentralizado é estudado para resolver problemas de reputação, por exemplo, em redes Peer-to-Peer [Guedes, 2007].

\section{Usuário vs. recurso}

Junto aos sistemas centralizados ou descentralizados, os sistemas de reputação são classificados por usuário ou por recurso. Os sistemas de confiança/reputação classificados como de usuário (person/agent) são orientados a calcular a reputação de entidades que agem como pessoas. Nos sistemas classificados como sistemas de reputação de recurso (resource), o enfoque é modelar sistemas para recursos, que podem ser produtos ou serviços. Muitos sistemas de recursos usam a reputação dos usuários para construir o valor da reputação dos recursos [Wang e Vassileva, 2007].

Os sistemas de reputação/confiança de usuário centralizados estão principalmente na área de comércio eletrônico. Nesse tipo de sistemas, um nó central atua como coletor das informações das transações e calcula a reputação das entidades a partir das avaliações realizadas por outras entidades. Os sistemas de reputação de recursos centralizados servem como uma guia para selecionar os recursos mais populares.

\section{Global vs. local}

Em sistemas de reputação global (global reputation), a reputação de uma entidade é baseada na opinião geral da comunidade e é pública e visível para todos os membros. Nos sistemas de reputação local (personalized), a reputação de cada entidade é construída a partir da opinião de um grupo de entidades selecionadas por uma entidade em particular [Wang e Vassileva, 2007]. Em sistemas de reputação local descentralizados de usuários (person/agent), cada entidade é responsável por gerar um valor de confiança/reputação de outros usuários baseado diretamente em suas interações com outros usuários. Nesse tipo de sistemas, as entidades juntam informação da rede para aprender a reputação das outras entidades e para criar suas próprias redes de confiança/reputação. Em sistemas de reputação descentralizados de usuários é possível criar uma reputação global e pública com base nos valores das reputações locais.

\subsubsection{Vulnerabilidades em sistemas de confiança e reputação}

O fornecimento de apoio aos usuários na tomada de decisões é o objetivo principal dos sistemas de confiança e reputação. O valor dessa função de apoio à decisão depende da confiabilidade e precisão das avaliações produzidas de confiança e reputação. Segundo a IEEE [1990], a confiabilidade é a capacidade de um sistema ou componente para executar suas funções necessárias sob condições estabelecidas durante um período de tempo especificado. Entretanto, os sistemas de confiança e reputação têm muitos tipos de vulnerabilidades que os torna alvos relativamente fáceis para ataques e manipulação [Jøsang, 2010, Jøsang e Golbeck, 2009]. Como exemplos de algumas vulnerabilidades que são reportadas na literatura temos: 
- Playbooks: consiste de uma sequência de ações que maximiza o ganho de um participante de acordo com determinados critérios. Um exemplo simples desse tipo de vulnerabilidade é um usuário que durante um período de tempo realiza serviços honestamente e ganha um alto valor de reputação, em sequência, com esse valor de reputação oferece serviços de baixa qualidade.

- Avaliações falsas: as avaliações fornecidas não refletem a verdadeira opinião do avaliador. Esse comportamento é considerado não ético e representa um tipo de ataque. No entanto, é difícil determinar quando esse tipo de ataque acontece, por que os agentes numa comunidade não têm acesso à opinião genuína dos usuários, e só podem enxergar o que os outros usuários expressam.

- Discriminação: significa que uma entidade fornece serviços de alta qualidade a um grupo e serviços de baixa qualidade para outro grupo.

- Conspiração: significa que um grupo de entidades coordena o seu comportamento e, por exemplo, fornece recomendações injustas ou falsas, ou pratica a discriminação.

- Proliferação: significa que um agente oferece o mesmo serviço por vários canais diferentes, aumentando assim a probabilidade de ser escolhido por um terceiro.

- Reputação tardia: significa que o atacante usa o intervalo de tempo entre uma instância de uma prestação de serviços e o efeito de avaliação pelo correspondente serviço, por exemplo, fornecendo vários serviços de baixa qualidade em um curto período antes que sua classificação (reputação) sofra uma degradação significativa.

- Reentrada/troca de identidade: dentro de uma comunidade podem existir diferentes subcomunidades. A reentrada/troca de identidade significa que uma entidade com baixa pontuação deixa uma subcomunidade e, posteriormente, ingressa em outra com uma identidade diferente, assim evita as consequências da baixa pontuação associada com a identidade anterior dentro da comunidade.

- Desequilíbrio no valor: este tipo de ataque é possível quando o valor de uma avaliação não é proporcional ao valor real do objeto avaliado. Como exemplo desse tipo de ataque é a designação de valores baixos, em grande quantidade, aos serviços disponibilizados por outros usuários e a designação de valores altos a serviços de só alguns usuários, mas em pouca quantidade. Esse tipo de ataque é considerado enganoso e não ético.

- O ataque Sybil: é quando uma única entidade estabelece múltiplas identidades falsas dentro de um domínio de sistemas de confiança e reputação para fornecer múltiplas avaliações sobre o mesmo serviço.

- Nenhum incentivo para fornecer avaliações: as entidades têm poucos incentivos para fornecer avaliações.

- Dificuldade para obter feedback ${ }^{1}$ negativo: em alguns casos pode ser desafiante obter

\footnotetext{
${ }^{1}$ Tradução da autora. feedback: retorno de informação.

Definição de feedback: "é o procedimento que consiste no provimento de informação a uma pessoa sobre o desempenho, conduta, eventualidade ou ação executada por esta, objetivando orientar, reorientar e/ou estimular uma ou mais ações de melhoria, sobre as ações futuras ou executadas anteriormente". Fonte: Wikipédia. Último acesso 10 novembro 2012
} 
feedbacks sobre as experiências negativas por causa da relutância das pessoas em ofender as pessoas avaliadas e porque podem temer algum tipo de represália por parte do avaliado.

- Atacantes notórios: existência de participantes cuja única finalidade é perturbar a ordem em uma comunidade, para quem os incentivos por bom comportamento ou a sanção por um mau comportamento não têm efeito algum.

\subsubsection{Mecanismos de imunidade}

Cruz et al. [2007] fazem um compêndio do trabalho de Dellarocas [2004] sobre mecanismos de imunidade e os efeitos de avaliações falsas (não confiáveis, não reais) em sistemas de leilão na internet e propõem mecanismos de imunidade para mitigar as vulnerabilidades de sistemas de reputação e falsos positivos e negativos.

- Anonimato: anonimato pode ser usado de uma maneira controlada. Em uma rede pode-se saber as identidades de todos os participantes, mas manter a sua identidade oculta durante as transações ou atribuir pseudônimos aos participantes previne as ações de má-fé entre eles e, assim, elimina ou reduz os falsos negativos (bad-mouthing). No entanto, esse mecanismo não é muito eficaz com comportamentos discriminatórios ou falsos positivos produzidos por favoritismo entre os usuários conhecidos (usuários conhecem o pseudônimo dos seus amigos).

- Mediana: o uso da média aritmética torna o sistema vulnerável para os usuários malintencionados que tentam distribuir estrategicamente suas avaliações para maximizar a sua própria reputação e minimizar as dos outros. A utilização da mediana no cálculo de reputação torna esse tipo de ação mais difícil de ser realizada.

- Análise Frequente: se a reputação de um usuário é calculada por períodos de tempo, uma mudança repentina nas suas avaliações mais recentes pode ser rapidamente identificada. Nesse caso, possíveis avaliadores desleais podem ser identificados por esse mecanismo. Esse mecanismo pode ser usado contra o comportamento discriminatório dos falsos negativos.

\subsection{Considerações finais}

A interação dos usuários em sistemas Web 2.0 possibilita a geração de novo conhecimento formado a partir da informação compartilhada. Os usuários envolvidos atuam como filtros ativos de informação. A confiança e a reputação são conceitos importantes na vida cotidiana das pessoas e esses conceitos também foram adotados nas comunidades online.

A confiança, além das propriedades descritas na Seção 2.3.2, possui as propriedades de autopreservação e autoampliação [Gomes, 2009]. Segundo Golbeck e Hendler [2006], essas propriedades se incrementam em função de ações exitosas (por exemplo, um bom comentário, uma boa pergunta, uma boa resposta, um bom conteúdo etc.), e se decrementam em caso de ações ruins (por exemplo, um comentário sem lógica, conteúdo impróprio etc.). Algumas redes sociais, como LinkedIn ${ }^{2}$, têm o conceito de confiança na sua rede de conexões, seu lema reflete isso: "Encontrar as pessoas que precisas por meio das pessoas nas quais confias". Nesse caso, criar um link com uma pessoa implica

\footnotetext{
${ }^{2}$ Disponível em: www.linkedin.com/. Último acesso: 04 julho 2012.
} 
ter certa quantidade de confiança nela.

Os sistemas de confiança oferecem uma visão particular, enquanto os sistemas de reputação oferecem uma visão do grupo. Neste capítulo foram abordados os principais conceitos utilizados na literatura sobre confiança e sistemas de reputação, além disso, apresentamos a importância desses conceitos para o cenário da Web 2.0. 


\section{Capítulo 3}

\section{Trabalhos relacionados}

"A situação não define o caráter, mas define a reputação."

Thais Sampaio

Nos últimos anos e com o crescimento dos sistemas na web, os sistemas de confiança e reputação têm gerado interesse em diversas áreas acadêmicas. Neste capítulo estabelecemos uma descrição de alguns dos trabalhos relacionados ao cálculo de confiança e reputação em sistemas web, com o intuito de realizar uma análise comparativa entre eles, e estabelecer os fundamentos para o modelo proposto neste trabalho.

\subsection{Trabalhos relacionados ao cálculo de confiança e reputação}

Dentre os principais trabalhos relacionados a sistemas de reputação/confiança presentes na literatura, foram considerados os mais relevantes dentre aqueles que realizam o cálculo em sistemas descentralizados/centralizados e orientados a usuários, segundo a classificação da Seção 2.4.1, e principalmente que sejam orientados para comunidades (redes sociais, comunidade de prática, redes P2P). A seleção de tais trabalhos foi realizada considerando a ocorrência deles nas referências de artigos e trabalhos encontrados mediante pesquisa nos principais motores de busca com palavras como "Reputation System in Social Network", "Reputation and Trust System", "Sistemas de Reputação em comunidades web", entre outras.

\subsubsection{TidalTrust: Confiança em redes sociais baseadas na web}

No trabalho apresentado por Golbeck [2005] como parte de sua tese de Doutorado, Computing and Applying Trust in Web-Based Social Networks, a autora mostra como o uso das redes de confiança em redes sociais ajuda no cálculo de reputação e recomendação dos usuários da própria rede. Seu algoritmo de inferência de confiança, denominado TidalTrust, calcula o grau de confiança de um usuário (um usuário é representado como um nó em uma rede) a partir da avaliação feita pelos seus vizinhos. Como apresentado na Figura 3.1, para fazer a inferência do nó A (chamado de source) para o nó G (chamado de sink) o algoritmo começa com o nó A, e considera cada um de seus vizinhos considerados bons (ou com boa reputação), os outros são ignorados. Cada bom vizinho devolve um valor de avaliação do nó G. Então o nó A faz uma média dessas avaliações e arredonda o valor final. Assim, dependendo da avaliação dos vizinhos, um valor de reputação é 
inferido de $\mathrm{A}$ até $\mathrm{G}$.

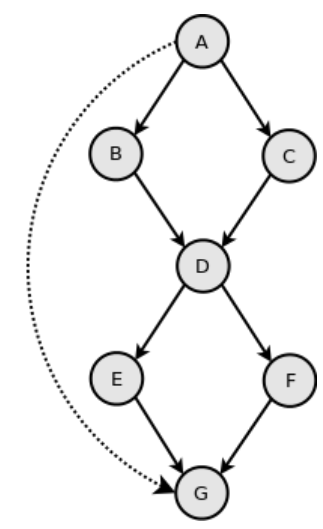

Figura 3.1: Inferência de confiança do nó A até o nó G. Adaptação de Golbeck [2005].

O algoritmo descrito foi utilizado para cálculo de reputação em um sistema de $e$-mail chamado de TrustMail. Nessa aplicação, são mostradas as avaliações de confiança dos remetentes de cada mensagem. Os usuários podem classificar suas caixas de entrada de acordo com a confiabilidade do remetente. Em outra aplicação seu modelo é utilizado em um sistema de recomendação de filmes chamado de FilmTrust, em que, a confiança é usada para personalizar o sítio web de cada usuário, exibindo as avaliações dos filmes recomendados e ordenando por relevância de opiniões. Em redes sociais, a informação é diversa, desde a informação do conteúdo até a informação dos usuários. As avaliações nesse tipo de sistemas, muitas vezes são focadas somente no conteúdo, e como a própria autora indica, isso é uma das limitações do modelo: a falta de disponibilidade de avaliações de confiança dos usuários da rede.

\subsubsection{T-SWEETS: Inferência de confiança em redes sociais}

Nas redes sociais é possível encontrar um ambiente em que as pessoas colaboram, propiciando a troca de experiência e a identificação de potenciais colaboradores para os próprios membros (colaboradores de confiança). Nessa estrutura é natural que um usuário não tenha contato pessoal com alguns outros usuários, porém, podem ser exploradas informações entre os membros para a identificação de relacionamentos ocultos de confiança. No trabalho apresentado por Silva et al. [2012] propõe-se um algoritmo de inferência de confiança, que explora os seguintes elementos:

- Compatibilidade entre usuários $(\operatorname{Corr}(a, b))$ : A similaridade ou correlação depende do contexto. Ela está baseada na relação de similaridade entre as avaliações realizadas entre os usuários $a$ e $b$ e a similaridade dos conhecimentos produzidos por eles.

- Transitividade de confiança $(\tau(a, b))$ : Pessoas indicam pessoas. O valor de confiança entre dois usuários $a$ e $b$ pode ser designado diretamente ou calculado a partir de uma composição de todos os caminhos que levem de $a$ até $b$.

- Nível de maturidade $(M(a))$ : Relevância do conhecimento compartilhado. A qualidade do conteúdo é calculada a partir de uma média ponderada das avaliações realizadas por outros usuários ao conteúdo compartilhado. 
- Reputação $(R(a))$ : Por atribuições de confiança. O cálculo de reputação consiste em uma média aritmética do conjunto de valores de confiança designados pelos usuários ao usuário $a$ e a quantidade de usuários nesse conjunto.

Assim, a inferência de confiança está definida por:

$$
C(a, b)=\frac{\alpha(\operatorname{Corr}(a, b))+\beta(T(a, b))+\gamma(M(b))+\delta(R(b))}{\alpha+\beta+\gamma+\delta}
$$

No qual, os valores $\alpha, \beta, \gamma$ e $\delta$ determinam a relevância de cada elemento e dependem do contexto em que o algoritmo é inserido.

O trabalho apresentado por Silva et al. [2012] identificou elementos úteis para serem usados na inferência de confiança em um ambiente social, principalmente a compatibilidade entre usuários. No entanto, não indica que tipo de mecanismos podem ser usados para enfrentar algumas das vulnerabilidades presentes em sistema de confiança e reputação, entre eles: Playbooks, conspiração ou ataque Sybil. Também, não é especificado como são tratadas as designações de valores negativos de confiança ou nas avaliações de conteúdo (valores que podem ser importantes na existência de um esquema de punições por conteúdo inapropriado).

\subsubsection{O modelo $\mathrm{ReCoP}$ e a reputação em comunidades de prática}

Atualmente, os sistemas de reputação mais utilizados estão na área de comércio eletrônico, assim, diversos modelos foram propostos para obter algum valor de reputação. No trabalho apresentado por Cruz [Cruz et al., 2007][Cruz, 2008] propõe-se um modelo para o Cálculo de Reputação em Comunidades de Prática ${ }^{1}$. Esse modelo considera possíveis tipos de interações usados em ambientes virtuais, estima estratégias aplicáveis a esses tipos de interação e adota alguns mecanismos de imunidade contra possíveis avaliações desonestas (descritos na Seção 2.4.3).

A implementação é feita no ambiente ActivUFRJ ${ }^{2}$. O objetivo desse trabalho é incentivar os membros de uma comunidade de prática a construir redes de confiança (compartilhando entre os membros da comunidade artefatos de interesse, conhecimentos e experiências sobre um tema).

O cálculo de reputação no modelo ReCoP está representado pela Equação 3.2:

$$
\operatorname{Rp}(\mathrm{P})=\frac{R p\left(a v a l_{1}\right)+R p\left(a v a l_{2}\right)+\ldots R p\left(a v a l_{n}\right)}{n}
$$

A reputação do usuário $P$ é estabelecida pela média das reputações obtidas nas suas avaliações mais recentes (que podem ser do mês corrente ou em un intervalo de tempo definido pela comunidade). A reputação de uma avaliação $\left(R p\left(\right.\right.$ aval $\left.\left._{i}\right)\right)$ é definida por:

$$
\operatorname{Rp}(\text { avaliação })=\sum_{m=1}^{q} r(m) * w(m)
$$

\footnotetext{
${ }^{1}$ Comunidades de prática: são grupos sociais que compartilham um interesse por algo que fazem e aprendem como fazê-lo melhor na medida que interagem regularmente. Matéria completa sobre Comunidades de Prática disponível em: www.ewenger.com.

${ }^{2}$ ActivUFRJ - sistema que apoia a formação de comunidades de prática no contexto acadêmico.
} 
Em que $r(m)$ é o valor da avaliação do usuário $m$ e $w(m)$ é o peso do usuário ou meta-avaliador que realizou a avaliação, $w(m)$ está definida por:

$$
w(m)=k *\left(\frac{R p(m)}{\sum_{m=1}^{n} R p(m)}\right)
$$

Dentre os mecanismos de reputação adotados pelo modelo está a utilização de Reputação Inicial, Grau de Concordância e Meta-avaliação no cálculo de reputação dos usuários e para esses mecanismos, foram dispostos os seguintes mecanismos de imunidade:

- Controle de identidade.

- Histórico de participação (para reconhecer tendências de comportamento).

- Peso de meta-avaliador (valor entre 1-10)

Considera-se também que o número de avaliações necessárias para que um item possa ser considerado no cálculo seja maior ou igual a 2.

No cálculo de reputação, o modelo ReCoP tenta considerar a maior quantidade de dados confiáveis da rede. Esses valores são baseados nas avaliações dos itens realizadas por outros usuários chamados de meta-avaliadores. Dentre os mecanismos de reputação definidos no modelo aparece a Rede de Confiança, que é uma rede criada pelos próprios membros da comunidade de acordo com seus interesses. Esse mecanismo não está incluso no escopo desse trabalho, mas Cruz et al. [2007] ressalta a importância da sua inclusão no modelo de cálculo de reputação.

\subsubsection{Modelo de reputação híbrido: Cálculo de reputação de agentes de software baseado em testemunhos}

No trabalho apresentado por Guedes [2007], propõe-se um modelo de reputação híbrido para sistemas multiagentes abertos que reúnem as características de abordagens de Modelos de Reputação centralizadas e descentralizadas. As reputações são promovidas pelos próprios agentes e o sistema centralizado, o qual fornece reputações confiáveis baseadas em testemunhas sobre comportamentos fora das normas do sistema. Nesse modelo, os agentes são aptos a avaliar o comportamento de outros agentes, tendo a capacidade de armazenar as reputações daqueles com os quais interagiram (modelo descentralizado). Na sua abordagem, considera que os sistemas multiagentes são compostos por organizações, em que os agentes desenvolvem papéis. Assim, as organizações avaliam a reputação dos seus participantes a partir dos testemunhos fornecidos por outros que interagiram com eles. Os testemunhos fornecidos indicam o mau comportamento dos participantes no sistema. Um subsistema de julgamento determina se o testemunho é verdadeiro. Com base no veredicto, o subsistema de reputação pune o agente que violou as regras, caso contrário, quem fez um mau testemunho é punido. Esse valor de reputação fica disponível para que qualquer indivíduo do sistema possa realizar a consulta. Se um agente "A" quer interagir com outro "B", então solicita o valor da sua reputação, tendo como resposta tanto o valor de reputação do indivíduo em questão fornecido pelo próprio agente e outro pelo sistema, assim "A" pode decidir se interage ou não.

A desvantagem do modelo usado, como o autor do trabalho indica, está no sistema de julgamento. Para um melhor cálculo de reputação é necessário que os agentes forneçam testemunhos de 
maus comportamentos de agentes com os quais interagiram, mas sem esses testemunhos, o valor de reputação dos infratores não é afetado e eles não são punidos. Esse tipo de vulnerabilidade foi descrito na Seção 2.4.2, "Dificuldade para obter feedback negativo", em que os agentes têm dificuldade em fornecer informação sobre maus comportamento por temor a represálias. No quandro resumo da classificação de modelos para o cálculo de reputação/confiança (Tabela 3.1) esse modelo está representado por REPORT*.

\subsubsection{LeaderRank: Identificação de líderes em redes}

As comunidades online podem amplificar o poder de influência de um número pequeno de usuários em benefício de todos os outros usuários da rede. Para consolidar a busca de informação nesse tipo de comunidade, é essencial utilizar uma topologia de liderança e identificar os usuários mais influentes (prestígio). Lü et al. [2011] elaboraram um algoritmo adaptativo e livre de parâmetros, chamado de LeaderRank, para quantificar a influência dos usuários em uma comunidade a partir das redes de liderança.

O modelo considera uma rede de $N$ nós e $M$ enlaces direcionados. Os nós correspondem aos usuários e os enlaces são relações de líder e seguidores. Para classificar os usuários, é incluído um nó base, que conecta cada nó do grafo, assim o grafo torna-se fortemente conexo. Para iniciar o processo, é designado um valor inicial para cada nó (exceto o nó base), o qual, eventualmente é distribuído por meio dos enlaces direcionais. O processo continua até chegar a um ponto de consenso. A seguinte equação representa a definição desse algoritmo:

$$
s_{i}(t+1)=\sum_{j=1}^{N+1} \frac{a_{j i}}{k_{j}^{o u t}} s_{j}(t)
$$

Em que, $\frac{a_{j i}}{k_{j}^{\text {out }}}$ representa a probabilidade de que um nó vá até outro nó da rede no tempo $t+1$, $a_{j i}=1$ se o nó $i$ direciona ao nó $j$, e $k_{j}^{o u t}$ denota o grau de saída do nó $j$ (número de líderes do nó $j$ ). Assim, $s_{i}(t)$ denota o valor da reputação do usuário $i$ no tempo $t$. Ao chegar ao consenso, o valor da reputação do nó base, $s_{g}$, é distribuído a todos os nós:

$$
S_{i}=s_{i}\left(t_{c}\right)+\frac{s_{g}\left(t_{c}\right)}{N}
$$

Esse algoritmo apresenta as seguintes vantagens: é um algoritmo livre de parâmetros, aplicável a diversos tipos de grafos ou redes, converge num único valor de reputação e tem independência de condições iniciais. Os valores considerados no algoritmo partem de uma rede de liderança em que são aceitos unicamente valores positivos na designação de liderança. Valores negativos como desconfiança em alguém não são considerados, o que pode causar perda de informação gerada a partir da experiência dos próprios usuários na sua interação com outros usuários.

\subsubsection{Algoritmos baseados em PageRank}

O algoritmo original, introduzido por Brin e Page [1998], calcula o valor e importância ou qualidade de páginas da web usando o número de ligações a uma página como um voto para o sítio web. Quanto mais votos tem uma página, mais importante será a página. A importância da página 
que outorga o voto determina o quão importante é o voto em si. A Equação 3.3 é a original que foi publicada quando o PageRank foi proposto.

$$
P R_{t}(A)=(1-d)+d\left(\frac{P R_{t-1}\left(y_{1}\right)}{C\left(y_{1}\right)}+\ldots+\frac{P R_{t-1}\left(y_{n}\right)}{C\left(y_{n}\right)}\right)
$$

Em que $y_{1}, \ldots, y_{n}$ são páginas que apontam para a página $A$, a função $C$, ou função de compromisso, representa o número de enlaces de saída que uma página tem, a variável $d$ é um fator de amortecimento usualmente considerado 0,85 .

\section{EigenTrust}

O modelo EigenTrust, proposto por Kamvar et al. [2003], é um modelo bem conhecido em sistemas de reputação em redes P2P e deriva do algoritmo PageRank. Basicamente, cada agente faz uso da propriedade de transitividade de confiança para determinar um valor global de confiança por cada agente. Um agente $x$ designa um valor de confiança a outros agentes $y$ baseado no seu histórico de contribuição. O modelo proposto faz uso de informação de matrizes de confiança e realiza uma série de iterações até que os valores estejam estáveis, gerando um valor global de confiança para cada agente. Um diferencial nessa proposta, foi a presença de agentes especiais dignos de confiança chamados de pre-trusted agentes, os quais são essenciais para garantir a convergência e detectar usuários maliciosos.

O modelo EigenTrust apresenta três diferentes versões: o Básico, o Distribuído e o Seguro. Na versão básica, cada agente designa um valor de confiança a seus conhecidos de acordo com suas interações, gerando valores de confiança locais. O conjunto de todos esses valores dá origem à matriz de valores de confiança. O processo de cálculo de confiança continua iterativamente até que os valores da matriz convirjam. A versão distribuída foi criada com o intuito de evitar que usuários mal-intencionados se agrupem deliberadamente para elevar seus valores globais de confiança. Nessa versão, são usados os agentes pre-trusted para calcular os valores globais de confiança. Na versão segura do modelo, os valores de confiança de cada agente $x$ são calculados por outros agentes $y$, a fim de evitar que $x$ manipule seu próprio valor de confiança. Com o objetivo de evitar usuários mal-intencionados que retornem resultados equivocados, os valores de confiança são armazenados por mais de um agente.

Como indica Mármol e Pérez [2009], na sua análise desse modelo, os pre-trusted agentes, que são aqueles que proporcionam serviços honestos, nem sempre reportam valores honestos de confiança. Portanto, o uso deles no cálculo de valores globais pode gerar resultados não muito confiáveis.

O trabalho apresentado por Zhou e Hwang [2007] apresenta uma alternativa ao trabalho de Kamvar na sua versão distribuída do EigenTrust. Zhou e Hwang, em seus estudos com o eBay, concluíram que o número de feedbacks segue a uma lei de distribuição de poder. Essa distribuição implica que nós com poucos feedbacks são muito comuns, e nós com grandes quantidades de feedbacks não são usuais. Portanto, só poucos nós são selecionados como nós de poder. O algoritmo PowerTrust funciona como o algoritmo de EigenTrust na versão distribuída, com a troca dos nós pre-trusted por nós de poder. 


\section{O NodePosition e a avaliação da posição dos usuários em redes sociais}

Kazienko et al. [2009] estudam a avaliação da posição dos nós em um grafo dirigido e ponderado que representa uma rede social, em que os nós são os usuários e os enlaces descrevem o fluxo de informações. A posição de um nó é usada para descobrir os usuários fundamentais da rede, que são os mais importantes na população e são potencialmente os de maior influência e, provavelmente, os de mais alto nível de confiança. Nesse trabalho, é considerada tanto a posição dos vizinhos dos nós como a força da sua conexão na rede. Na fase de experimentação do modelo, é usada uma rede de usuários de correio eletrônico para calcular a posição dos usuários e descobrir os nós mais relevantes. Na Figura 3.2 apresenta-se um exemplo desse tipo de rede.

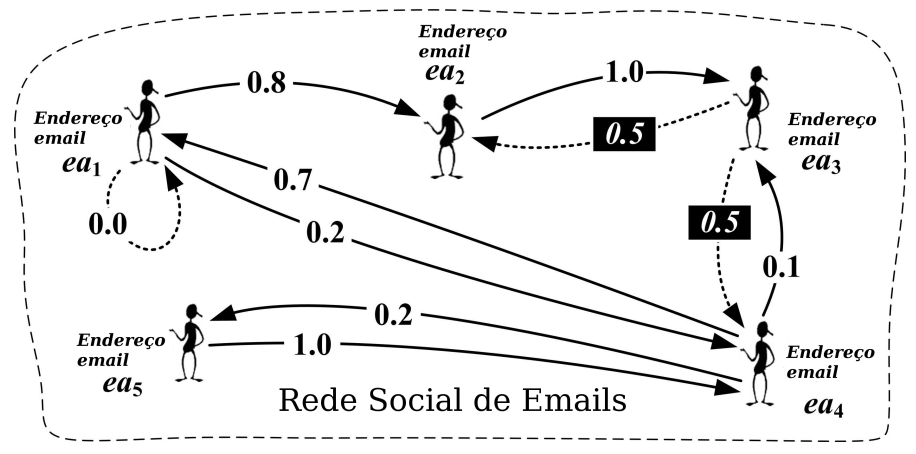

Figura 3.2: Exemplo de uma rede social de mensagens com os valores das funções de compromisso. Adaptação de Kazienko et al. [2009].

Nessa abordagem usa-se uma modificação do algoritmo PageRank, cuja medida de posição de nós leva em consideração não só suas conexões diretas, mas também a qualidade da conexão. Essa variação é dada pela Equação 3.4, apresentando o modelo Node Position:

$$
N P(x)=(1-\varepsilon)+\varepsilon\left(N P\left(y_{1}\right) * C\left(y_{1} \rightarrow x\right)+\ldots+N P\left(y_{m}\right) * C\left(y_{m} \rightarrow x\right)\right)
$$

No qual $\varepsilon$ é um coeficiente constante no intervalo de $[0 ; 1]$, a função de compromisso $C(y \rightarrow x)$ é definida como $C(y \rightarrow x)=\frac{A(y \rightarrow x)}{\sum_{j=1}^{m} A\left(y \rightarrow x_{j}\right)}$, e $A(y \rightarrow x)$ é a função que denota a atividade do nó $y$ dirigido ao nó $x$, como por exemplo, o número de mensagens encaminhadas por $y$ para $x ; m$ denota o número de todos os nós da rede social.

Essa medida de posição viabiliza a análise do comportamento dos usuários na rede. No trabalho subsequente [Musiał et al., 2009], a variação é comparada com outros métodos que são usados para avaliar a posição dos usuários (chamada também de prestígio) em uma rede social. Esses métodos são: prestígio ou centralidade por grau de entrada, centralidade por grau de saída, centralidade por proximidade, centralidade por excentricidade e Node Position. De acordo com os experimentos realizados nesse trabalho, o Node Position foi o mais preciso, porém ele pode ser ineficaz em redes maiores. O método Node Position tem uma vantagem frente aos outros devido à flexibilidade que o coeficiente outorga (o uso de uma condição de parada pode resultar em um número menor de iterações). No entanto, o modelo não descreve a aceitação de designações de valores negativos na função de compromisso para cálculo da posição dos nós, essa definição está descrita na Seção 5.2.2. 


\subsubsection{TrustExpert: Sistema de reputação em subcomunidades}

As comunidades virtuais são cada vez mais heterogêneas, o que implica que uma comunidade pode ser vista como uma coleção de subcomunidades. Gal-Oz et al. [2008] propõem um modelo de reputação de usuários de uma comunidade capaz de tratar com comunidades heterogêneas, nas quais, a reputação de um usuário é distribuída entre as diversas subcomunidades.

O modelo contém três módulos: o módulo de inferência de confiança, que identifica os relacionamentos de confiança entre os membros; o módulo de criação de subcomunidades, que usa o módulo anterior para criar subcomunidade de confiança e; o módulo de cálculo de reputação, que primeiro calcula valores locais de reputação dentro das subcomunidades e depois calcula os valores globais de reputação para a comunidade. Contudo, também leva em consideração a experiência dos usuários e avaliação por intervalos de tempo (os pesos das avaliações são diretamente proporcionais aos períodos de criação, quanto mais recente maior o peso). O experimento usado para avaliar o modelo usou o conjunto de dados públicos da comunidade de recomendação de filmes MovieLens ${ }^{3}$. Os resultados obtidos mostraram que o modelo TrustExpert melhora o sistema de predição em relação a outros tipos de abordagens para o cálculo de confiança. No entanto, o modelo está fortemente ligado às personalidades que mostram os usuários. Quanto mais personalidades expressa o usuário, mais ele estará sujeito a subcomunidades e com isso o esquema do algoritmo se torna mais complexo.

Na Tabela 3.1 é apresentado o resumo dos trabalhos relacionados descritos sobre os modelos de confiança e reputação e suas principais características. A descrição da tipologia usada é especificada na Seção 2.4.1 (como sistemas de tipo centralizado/descentralizado, usuário/recurso, local/global). Em adição às propriedades descritas, foi incluída a coluna de "Av. (-)", que indica que o modelo aceita valores negativos para o cálculo de reputação/confiança.

\begin{tabular}{|l|c|c|c|c|c|c|c|c|c|}
\hline \multirow{2}{*}{ Modelo } & \multicolumn{2}{|c|}{$1^{\circ}$ Propriedade } & \multicolumn{2}{c|}{$2^{\circ}$ Propriedade } & \multicolumn{2}{c|}{$3^{\circ}$ Propriedade } & Tipo de Av. & Av. \\
\cline { 2 - 10 } & Cent. & Desc. & Usuário & Cont. & Global & Local & Usuário & Cont. & $(-)$ \\
\hline \hline TidalTrust & & $\mathrm{x}$ & $\mathrm{x}$ & & & $\mathrm{x}$ & $\mathrm{x}$ & & $\mathrm{Não}$ \\
\hline ReCoP & $\mathrm{x}$ & & $\mathrm{x}$ & & $\mathrm{x}$ & $\mathrm{x}$ & $\mathrm{x}$ & $\mathrm{x}$ & Sim \\
\hline REPORT* & $\mathrm{x}$ & $\mathrm{x}$ & $\mathrm{x}$ & & $\mathrm{x}$ & $\mathrm{x}$ & $\mathrm{x}$ & & Sim \\
\hline NodePosition & $\mathrm{x}$ & & $\mathrm{x}$ & & $\mathrm{x}$ & & & $\mathrm{x}$ & Não \\
\hline LeaderRank & $\mathrm{x}$ & & $\mathrm{x}$ & & $\mathrm{x}$ & & $\mathrm{x}$ & & Não \\
\hline PageRank & $\mathrm{x}$ & & & $\mathrm{x}$ & $\mathrm{x}$ & & $\mathrm{x}$ & $\mathrm{x}$ & Não \\
\hline EigenTrust & & $\mathrm{x}$ & $\mathrm{x}$ & & $\mathrm{x}$ & $\mathrm{x}$ & $\mathrm{x}$ & & Sim \\
\hline PowerTrust & & $\mathrm{x}$ & $\mathrm{x}$ & & $\mathrm{x}$ & & $\mathrm{x}$ & & Sim \\
\hline TrustExpert & $\mathrm{x}$ & & $\mathrm{x}$ & & $\mathrm{x}$ & & $\mathrm{x}$ & & Sim \\
\hline
\end{tabular}

Tabela 3.1: Quadro resumo da classificação de modelos para o cálculo de reputação/confiança.

\subsection{Considerações finais}

Neste capítulo foram apresentados alguns dos trabalhos relacionados encontrados na literatura para o cálculo de reputação. No capítulo seguinte será apresentada uma análise de domínio, realizada a fim de verificar as ocorrências das formas de coletas de dados e os mecanismos utilizados

\footnotetext{
${ }^{3}$ Experts-exchange. Disponível em: http://www.experts-exchange.com/.
} 
em sistemas de reputação na Web 2.0. O domínio explorado abarca sistemas que possuem características de sistemas colaborativos e que tenham mecanismos para o cálculo de reputação de seus participantes a partir da interação. 


\title{
Capítulo 4
}

\section{Análise de domínio: Cálculo de reputação em sistemas Web 2.0}

\author{
"São necessários 20 anos para construir uma reputação e \\ cinco minutos para destruí-la" \\ Warren Buffett
}

Neste capítulo, é apresentada uma avaliação de alguns sítios da Web 2.0 que utilizam a reputação como parte de suas funcionalidades para classificar usuários. A avaliação foi realizada de forma inspirada na técnica denominada FODA (Feature-Oriented Domain Analysis), para a identificação de características comuns e variáveis de aplicações do domínio.

\subsection{FODA}

O termo domínio, em engenharia de software, é usado para denotar um conjunto de sistemas com as mesmas funcionalidades e a análise de domínio é uma das etapas da engenharia de domínio. Segundo Prieto-Díaz e Arango [1991], a engenharia de domínio possibilita que características comuns e variáveis sejam identificadas e organizadas utilizando um processo previamente definido. A análise de domínio identifica, coleta e organiza informações relevantes do domínio, utilizando para tal o conhecimento existente e as técnicas para modelagem de informação [Kang et al., 1990]. Segundo Oliveira [2010], as aplicações de um mesmo domínio que possuem funcionalidades recorrentes, podem valer-se de reúso por meio de componentes.

Neste trabalho, foi escolhida a técnica FODA ou Feature-Oriented Domain Analysis [Kang et al., 1990], um método de engenharia de domínio orientado a características. Ele busca identificar, coletar e organizar informações relevantes do domínio, as características comuns e variáveis de aplicações. De acordo com Kang et al. [1990], essas características são atributos do sistema que afetam diretamente os usuários finais.

Neste trabalho, focamos a fase de identificação de características do FODA. 


\subsection{Estudo: Avaliação e cálculo de reputação em sistemas web 2.0}

Para classificar as características levantadas, foi utilizado o modelo 3C de colaboração apresentado na Seção 2.2.1. A análise de domínio foi feita de modo similar à apresentada nos trabalhos de Oliveira e Gerosa [2010] e Michalsky et al. [2010], nos quais foi feita uma análise tendo como domínio o compartilhamento de conteúdos em redes sociais e em sítios web de jornalismo online, respectivamente.

A análise realizada neste trabalho, restringiu-se a sistemas colaborativos da Web 2.0 que tenham dentre suas funcionalidades o cálculo de reputação ou classificação de usuários a partir da interação. Alguns dos sítios avaliados usam o valor de reputação como uma medida aproximada de quanto a comunidade confia nos conhecimentos de um usuário, outros sítios usam esse valor só como um indicador da atividade realizada pelos usuários. Foram avaliados um total de 17 sítios, descritos a seguir (Tabela 4.1), dentre os quais se destacam os fóruns de discussão.

\begin{tabular}{|l|l|l|}
\hline & Link do sítio web & Nome do sítio \\
\hline \hline $1^{o}$ & www.stackoverflow.com & Stackoverflow \\
\hline $2^{o}$ & www.guj.com.br & GUJ \\
\hline $3^{\circ}$ & www.shutterasia.com & Shutterasia \\
\hline $4^{o}$ & www.osqa.net & Osqa \\
\hline $5^{o}$ & www.daniweb.com & Daniweb \\
\hline $6^{o}$ & slashdot.org & Slashdot \\
\hline $7^{o}$ & www.reddit.com & Reddit \\
\hline $8^{o}$ & news.ycombinator.com & Hacker news \\
\hline $9^{o}$ & br.kekanto.com & Kekanto \\
\hline $10^{\circ}$ & www.ratemyprofessors.com & Rate my professor \\
\hline $11^{\circ}$ & launchpad.net & Launchpad \\
\hline $12^{\circ}$ & www.allvoices.com & Allvoices \\
\hline $13^{o}$ & wave.google.com & Google wave \\
\hline $14^{o}$ & www.scribophile.com & Scribophile \\
\hline $15^{\circ}$ & www.colourlovers.com & ColourLovers \\
\hline $16^{o}$ & www.dihitt.com.br & Dihitt \\
\hline $17^{o}$ & visible.me & Visible.me \\
\hline
\end{tabular}

Tabela 4.1: Lista de sítios web avaliados na análise de dominio.

Cada característica foi avaliada em cada sítio web em que aparece e classificada de acordo com sua função na colaboração: comunicação, coordenação, cooperação ou interação com o sistema. Foram também avaliadas suas variabilidades. Finalmente, foram incluídas algumas particularidades de caráter adicional. As características foram descritas seguindo o padrão apresentado na Tabela 4.2 [Michalsky et al., 2010].

A descrição das características consideradas para a análise de domínio, é apresentada no trabalho de Michalsky et al. [2010]. Essas características são: comentário, enquete, lista de discussão, denúncia, seguir tópico, atividades recentes, avaliação, busca, categorização, compartilhamento, navegação, produção, recomendação, TAGs, upload, filtragem colaborativa, salvar e versão de impressão; contudo, foram adicionadas as características de Estatística e Favoritos, pois elas representam as escolhas realizadas pelos usuários dentre o conteúdo compartilhado. 


\begin{tabular}{|l|l|}
\hline Nome & $\begin{array}{l}\text { O nome sintetiza o padrão. É usado na comunicação diária } \\
\text { dentro do projeto. }\end{array}$ \\
\hline Intenção & $\begin{array}{l}\text { Descreve o ponto central de uma solução em apenas uma } \\
\text { frase. }\end{array}$ \\
\hline Contexto & Descreve a situação em que o padrão é usado. \\
\hline
\end{tabular}

Tabela 4.2: Padrão de descrição de características colaborativas.

Na Tabela 4.3 estão descritas algumas características adicionais presentes em alguns dos sítios web analisados.

\begin{tabular}{|l|l|}
\hline Nome & Descrição (Possibilita aos participantes ...) \\
\hline \hline Rede de amigos & Adicionarem usuários a sua rede a amigos. \\
\hline Privilégios & $\begin{array}{l}\text { Terem acesso a características específicas sobre o sistema a } \\
\text { partir de seu grau de reputação (karma) no sistema. }\end{array}$ \\
\hline Distintivos & $\begin{array}{l}\text { Terem diversos distintivos (emblemas, símbolos, medalhas, } \\
\text { insígnias, estrelinhas, entre outros) a partir de seu grau de } \\
\text { reputação ou karma no sistema. }\end{array}$ \\
\hline Moderação & $\begin{array}{l}\text { Terem acesso a atividades de moderação do conteúdo com- } \\
\text { partilhado no sistema a partir do grau de reputação. }\end{array}$ \\
\hline
\end{tabular}

Tabela 4.3: Lista das características dependentes da reputação.

Apenas algumas das características levantadas possuem variabilidades, que são apresentadas nesta subseção, indicando seus diferentes usos e contextos.

Um termo considerado importante nesta análise é o termo karma. Nos sistemas avaliados, esse termo é representado por um número que é um reflexo da contribuição que o usuário fez no sistema e usualmente é referido como pontos de reputação. Ele é usualmente calculado por meio de uma soma simples ou média das avaliações. Esse tipo de representação pode ser observado na Figura 4.1 em que é indicado o valor quantitativo da reputação dos usuários. Na mesma figura, é apresentado outro tipo de representação de karma, além de distintivos do usuário.
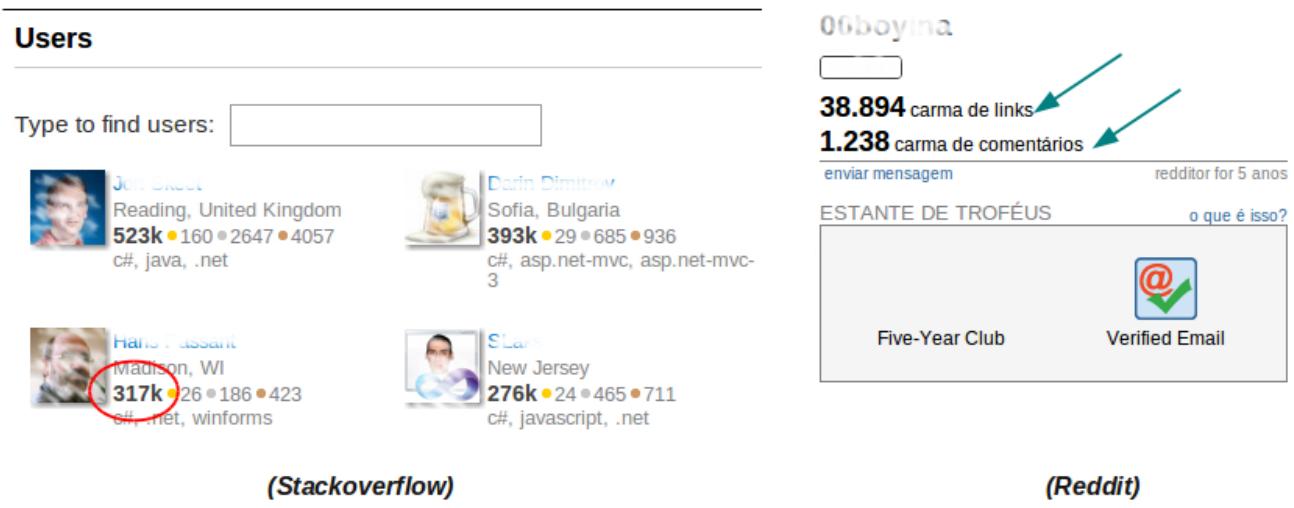

Figura 4.1: Representação da reputação dos usuários nos sítios web Stackoverflow e Reddit.

Entre as características adicionais estão os Distintivos. Essa característica é apresentada em 
forma de símbolos que são outorgados aos usuários como recompensa pela sua contribuição no sítio web. Esses símbolos representam desde qualidade do conteúdo até tempo de participação. Na Figura 4.2 são apresentados alguns exemplos encontrados nos sítios web avaliados. Os números que acompanham esses distintivos indicam a quantidade de usuários que possuem tal distinção (Último acesso:15 janeiro 2013).

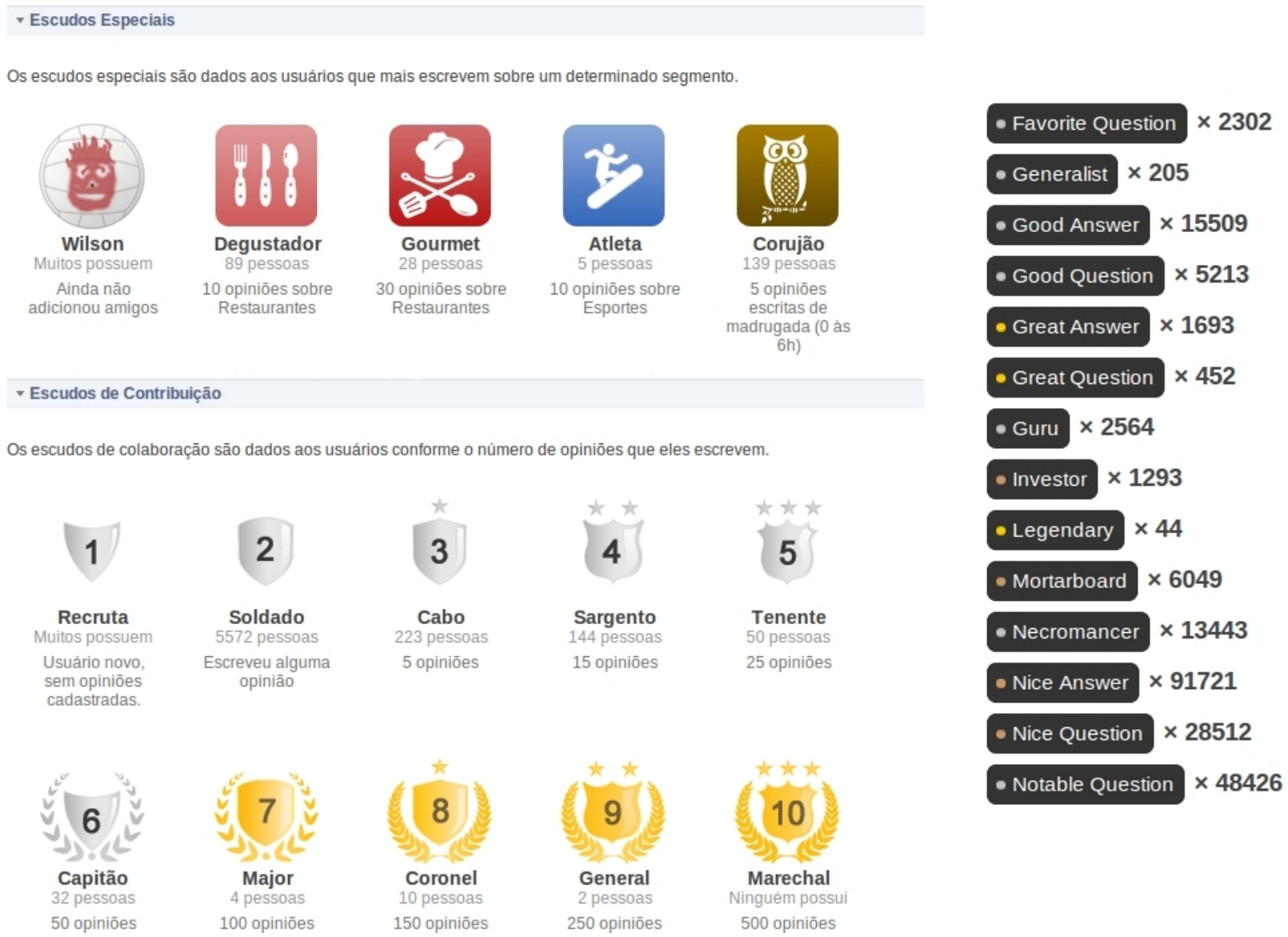

Figura 4.2: Distintivos nos sitios web Kekanto e Stackoverflow.

\subsection{Análise das características}

Na Tabela 4.4 é apresentado o resultado da análise em que é classificada cada característica, incluindo as características adicionais como Rede de amigos, Privilégios, Distintivos e Moderação. Cada interseção marcada representa que a característica está implementada no sítio web. As marcadas com $\mathbf{P}$ indicam que a característica está presente, mas não influencia no cálculo de reputação dos usuários e as marcadas com $\mathbf{I}$ influenciam (a influência pode ser positiva ou negativa).

Algumas características como Produção contemplam funcionalidades adicionais como: iniciar, editar e fechar post, criar novas wikis, links, opiniões, notícias e atualizar dados. Na análise feita, pode-se observar que a característica que influi diretamente no cálculo de reputação é a avaliação, que pode ser positiva ou negativa; no caso de ser negativa, indica que a contribuição é de baixa qualidade ou inapropriada. Outras características como Comentário, Denúncia e Produção apoiam no cálculo de reputação, mas não diretamente, pois essas contribuições são avaliadas por outros 
usuários e, assim, passam por um filtro de qualidade.

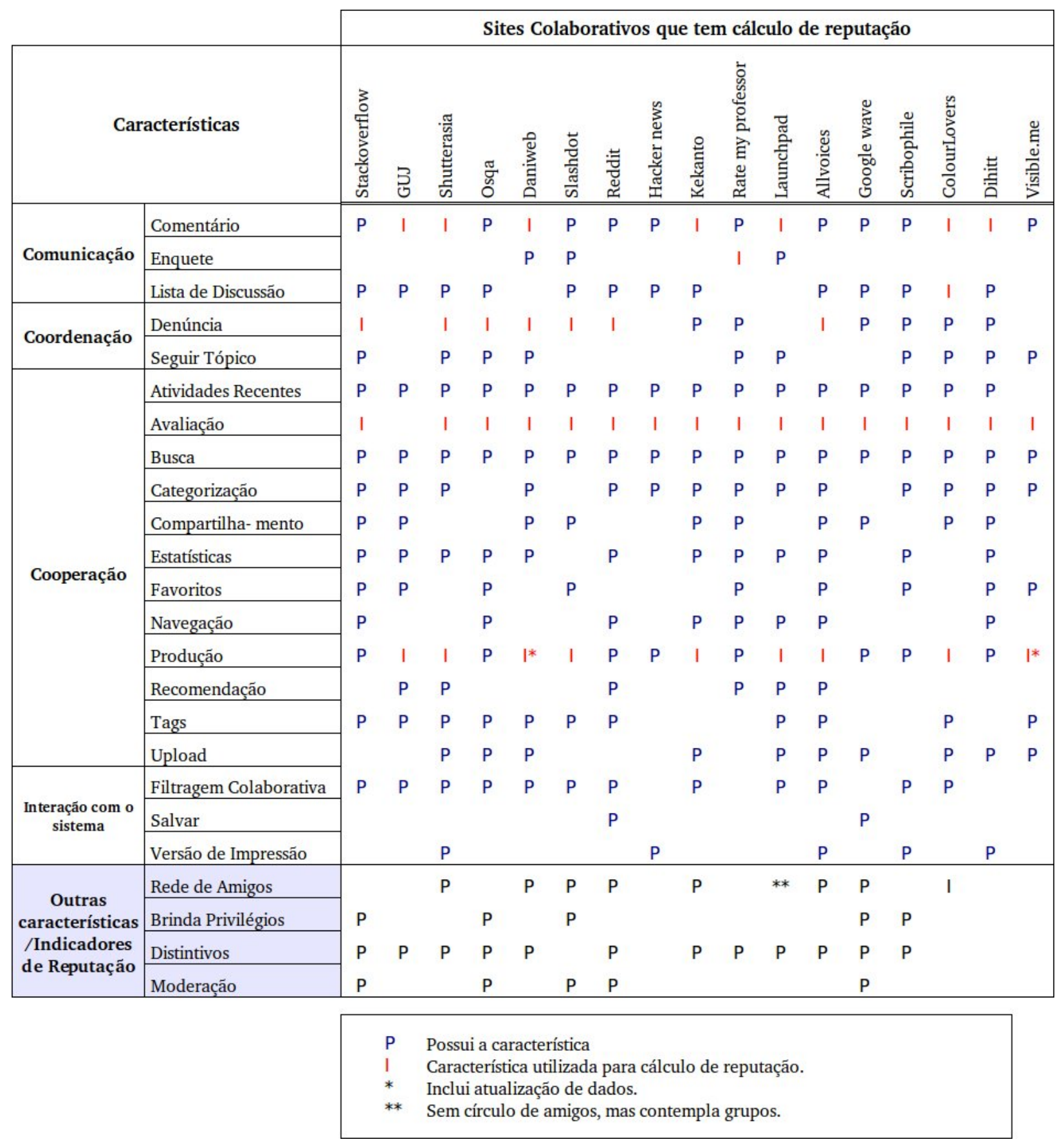

Tabela 4.4: Avaliação das características.

Pouco mais de $50 \%$ dos sítios web avaliados na Tabela 4.4 possibilita a criação de redes de usuários (Rede de Amigos). Somente em alguns casos o nível ou grau de reputação indica algum nível de status no sistema. Os sítios web que possuem a característica de Brindar Privilégios utilizam o grau de reputação (karma) para outorgar funcionalidades adicionais aos usuários do sistema.

Em alguns dos sistemas avaliados, há uma lista das funcionalidades disponíveis, mas é preciso ter um mínimo de reputação (a reputação é representada numericamente). A seguinte lista foi extraída 
do sítio Stackoverflow:

- 15 Possibilita aos usuários avaliarem.

- 15 Possibilita aos usuários sinalizarem um conteúdo como não apropriado.

- 50 Possibilita aos usuários deixarem comentários.

- 100 Possibilita editar as mensagens da comunidade.

- 125 Possibilita denunciar conteúdo (mas custa 1 ponto de reputação).

- 250 Possibilita aos usuários fecharem e reabrirem perguntas.

- 1500 Possibilita aos usuários criarem TAGs.

- 2000 Possibilita aos usuários editarem conteúdo postado por outros usuários, entre outras.

Os usuários que tiverem suas contribuições julgadas de forma positiva pela comunidade ganham pontos e distintivos de destaques (indicadores de reputação). Essa característica está presente em alguns dos sítios web avaliados com o nome Distintivos. Muitos usuários ganham distintivos conforme realizam atividades no sistema.

Outra característica avaliada é a de Moderação. Os sítios web colaborativos têm uma importante quantidade de dados, que são produzidos diariamente por usuários das mais diversas áreas culturais. Para preservar a qualidade da informação compartilhada, o papel de moderador cumpre uma tarefa importante, que é a de manter o conteúdo limpo de informação inapropriada. A totalidade dos sítios web avaliados possui a funcionalidade de moderação, mas ela não está aberta para toda a comunidade. Os sítios web indicados com $\mathbf{P}$ nessa característica possibilitam aos usuários com melhores níveis de reputação serem colaboradores ativos na moderação dos conteúdos. Essa característica possibilita que o sistema seja auto-sustentável, e gerenciado pelos próprios usuários que têm maior atividade e interesse na colaboração.

\subsection{Considerações finais}

Neste capítulo, foi apresentada uma análise de domínio para a identificação de características comuns em sistemas Web 2.0 para o cálculo de reputação dos usuários. O termo karma é considerado por alguns usuários como uma pontuação em um jogo de colaboração, visto que para eles o valor não é de muita relevância, uma vez que há casos nos quais os usuários com alto valor no karma e com distintivos altos colaboram pobremente no sistema, com conteúdo de baixa qualidade, porém em grande quantidade. Em redes especializadas, cujos usuários têm interesses comuns, o valor de reputação pode ser de ajuda na filtragem de indivíduos que aportam conteúdo de baixa qualidade. Aqui a expectativa é incentivar os usuários na produção de conteúdo de boa qualidade e em boa quantidade. A análise realizada neste capítulo foi usada na concepção do modelo apresentado no capítulo seguinte para o cálculo de reputação dos participantes de uma rede social. 


\section{Capítulo 5}

\section{Modelo proposto para o cálculo de reputação de participantes}

"Se você encontrar um caminho sem obstáculos,
ele provavelmente não leva a lugar nenhum."

Frank Clark

Neste capítulo é descrito o modelo proposto para o cálculo de reputação em Redes Sociais.

\subsection{Descrição}

O modelo proposto parte da premissa de que, dentro de uma comunidade, os participantes interagem, compartilham conteúdo e têm critérios de avaliação da qualidade dos dados. As interações dependem do grau de familiaridade ou domínio de conhecimento na área, assim, podemos considerar que cada usuário tem um grau de reputação que reflete sua participação no sistema. De forma igual, os usuários conhecem e interagem com outros usuários, compartilham atividades e, em alguns casos, estabelecem laços de amizade criando uma rede de relacionamento.

Em sistemas colaborativos, a confiança cumpre um papel importante no compartilhamento de conteúdo. Os dados criados por usuários com boa reputação são mais valorizados em qualidade do que dados compartilhados por usuários com má reputação. Cada interação, que pode ser qualitativa ou quantitativa, realizada por um usuário afeta sua reputação na rede. Nas interações qualitativas os usuários fornecem valores de qualidade ao conteúdo criado por outros usuários, ou a outros usuários. Interações que não podem ser medidas qualitativamente podem ser medidas pela quantidade, como por exemplo, o número de visitas a uma página, utilização de TAGs, número de comentários postados, entre outros.

Nesse cenário, foi idealizado o esquema da Figura 5.1 que combina dois tipos de abordagens: dados de confiança de uma rede de relacionamento (a partir de uma rede de confiança) e dados originados da interação dos usuários (obtidos mediante mecanismos de interação). Nesse modelo, o ponto de partida é a informação fornecida pelos usuários, dividida em dois tipos de entrada:

1. A rede de confiança: os próprios usuários designam valores de confiança aos usuários da sua rede de amizade ou relacionamento. 
2. Os mecanismos de interação: os mecanismos de interação são aqueles que capturam as ações dos usuários, como realização de comentários, envio de fotos, avaliação de itens, entre outros. Esses mecanismos podem ser de avaliação ou de contribuição ( 5.2.1). Com a análise de domínio descrito no capítulo anterior (Capítulo 4), foram identificados os principais mecanismos contribuidores no cálculo de reputação em sítios web.

Essa informação pode ser usada para calcular um valor de reputação dos participantes a partir da suas interações com outros participantes. A classificação resultante objetiva apoiar os usuários a interagirem com usuários de boa reputação e evitar usuários pouco confiáveis.

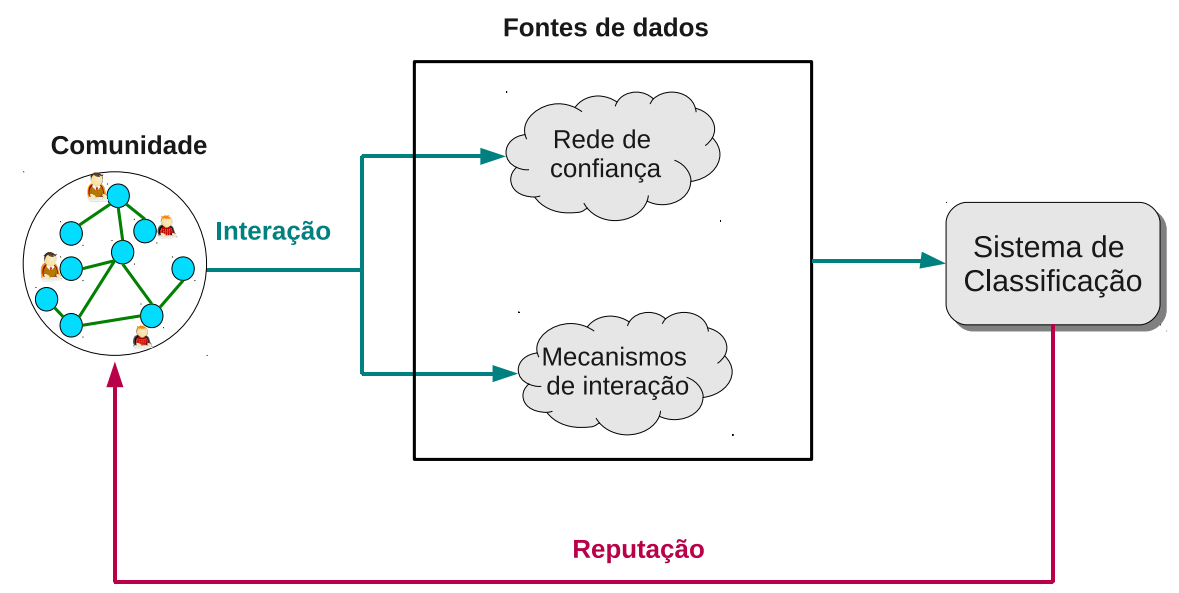

Figura 5.1: Esquema do modelo proposto que combina abordagens dos sistemas de interação e confiança.

\subsection{Cálculo de reputação}

Neste trabalho é usada uma adaptação do algoritmo PageRank para o cálculo de reputação dos usuários de uma rede social, levando em consideração: dados qualitativos e quantitativos das interações dos usuários, e as avaliações de confiança realizadas entre os participantes.

A adaptação do algoritmo original para seu uso em redes sociais parte das seguintes necessidades:

- Admitir valores negativos de associação entre os nós da rede [Massa, 2005], comportamento que é possível nas comunidades virtuais.

- A função de compromisso do algoritmo PageRank sugere que cada enlace tem um peso de 1, mas, em comunidades, os enlaces (avaliações) entre os usuários e os conteúdos não estão restritos a valores 0 ou 1. Por exemplo, as avaliações de conteúdo podem estar dentro do intervalo [0..1] ou ser negativas (como no caso de avaliações de denúncia).

Com isso, neste trabalho é proposta uma adaptação do algoritmo PageRank, seguindo como base os trabalhos desenvolvidos por Musiał et al. [2009] e Kazienko et al. [2009], com o algoritmo Node Position, apresentado no Capítulo 3. A proposta definida está dividida em três partes: 
- Na primeira, define-se as fontes de dados usadas para o cálculo, como por exemplo a rede de confiança e dados dos mecanismos de interação.

- Na segunda, indica-se a formulação do sistema de reputação usando as fontes de dados descritas.

- Na terceira, apresenta-se alguns mecanismos de imunidade para o modelo proposto com o objetivo de oferecer suporte a alguns dos desafios de sistemas de reputação.

\subsubsection{Fontes de Dados}

Os dados provenientes das diferentes fontes podem ser de dois tipos: dados qualitativos ou dados quantitativos. Os dados qualitativos representam os valores da qualidade das entidades na visão de outras entidades. Os dados quantitativos representam o valor da contribuição realizada pelas entidades. Para exemplificar são apresentados na Tabela 5.1 alguns dados classificados como dados quantitativos e qualitativos.

\begin{tabular}{|l|l|}
\hline Dados Quantitativos & Dados Qualitativos (interpretativos) \\
\hline \hline Criação de comentários & Avaliação de comentários \\
\hline Criação de TAGs & Avaliação de fotos \\
\hline Upload de fotos & Avaliação de perguntas \\
\hline Realização de perguntas & Avaliação de respostas \\
\hline & Denúncia de conteúdo inapropriado \\
\hline & Denúncia de abuso \\
\hline & Avaliação de usuários na rede de relacionamento \\
\hline
\end{tabular}

Tabela 5.1: Tabela resumo dos tipos de dados.

\section{Rede de confiança}

Parte da fonte de dados do modelo deste trabalho é a rede de confiança dos participantes. Um usuário tem um conjunto de amigos na sua rede de amizade. O laço de amizade criado por um usuário com outros é produto de algum acontecimento prévio como, por exemplo, ambos os participantes se conheciam anteriormente, esses participantes são colegas em algum curso, se conheceram na rede e decidiram adicionar-se, entre outros. Na criação dessa rede de confiança, os usuários designam valores de confiança aos membros da sua rede de amizade.

Um dos trabalhos no campo da ciência da computação que formaliza o conceito de confiança é a dissertação de doutorado de Marsh [1994], "Formalising Trust as a Computational Concept". A estratificação dos valores de confiança considerados neste trabalho são os especificados por Marsh e estão dentro do intervalo de $[-1,1]$ como pode ser visualizado na Tabela 5.2. Esses valores indicam o quanto um participante confia em outro e está sujeito à premissa geral: "Compartilhar informação de qualidade". Essa premissa define que: "Eu, o usuário $y$, confio que o usuário $x$ compartilhará informação de qualidade e relevância para a comunidade". A confiança, nesse caso, é definida como o valor esperado do resultado obtido a partir das ações do usuário $x$; no entanto, a premissa pode ser aprofundada ainda mais, como, por exemplo, compartilhar comentários de qualidade, compartilhar boas fotos, avaliar conteúdo, editar informação, criar perguntas, fornecer respostas, entre outros, 
que podem servir para refinar os resultados no cálculo de reputação (realizando o cálculo por habilidade). Para os fins deste trabalho, foi utilizada só uma medida de confiança - a premissa geral.

\begin{tabular}{|l|c|}
\hline Confiança & Faixa \\
\hline \hline Confiança absoluta & +1 \\
\hline Confiança muito alta & $>0,9$ \\
\hline Confiança alta & 0,75 até 0,9 \\
\hline Confiança média alta & 0,5 até 0,75 \\
\hline Confiança média baixa & 0,25 até 0,5 \\
\hline Confiança baixa & 0 até 0,25 \\
\hline \hline Desconfiança baixa & $-0,25$ até 0 \\
\hline Desconfiança média baixa & $-0,5$ até $-0,25$ \\
\hline Desconfiança média alta & $-0,75$ até $-0,5$ \\
\hline Desconfiança alta & $-0,9$ até $-0,75$ \\
\hline Desconfiança muito alta & $<-0,9$ \\
\hline Desconfiança absoluta & $-1,0$ \\
\hline
\end{tabular}

Tabela 5.2: Possivel estratificação de valores de confiança. Adaptação de Marsh [1994].

Na Figura 5.2 é apresentado um esquema de uma rede de confiança, em que os usuários são representados pelos nós $w, x, y$ e $z$. Cada um deles tem um conjunto de amigos na sua rede de amizade (os relacionamentos são representados pelas setas bidirecionais) e as avaliações efetuadas pelos usuários (valores apresentados por "confiança( nó $\rightarrow$ nó)") são usadas para calcular o valor da reputação. A rede de confiança tem como objetivo o fornecimento de valores qualitativos ao sistema de reputação.

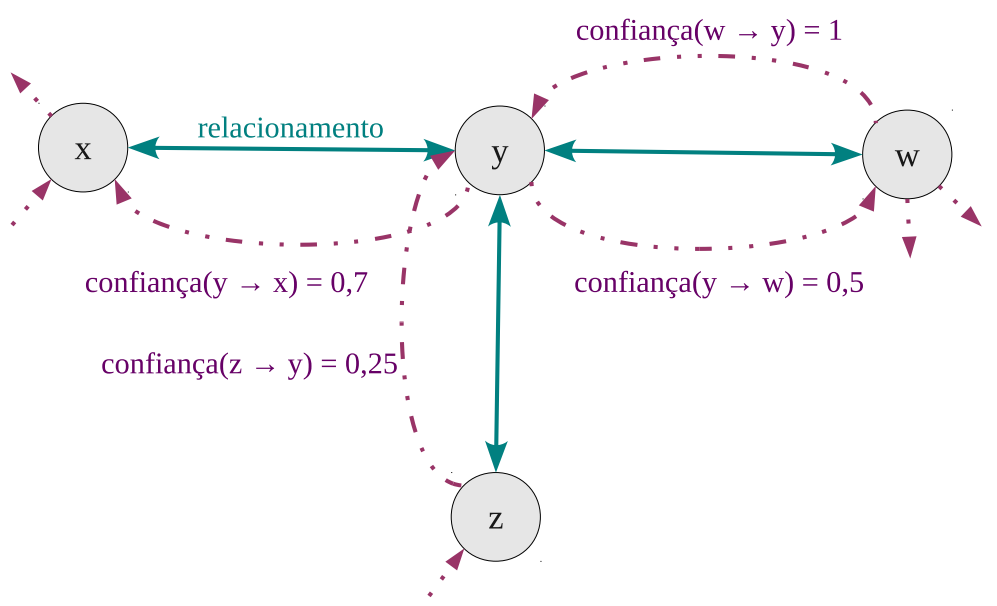

Figura 5.2: Representação de rede de confiança.

\section{Mecanismos de interação}

Os mecanismos de interação capturam os valores das interações dos usuários. Essas interações podem ser de contribuição ou avaliação. As interações de contribuição não precisam de mecanismos de avaliação para medir a qualidade da contribuição, pois simplesmente indicam que o usuário fez contribuições no sistema. Exemplos desse tipo de interação são: adicionar comentário, fazer upload de foto, criar novas perguntas, iniciar nova discussão, entre outros. 
Na Figura 5.3 é apresentado um esquema desse tipo de interação, em que o valor das contribuições realizadas pelos usuários é armazenado em cada nó do grafo.

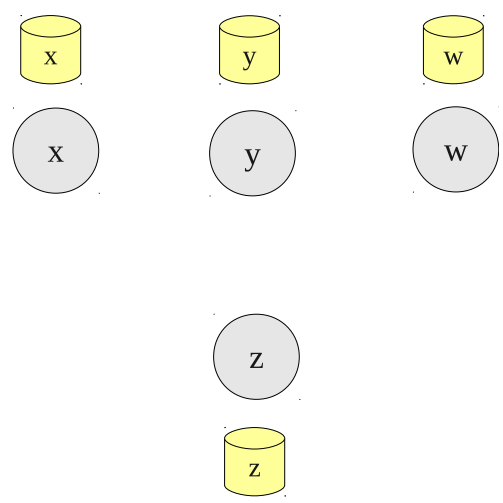

Figura 5.3: Informação da contribuição. A informação das contribuições de cada nó está armazenada no próprio nó.

Por intermédio dos mecanismos de avaliação são capturados os valores das interações de avaliação. Esses valores representam a qualidade das interações de contribuição. Cada participante realiza diferentes contribuições, que chamaremos de itens, e cada item é avaliado por diversos participantes.

Na Figura 5.4 é apresentada uma rede baseada nas interações de avaliação realizadas pelos usuários. Nesse tipo de rede não há necessidade de relacionamentos de amizade entre os participantes. Outro aspecto a ser levado em consideração é que qualquer usuário y pode designar valores de qualidade aos $k$ itens de qualquer outro usuário $x$, sendo $k$ é o número de itens compartilhados pelo usuário $x$.

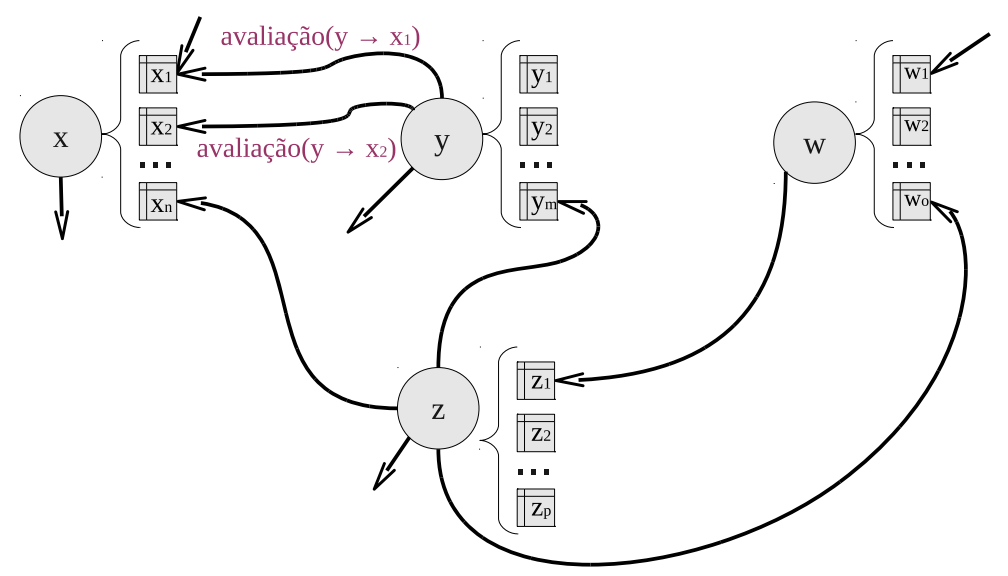

Figura 5.4: Rede de interação de avaliação. As setas representam a designação de avaliações a conteúdo que foi compartilhado. 


\subsubsection{Reputação dos usuários}

Os dados originados a partir da rede de confiança e dos mecanismos de interação são considerados para o cálculo de reputação dos usuários.

A adaptação do algoritmo PageRank para o cálculo de reputação dos usuários (CR - Collaborative Reputation) usa os valores das fontes de dados descritas anteriormente. Na Equação 5.1 é apresentada essa adaptação, em que $C R_{t}(x)$ é a reputação do usuário $x$ no tempo $t$; trust $(x)$ é derivado das redes de confiança; rate $(x)$, provém das avaliações dos usuários; e contribution $(x)$ representa o valor da contribuição de $x$ :

$$
C R_{t}(x)=(1-d)+d\left(\alpha_{t-1} \text { trust }_{t-1}(x)+\beta_{t-1} \text { rate }_{t-1}(x)+\text { contribution }_{t-1}(x)\right)
$$

Cada fonte de dados tem pesos diferentes que dependem dos objetivos e prioridades do sistema em que é usado. Em sistemas gerenciadores de vendas, o valor de confiança (trust) dos vendedores é mais relevante que as próprias interações entre os usuários, uma vez que para esses sistemas é mais importante a geração de confiança nos vendedores. Para manter a integridade dos dados fornecidos, a soma desses pesos $\alpha$ e $\beta$ tem de ser igual a 1 ( $\alpha$ e $\beta$ não são negativos). No caso, esses valores são calculados colaborativamente, e dependem da reputação dos usuários que colaboram e da quantidade de dados gerados por eles, por tipo de dado.

A definição desse mecanismo de designação de pesos teve como base os trabalhos desenvolvidos por Ludwig et al. [2009] e Nguyen et al. [2010], em que se definem pesos para cada fonte de dados usadas nos seus modelos.

O valor de trust, para o usuário $x$, é definido pela seguinte equação:

$$
\text { trust }_{t-1}(x)=C R_{t-1}\left(y_{1}\right) * C\left(y_{1} \rightarrow x\right)+\ldots+C R_{t-1}\left(y_{n}\right) * C\left(y_{n} \rightarrow x\right)
$$

Em que, $y_{1}, \ldots, y_{n}$ são conhecidos de $x$ que estão em relação direta com $x$ e forneceram um valor de confiança nas habilidades de $x$. Aqui é modificada a função de compromisso $C(y \rightarrow x)$ do algoritmo original, com base no trabalho de Musiał et al. [2009] e Kazienko et al. [2009]. Essa modificação é definida pela Equação 5.3:

$$
C(y \rightarrow x)=\frac{\sum_{1}^{i} A v(y \rightarrow x)}{\sum_{n=1}^{N}\left|A v\left(y \rightarrow x_{n}\right)\right|}
$$

Em que, $\sum_{1}^{i} A v(y \rightarrow x)$ representa a soma dos valores das avaliações do usuário $y$ aos $i$ itens do usuário $x ; \sum_{n=1}^{N}\left|A v\left(y \rightarrow x_{n}\right)\right|$ representa a soma total das avaliações feitas pelo usuário $y$. Nesse caso, é usada uma soma dos valores absolutos das avaliações, isso pelo fato da possibilidade de ocorrência de valores negativos na designação de valores de qualidade. No caso das avaliações de confiança, o valor de $i$ considerado neste trabalho será 1, pois só será válida a última designação de confiança de usuário a usuário. Em nossa abordagem, são feitas algumas variações nos critérios originais da função $C(y \rightarrow x)$ definidas em Kazienko et al. [2009], e estas são descritas na Tabela 5.3.

Um parâmetro adicional para obter o valor de rate é a similaridade de contexto ( $\operatorname{sim}$ ) ou o grau 


\begin{tabular}{|c|c|}
\hline $\begin{array}{l}\text { Critérios da função } C(y \rightarrow x) \text { segundo } \\
\text { Kazienko et al. [2009] }\end{array}$ & Critérios usados no modelo proposto \\
\hline $\begin{array}{l}\text { 1. O valor da função de compromisso está no } \\
\text { intervalo }[0 \ldots 1]: \forall(x, y \in N), C(y \rightarrow x) \in \\
{[0 \ldots 1], \text { em que } N \text { é o conjunto de todos os nós }} \\
\text { da rede. }\end{array}$ & $\begin{array}{l}\text { O valor da função de compromisso, além de } \\
\text { estar no intervalo [0...1], pode considerar va- } \\
\text { lores negativos, isso porque as avaliações dos } \\
\text { usuários podem ser de chamadas de atenção a } \\
\text { conteúdo inapropriado ou valores de descon- } \\
\text { fiança, por exemplo. }\end{array}$ \\
\hline $\begin{array}{l}\text { 2. A soma das funções de compromisso tem de } \\
\text { ser igual a } 1 \text {, para cada nó da rede. } \forall(x \in N) \text {, } \\
\sum_{x \in N} C(x \rightarrow y)=1 \text {. }\end{array}$ & $\mathrm{O}$ critério permanece igual. \\
\hline $\begin{array}{l}\text { 3. Se não há uma relação de } y \text { para } x \text {, então } \\
C(y \rightarrow x)=0 \text {. }\end{array}$ & $\mathrm{O}$ critério permanece igual. \\
\hline $\begin{array}{l}\text { 4. Se um membro } y \text { não é ativo para algum } \\
\text { outro membro, mas outros } n \text { membros } x_{i} \text {, } \\
i=1, \ldots, n \text { são ativos para } y \text {, então, para sa- } \\
\text { tisfazer o critério } 3 \text {, a soma } 1 \text { é distribuída } \\
\text { equitativamente entre todos os conhecidos de } \\
y . \forall\left(x_{i} \in N\right), C\left(y \rightarrow x_{i}\right)=1 / n \text {. }\end{array}$ & O critério permanece igual. \\
\hline $\begin{array}{l}\text { 5. As relações não são reflexivas e, a respeito } \\
\text { do critério } 3 \text {, a função de compromisso de um } \\
\text { nó para si mesmo é igual a } 0: \forall(x \in N) \text {, } \\
C(x \rightarrow x)=0 \text {. }\end{array}$ & $\begin{array}{l}\text { Possibilita relações reflexivas. A função de } \\
\text { compromisso do nó } x \text { para si mesmo está } \\
\text { definida pela Equação } 5.7 \text {, isso devido à pre- } \\
\text { sença das interações de contribuição, em que } \\
\text { não intervêm as avaliações de outros usuários } \\
\text { e só depende do usuário } x \text {. }\end{array}$ \\
\hline
\end{tabular}

Tabela 5.3: Comparação de critérios da função de compromisso definida em Kazienko et al. [2009] e o modelo proposto.

de concordância com o perfil do usuário que faz uma avaliação referente ao conteúdo avaliado. Por exemplo, o valor da avaliação de um usuário especialista em arquitetura moderna, que avalia uma foto de arquitetura antiga, não pode ser igual a uma avaliação de outro usuário que é especialista em arquitetura antiga. Nesse caso, o valor de concordância de contexto entre o conteúdo avaliado e o avaliador deve ser um parâmetro que ajude o cálculo de reputação. Na Equação 5.4 é definido o valor da variável rate. O parâmetro de similaridade ou concordância está fora do alcance deste trabalho, mas pode ser considerado em um estudo futuro na melhora do modelo. Por enquanto, o valor de $\operatorname{sim}(z \rightarrow x)=1$, em que $z$ é um nó que avalia o conteúdo do nó $x$ (Equação 5.5).

$$
\begin{gathered}
\text { rate }_{t-1}(x)=C R_{t-1}\left(z_{1}\right) * C\left(z_{1} \rightarrow x\right) * \operatorname{sim}\left(z_{1} \rightarrow x\right)+\ldots+C R_{t-1}\left(z_{n}\right) * C\left(z_{n} \rightarrow x\right) * \operatorname{sim}\left(z_{n} \rightarrow x\right) \\
\text { rate }_{t-1}(x)=C R_{t-1}\left(z_{1}\right) * C\left(z_{1} \rightarrow x\right)+\ldots+C R_{t-1}\left(z_{n}\right) * C\left(z_{n} \rightarrow x\right)
\end{gathered}
$$

O último parâmetro do modelo é contribution, o qual representa o valor das contribuições feitas pelo usuário $x$, em relação aos outros usuários. Na Equação 5.6 apresenta-se esse valor.

$$
\text { contribution }_{t-1}(x)=C R_{t-1}(x) * C^{\prime}(x)
$$

No caso de contribution é usada uma função $C^{\prime}(x)$ que é diferente da função de compromisso descrita anteriormente. A função de compromisso $C^{\prime}(x)$ é definida pela Equação 5.7. Em que, contribution $(x)$ representa o valor das contribuições que o usuário $x$ fez. Para normalizar os dados, 
utilizamos o valor de $\sum_{n=1}^{N}\left|\operatorname{contribution}\left(x_{n}\right)\right|$, que representa o valor total das contribuições dos usuários da comunidade.

$$
C^{\prime}(x)=\frac{\sum \text { contribution }(x)}{\sum_{n=1}^{N} \mid \text { contribution }\left(x_{n}\right) \mid}
$$

Para o cálculo do valor das variáveis $\alpha_{t-1}$ e $\beta_{t-1}$, é necessário o uso de variáveis $\alpha^{\prime}$ e $\beta^{\prime}$ parciais. As variáveis parciais são calculadas de acordo com as Equações 5.8 e 5.9. Nelas, os valores são calculados de acordo com o grau de relevância que cada usuário da rede gera inconscientemente com suas interações e dependem da reputação dos usuários que realizam a colaboração e da quantidade de dados gerados por eles, por tipo de dado.

$$
\begin{aligned}
\alpha^{\prime}(y) & =\frac{A v_{t}(y)}{A v_{t}(y)+A v_{r}(y)} \\
\beta^{\prime}(y) & =\frac{A v_{r}(y)}{A v_{t}(y)+A v_{r}(y)}
\end{aligned}
$$

Em que, $A v_{t}(y)$ representa a quantidade de avaliações de confiança que o usuário $y$ fez, e $A v_{r}(y)$ representa a quantidade de avaliações a conteúdos que $y$ realizou. Neste ponto, os valores das variáveis $\alpha_{t-1}$ e $\beta_{t-1}$ totais estão de acordo com as Equações 5.10 e 5.11. Como parte importante na procura dos valores totais é considerada a importância do usuário que outorga os pesos parciais, determinam quão importante são os valores em si, para isso, é usada a média ponderada. Portanto:

$$
\begin{aligned}
\alpha_{t-1} & =\frac{\sum_{n=1}^{N} \alpha^{\prime}\left(y_{n}\right) * C R_{t-1}\left(y_{n}\right)}{\sum_{n=1}^{N} C R_{t-1}\left(y_{n}\right)} \\
\beta_{t-1} & =\frac{\sum_{n=1}^{N} \beta^{\prime}\left(y_{n}\right) * C R_{t-1}\left(y_{n}\right)}{\sum_{n=1}^{N} C R_{t-1}\left(y_{n}\right)}
\end{aligned}
$$

Para calcular a reputação de uma pessoa em de uma rede social, o modelo é usado iterativamente. O valor inicial $C R\left(x_{n}\right)=1, \forall\left(x_{n} \in N\right)$ e $N$ é o conjunto de todos os nós da rede. O número de iterações é ajustado pela aplicação por meio de uma condição de parada que denote uma diferença máxima aceitável de $C R_{k}(x)-C R_{k-1}(x)$ para cada membro $x$ da rede, no qual, $k$ representa o número da iteração.

\subsubsection{Mecanismos de imunidade}

Dentre os mecanismos de imunidade a serem levados em consideração estão:

- Regras para o cálculo de reputação.

- No caso das avaliações de conteúdo, são consideradas as avaliações de um usuário y ao conteúdo de outro usuário $x$, se $y$ tem interações de contribuição na rede.

- No caso das avaliações de confiança, se um membro y não é confiável para ninguém, mas outros $n$ membros $x_{i}, i=1, \ldots, n$ são confiáveis para $y$, então as avaliações de $y$ sofrem uma perda de peso, pois $y$ não demostra ser confiável para ninguém. 
- Controle de peso dos avaliadores por meio da reputação.

- Mecanismos de identificação de usuário.

- Período de tempo, a fim de evitar favorecer os membros menos recentes do sistema e discriminar os membros novos, no cálculo de reputação será considerado as interações dos usuários dos $n$ dias anteriores à data do cálculo de reputação. O valor de $n$ fica a critério do sistema em que o modelo será usado.

\subsection{Considerações finais}

Os usuários são fontes contínuas de informação, com a ajuda dos mecanismos computacionais é possível aproveitar essas informações pelo bem da comunidade, motivando-os a participar e contribuir na criação de conteúdo de boa qualidade e em boa quantidade. Este capítulo apresentou um modelo para o cálculo de reputação em redes sociais, que não tem somente como objetivo a identificação de usuários com boa reputação, mas também incentivar a colaboração na comunidade. 


\section{Capítulo 6}

\section{Cenário de avaliação}

Além de calcular a reputação dos usuários de uma rede social, o modelo deve ser eficiente, tolerante e resistente a algumas das vulnerabilidades de sistemas de reputação. Para avaliar a proposta, foi adotado um conjunto de dados do sítio Epinions.com, para os quais foram comparados alguns outros algoritmos que realizam uma classificação dos usuários considerando o prestígio e a relevância dos nós. Neste capítulo, é descrito o ambiente de avaliação da proposta e os algoritmos adotados na avaliação, dando especial atenção aos critérios considerados para os estudos.

\subsection{Ambiente de avaliação}

O modelo proposto foi avaliado usando um conjunto de dados ou dataset obtidos do sítio de Epinions.com. Esse conjunto de dados foi coletado por Massa e Avesani [2004] e contém os dados sumarizados na Tabela 6.1. Um procedimento adicional foi realizado nesse conjunto, foram eliminados os registros das avaliações dos documentos que não possuem um usuário criador no conjunto de dados, para manter um conjunto consistente.

\begin{tabular}{|l|c|}
\hline Número de usuários & $\sim 132 \mathrm{mil}$ \\
\hline Número de designações de confiança & 841.372 \\
\hline Número de usuários que receberam pelo menos uma designação de confiança & $\sim 85000$ \\
\hline Número de itens compartilhados & 1.560 .144 \\
\hline Número de avaliações dos itens compartilhados & 13.668 .319 \\
\hline Número de avaliações totais depois do tratamento & 13.668 .104 \\
\hline
\end{tabular}

Tabela 6.1: Informação estatística do conjunto de dados Epinions.com.

O conjunto de dados está dividido em 3 subconjuntos:

- UserRating: contém as avaliações de confiança entre os usuários. Os valores são 1 para confiança e -1 para não confiança.

- Rating: são as avaliações feitas pelos usuários em relação à qualidade do conteúdo compartilhado no sítio. Esses valores estão na faixa de 1 até 5 (1 - não é útil, 2 - pouco útil, 3 - útil, 4 - muito útil, 5 - mais que útil ), mas existem algumas avaliações com valor de 6 que significa conteúdo muito mais que útil ${ }^{1}$.

\footnotetext{
${ }^{1} \mathrm{~A}$ especificação desses valores foram tirados da página em que o dataset é disponibilizado. Disponível em: http://www.trustlet.org/wiki/Extended_Epinions_dataset. Último acesso: 04 novembro 2012.
} 
- Document: A quantidade de documentos que o usuário compartilha por mês.

Esses dados foram coletados por Massa e Avesani de Janeiro de 2001 a Agosto de 2003. A fim de avaliar o modelo proposto, o conjunto de dados foi dividido em subconjuntos. Os dados de cada divisão correspondem às atividades realizadas num determinado mês. A tabela a seguir mostra o resumo dos dados particionados (Tabela 6.2):

\begin{tabular}{|c|c|c|c|c|}
\hline \multirow{2}{*}{ Subconjunto } & \multicolumn{2}{|c|}{ Document (Contribution) } & \multirow{2}{*}{$\begin{array}{r}\text { Rating (Rate) } \\
\text { Quantidade }\end{array}$} & \multirow{2}{*}{$\begin{array}{r}\text { UserRating (Trust) } \\
\text { Quantidade }\end{array}$} \\
\hline & Quantidade & Acumulado & & \\
\hline $2000-12$ & 804.422 & 804.422 & & \\
\hline $2001-01$ & 59.670 & 1.509 .312 & 865.440 & 584.202 \\
\hline $2001-02$ & 75.533 & 822.570 & 734.346 & 12.691 \\
\hline $2001-03$ & 76.190 & 1.251 .577 & 1.155 .982 & 19.405 \\
\hline $2001-04$ & 50.664 & 965.054 & 897.671 & 16.719 \\
\hline $2001-05$ & 47.050 & 886.441 & 822.730 & 16.661 \\
\hline $2001-06$ & 45.293 & 903.179 & 841.728 & 16.158 \\
\hline $2001-07$ & 37.274 & 723.905 & 669.482 & 17.149 \\
\hline $2001-08$ & 75.135 & 1.664 .449 & 1.571 .791 & 17.523 \\
\hline $2001-09$ & 37.391 & 874.704 & 829.004 & 8.309 \\
\hline $2001-10$ & 54.359 & 1.189 .035 & 1.124 .640 & 10.036 \\
\hline $2001-11$ & 37.140 & 705.980 & 658.260 & 10.580 \\
\hline $2001-12$ & 15.025 & 300.263 & 278.125 & 7.113 \\
\hline $2002-01$ & 17.446 & 361.753 & 336.175 & 8.132 \\
\hline $2002-02$ & 19.942 & 418.211 & 390.915 & 7.354 \\
\hline $2002-03$ & 17.476 & 392.785 & 370.161 & 5.148 \\
\hline $2002-04$ & 35.548 & 1.007 .696 & 966.883 & 5.265 \\
\hline $2002-05$ & 14.235 & 340.148 & 320.231 & 5.682 \\
\hline $2002-06$ & 1.775 & 43.169 & 36.592 & 4.802 \\
\hline $2002-07$ & 5.911 & 145.109 & 134.156 & 5.042 \\
\hline $2002-08$ & 4.381 & 93.448 & 83.895 & 5.172 \\
\hline $2002-09$ & 2.847 & 53.123 & 46.406 & 3.870 \\
\hline $2002-10$ & 3.308 & 69.792 & 61.136 & 5.348 \\
\hline $2002-11$ & 2.226 & 46.227 & 39.264 & 4.737 \\
\hline $2002-12$ & 2.905 & 78.830 & 70.562 & 5.363 \\
\hline $2003-01$ & 1.404 & 39.419 & 31.397 & 6.618 \\
\hline $2003-02$ & 1.315 & 38.726 & 32.097 & 5.314 \\
\hline $2003-03$ & 1.499 & 36.655 & 30.728 & 4.428 \\
\hline $2003-04$ & 3.216 & 80.752 & 72.790 & 4.746 \\
\hline $2003-05$ & 3.835 & 100.064 & 91.558 & 4.671 \\
\hline $2003-06$ & 1.225 & 36.008 & 29.509 & 5.274 \\
\hline $2003-07$ & 2.462 & 51.253 & 43.686 & 5.105 \\
\hline $2003-08$ & 2.042 & 35.561 & 30.764 & 2.755 \\
\hline TOTAL & 1.560 .144 & 16.069 .620 & 13.668 .104 & 841.372 \\
\hline
\end{tabular}

Tabela 6.2: Conjunto de dados Epinions.com divididos em meses.

Na Figura 6.1 é apresentada a distribuição dos dados em meses:

\subsection{Resumo dos dados usados no estudo}

Um dos objetivos dos estudos, é analisar o comportamento do modelo proposto nas três variáveis: trust, rate e contribution. Para isso, escolhemos três subconjuntos que atendam às seguintes características: 


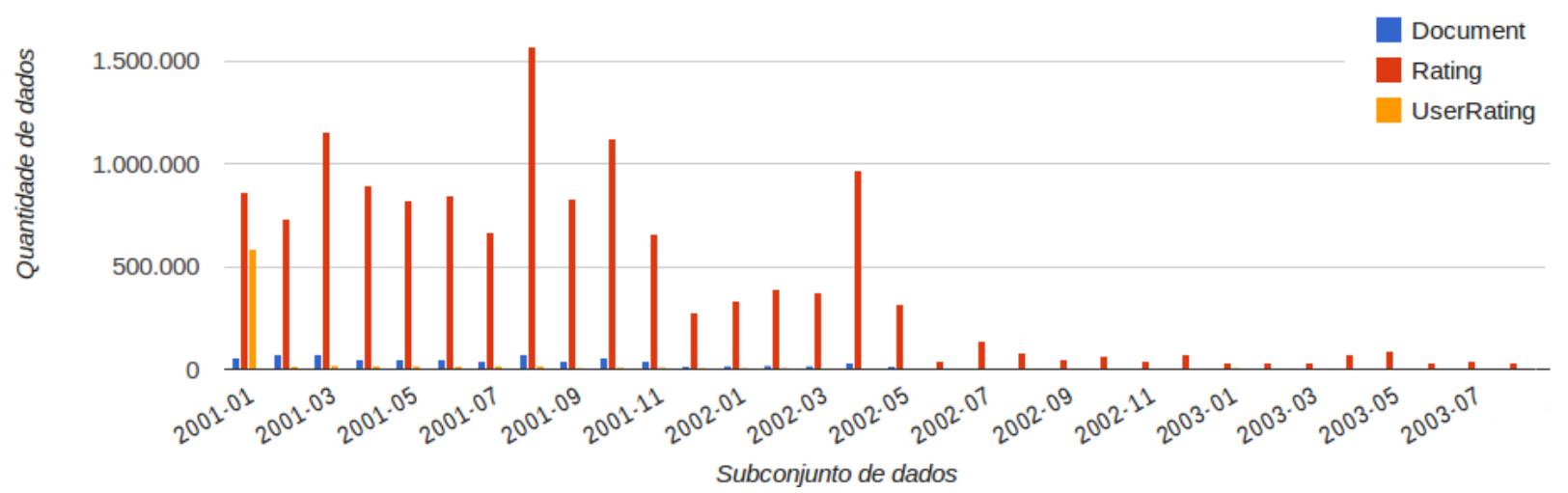

Figura 6.1: Quadro resumo de divisão em meses do conjunto de dados Epinions.com.

- Quantidade de dados de trust maior que os outros tipos de dados (rate e contribution).

- Quantidade de dados de rate maior que os outros tipos de dados (trust e contribution).

- Quantidade de dados de contribution maior que os outros tipos de dados (trust e rate).

No caso, os dados foram classificados (por mês) de acordo com a data de seu registro no sistema. Como observado na Figura 6.1, os dados de rate são muito maiores do que os das outras fontes (trust e contribution) em quase todos os meses. Para realizar o estudo com as três variações descritas anteriormente, agrupamos os dados:

- Os valores de contribuição referem-se às contribuições feitas pelos usuários e essas ações podem ser, por exemplo, adição de um comentário, edição de uma pergunta, avaliação de um conteúdo, entre outros. Portanto, a quantidade de dados considerados para essa variável é o conjunto de Document + Rating + Trust.

- Os valores numéricos de avaliação de conteúdo (da fonte Rating) são usados para a variável rate do modelo proposto e as avaliações de confiança UserRating para a variável trust.

A Figura 6.2 apresenta as características mencionadas.

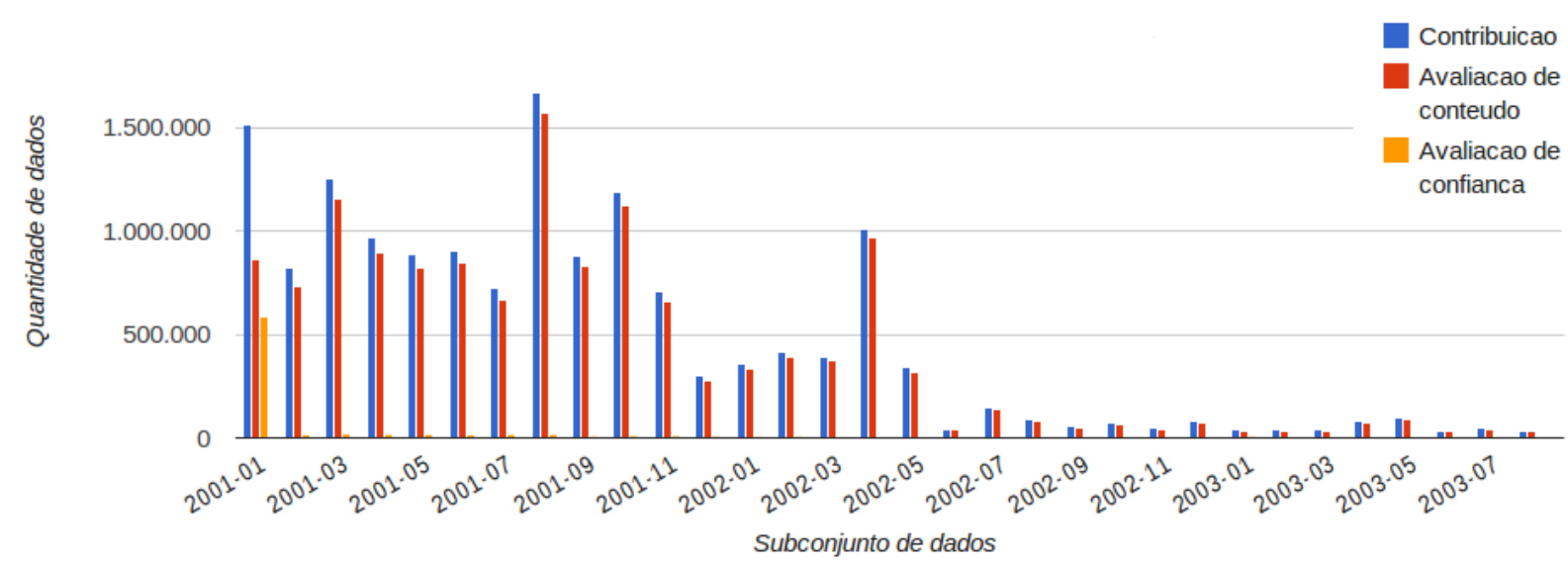

Figura 6.2: Quadro resumo dos subconjuntos com os valores acumulados para as fontes de contribuição $e$ avaliação. 
Para a avaliação foram considerados os seguintes 3 subconjuntos: 2001 - 01 no caso do trust, 2001 - 03 no caso do rate, 2001 - 08 no caso de contribution.

O uso de subconjuntos de dados para a realização dos experimentos foi uma tentativa para analisar o comportamento do modelo com cada tipo de fonte de dados, mas a geração e comparação de resultados com a íntegra dos dados não foi possível por restrições de tempo.

\subsection{Descrição dos algoritmos}

Na presente seção, são descritos os critérios que foram levados em consideração para a realização dos estudos. Os algoritmos selecionados para a realizar a comparação dos resultados são os seguintes:

1. O modelo Collaborative Reputation ou de Reputação Colaborativa (modelo proposto).

2. O algoritmo original do PageRank [Brin e Page, 1998].

3. O modelo ReCoP [Cruz, 2008].

4. O algoritmo LeaderRank [Lü et al., 2011].

\subsubsection{Proposta: Collaborative Reputation}

A formulação do modelo proposto é apresentada pela seguinte equação:

$$
C R_{t}(x)=(1-d)+d\left(\alpha_{t-1} \text { trust }_{t-1}(x)+\beta_{t-1} \text { rate }_{t-1}(x)+\text { contribution }_{t-1}(x)\right)
$$

O modelo proposto foi considerado com as seguintes especificações:

- Cada contribuição realizada pelo usuário afeta seu grau de reputação. Foram consideradas como contribuições:

- Criação de conteúdo.

- Avaliação de conteúdo e usuários. As avaliações negativas afetam negativamente não só ao item avaliado, mas também ao usuário que atribuiu a avaliação, isso com o intuito de mensurar falsos negativos.

A estratificação dos valores de contribuição usados no modelo proposto para avaliar o modelo é apresentada na Tabela 6.3. Foi estabelecido, para a realização da avaliação, que o valor de contribuição de tipo acusação é negativa para o usuário que recebe a avaliação. Uma contribuição de avaliação representa a interação do usuário no sistema e a ação deve ser considerada, mas essa interação é menos valorada que uma interação de edição visto que uma edição requer mais esforço por parte do usuário. Entretanto, a contribuição de criação possui um valor maior que a de edição por tratar-se de conteúdo novo e compartilhado pelo usuário criador.

- Para que as avaliações de um determinado conteúdo sejam consideradas, é necessário atingir um número mínimo a fim de garantir uma estimativa de reputação baseada em opiniões distintas. 


\begin{tabular}{|l|c|}
\hline Tipo de contribuição & Peso \\
\hline \hline Acusação & $-2,0$ \\
\hline Avaliação & 1,0 \\
\hline Edição & 3,0 \\
\hline Criação & 5,0 \\
\hline
\end{tabular}

Tabela 6.3: Faixa de valores pelo tipo de contribuição.

- O valor das avaliações foi normalizado segundo a Tabela 6.4. No caso, as avaliações de tipo "Denúncia" indicam uma penalidade tanto para o usuário que recebe a avaliação, quanto para o usuário que realiza a avaliação. A penalização é um meio de evitar acusações falsas e é usado, por exemplo, para calcular a reputação no sítio Stackoverflow ${ }^{2}$.

\begin{tabular}{|l|c|c|}
\hline Avaliação & Valor da avaliação & Conversão \\
\hline \hline Denúncia, valor daquele que recebe a denúncia & -5 & $-1,0$ \\
\hline Denúncia, valor daquele que realiza a denúncia & -2 & $-0,4$ \\
\hline -1 Avaliação não útil & 1 & 0,2 \\
\hline Avaliação pouco útil & 2 & 0,4 \\
\hline Avaliação útil & 3 & 0,6 \\
\hline Avaliaçãa muito útil & 4 & 0,8 \\
\hline Avaliação muito mais que útil & 5 & 1,0 \\
\hline
\end{tabular}

Tabela 6.4: Conversão de valores usados no conjunto de dados para valores usados no modelo proposto.

- O ataque Sybil [Douceur, 2002] é uma das vulnerabilidades atuais em sistemas de reputação. Para lidar como esse tipo de ataque, foi incluído no processo de cálculo de reputação um critério de avaliação nos nós. Esse critério indica que se um nó é conhecido pelo menos por algum outro nó (rede de confiança) ou demostra ter realizado atividades de contribuição (rede de interação), como compartilhar conteúdo além de avaliar outros itens do sistema, então esse nó é considerado honesto e pode participar da classificação.

\subsubsection{Algoritmo: PageRank}

O algoritmo original PageRank [Brin e Page, 1998] é descrito por:

$$
P R_{t}(A)=(1-d)+d\left(\frac{P R_{t-1}\left(y_{1}\right)}{C\left(y_{1}\right)}+\ldots+\frac{P R_{t-1}\left(y_{n}\right)}{C\left(y_{n}\right)}\right)
$$

No caso do Algoritmo PageRank, descrito no Capítulo 6, as seguintes especificações foram adotadas:

- Um sítio web pode ter um conjunto de páginas, das quais, uma é a principal (entidade principal) e as demais são subpáginas (entidades secundárias). De igual forma, em uma rede social, um usuário $x$ pode ser visto como uma entidade principal, e o conteúdo que o usuário $x$ compartilha pode ser considerado como entidades secundárias.

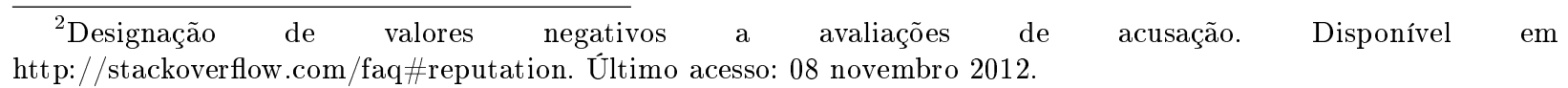


- O algoritmo usa dados das fontes rate (Rating - avaliações) para os nós filhos e trust (UserRating - confiança) para os nós pais.

- Nós filhos que não tem ligações provenientes de outros nós pais e sua única ligação com a rede é a relação com o nó criador, não são considerados para o cálculo de reputação. Na Fig. 6.3 é apresentado um esquema desse critério.

- PageRank é um algoritmo que calcula o grau de relevância de um nó a partir de seus relacionamentos com outros nós, em que cada relacionamento é considerado como uma ligação de confiança de um nó a outro nó, limitando o cálculo a valores positivos dos relacionamentos (na especificação do algoritmo não é indicado se existe relacionamentos entre as nós de uma rede que indiquem um valor negativo de confiança). Portanto, são usados os valores positivos do conjunto de dados, não considerando os dados em que o valor das avaliações é negativo para imitar o comportamento do cálculo na Web (no caso de avaliações no intervalo de 1-5, são consideradas só as avaliações $>=5$ ).

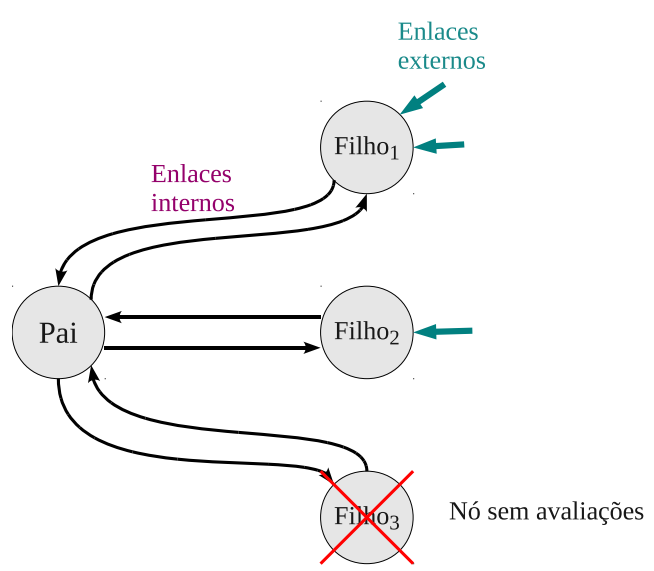

Figura 6.3: Representação gráfica dos nós considerados na estimativa de reputação no algoritmo PageRank.

\subsubsection{ReCop: Cálculo de reputação em comunidades de prática}

O modelo ReCoP foi apresentado no Capítulo 3. Para a realização da avaliação, foram consideradas as seguintes especificações:

- O modelo ReCoP só usa os valores de rate (Rating - avaliações), não considerando os valores de confiança ou trust (UserRating) na estimativa de reputação.

- O número de avaliações necessárias para que um item seja considerado no cálculo deve ser maior ou igual a 2. Também é considerado o cálculo por períodos de tempo.

- Para o cálculo de reputação nesse modelo, foi gerada uma reputação inicial dos usuários. Como foi selecionado o subconjunto 2001_01, a reputação dos usuários nesse mês é considerada como reputação inicial. Para os subconjuntos subsequentes, é considerado o valor de reputação construída previamente.

- A normalização dos dados foi realizada seguindo a Tabela 6.4. 


\subsubsection{LeaderRank}

O algoritmo LeaderRank foi apresentado no Capítulo 3.

- O algoritmo LeaderRank só usa os valores positivos da fonte de confiança (UserRating).

- Os valores de rate não são considerados para esse algoritmo, pois o LeaderRank é um mecanismo de reputação de usuários e os valores de rate são avaliações a conteúdo.

\subsection{Considerações finais}

Neste capítulo foram descritas as especificações que são consideradas na implementação dos algoritmos. A comparação dos experimentos foi realizada com dois tipos de algoritmos, aqueles que medem a relevância dos nós a partir das avaliações dos conteúdos (Collaborative Reputation, PageRank e ReCoP) e aqueles que medem o prestígio dos nós a partir do uso de topologias de confiança (LeaderRank). 


\title{
Capítulo 7
}

\section{Avaliação da abordagem: Resultados}

\author{
"Así como una jornada bien empleada produce un dulce sueño, \\ así una vida bien usada causa una dulce muerte."
}

Leonardo Da Vinci

Neste capítulo é apresentada a análise dos resultados obtidos a partir da utilização dos algoritmos para o cálculo de reputação: Collaborative Reputation, PageRank, ReCoP e LeaderRank. Essa análise tem como base os trabalhos apresentados por Kazienko et al. [2009] e Lü et al. [2011].

Para a realização da avaliação, foi implementado o seguinte procedimento:

- Analisar o comportamento do modelo proposto de acordo com cada tipo de fonte de dados: trust, rate e contribution.

- Como foi descrito na Seção 6.2, os três subconjuntos de dados usados nos estudos são: 2001-01, 2001 - 03 e 2001 - 08, com o intuito de analisar o comportamento do modelo proposto, nas variáveis trust, rate e contribution, com os outros algoritmos implementados.

- Com esse cenário, foram realizados os seguintes procedimentos:

1. Comparação da diversidade de valores

2. Comparação da ordenação

3. Estudo comparativo controlado

4. Tolerância a ruídos

5. Robustez contra ataques Sybil

Nas seguintes seções são descritos os procedimentos e analisados os resultados obtidos com os algoritmos implementados.

\subsection{Diversidade de valores}

Dificilmente poderia ser estimado quem é mais confiável se diversos usuários têm uma pontuação de reputação igual. Para classificar os usuários de maior reputação, é necessário que o valor que representa a sua interação no sistema seja diferente para cada um deles, assim se terá uma lista ordenada dos usuários pelo seu grau de reputação. Nesse cenário, tenta-se estimar a porcentagem 
de valores distintos de reputação a partir dos resultados obtidos com os modelos implementados.

Na Figura 7.1 apresenta-se os resultados obtidos com os modelos Collaborative Reputation, PageRank, ReCoP e LeaderRank. No primeiro subconjunto de dados, em que o conjunto de avaliações de confiança é maior, a porcentagem de diversidade da pontuação dos usuários obtida com o modelo proposto Collaborative Reputation (46,8\%) não supera o obtido com o PageRank (51,3\%), mas melhora os resultados gerados por $\operatorname{ReCoP}(9,8 \%)$ e LeaderRank $(42,1 \%)$. As porcentagens resultantes do Collaborative Reputation nos subconjuntos 2001 - 03 e 2001 - 08 melhora os obtidos com os outros modelos. Note-se que os resultados do modelo ReCoP são gerados a partir do conjunto de avaliações a conteúdo, enquanto que os resultados do LeaderRank são obtidos das avaliações de confiança. Tanto Collaborative Reputation quanto PageRank usam ambos tipos de avaliações.

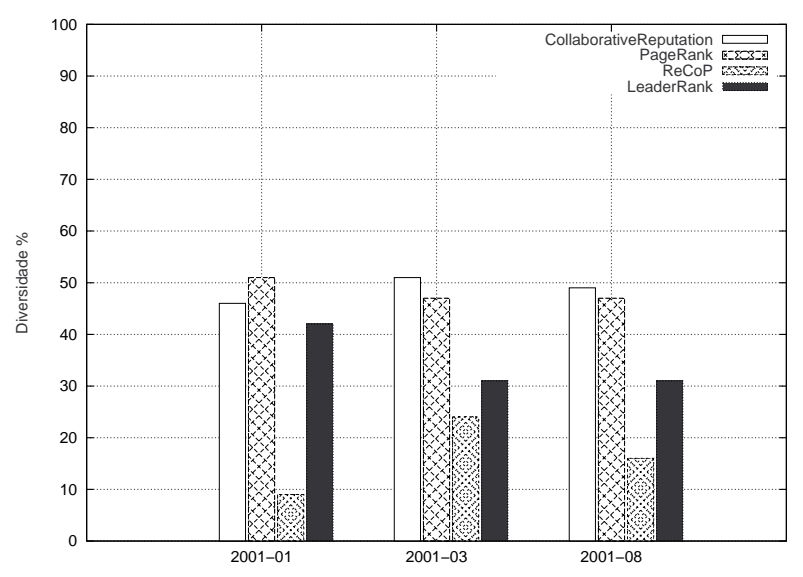

Figura 7.1: Porcentagem de diversidade na pontuação dos usuários dos subconjuntos de dados 2001 - 01, $2001-03$ e $2001-08$.

\subsection{Comparação da ordenação}

Depois de montar uma lista ordenada de usuários pelo grau de reputação para cada algoritmo, estas foram comparadas usando o coeficiente de concordância Kendall [Kendall, 1948]. Esse cálculo determinou a similaridade entre as listas ordenadas. Seja $X$ e $Y$ duas ordenações com $n$ itens, o coeficiente de concordância de Kendall $\kappa(X, Y)$ é definido pela Equação 7.1

$$
\kappa(X, Y)=\frac{1}{n(n-1)} * \sum_{i=1}^{n} \sum_{j=1}^{n} \operatorname{sgn}\left(x_{j}-x_{i}\right) * \operatorname{sgn}\left(y_{j}-y_{i}\right)
$$

Em que, $x_{i}$ e $y_{i}$ são as posições do mesmo item $i$ na ordenação $X$ e $Y$, respectivamente. A função $\operatorname{sgn}\left(x_{j}-x_{i}\right)$ é uma função de sinalização da diferença entre $x_{j}-x_{i}$. Isso significa que se o item $i$ segue ao item $j$ na ordenação $X$, então $\operatorname{sgn}\left(x_{j}-x_{i}\right)=-1$. Se ambos estão na mesma posição, então $\operatorname{sgn}\left(x_{j}-x_{i}\right)=0$, em outro caso, $\operatorname{sgn}\left(x_{j}-x_{i}\right)=+1$. O valor da função $\kappa(X, Y)$ está dentro do intervalo [-1..1], no qual 1 significa que a ordenação das listas comparadas são iguais e, -1 significa que a ordenação da segunda lista comparada ao respeito da primeira lista é totalmente inversa.

Esse procedimento visa analisar o comportamento do modelo proposto em relação aos resultados dos outros modelos analisados. Na Tabela 7.1 são apresentados os resultados de similaridade entre 
as ordenações obtidas com os modelos implementados. Nos três subconjuntos de dados, o modelo CollaborativeReputation teve uma maior correlação de similaridade com o PageRank, isso devido ao fato de ambos considerarem tanto avaliações de confiança a usuários como avaliações de conteúdo. Os menores valores de correlação entre os algoritmos nos três subconjuntos de dados foram obtidos por ReCoP e LeaderRank. ReCoP realiza o cálculo de reputação com base nas avaliações de conteúdo, enquanto que LeaderRank faz o cálculo com as avaliações de confiança. Os resultados de correlação obtidos entre esses dois modelos indica que há um grau de relação entre os valores das fontes de dados (usuários com boas avaliações a seu conteúdo também têm boas avaliações de confiança).

\begin{tabular}{|l|l|c|c|c|}
\hline $\begin{array}{l}\text { Subconjunto } \\
\text { de dados }\end{array}$ & Modelo & $\begin{array}{l}\text { Collaborative } \\
\text { Reputation } \\
\text { (\%) }\end{array}$ & PageRank (\%) & ReCoP (\%) \\
\hline \hline \multirow{3}{*}{$2001-01$} & PageRank & 26,9 & & \\
\cline { 2 - 5 } & ReCoP & 16,3 & 42,3 & \\
\cline { 2 - 5 } & LeaderRank & 22,1 & 61,2 & 12,0 \\
\hline \hline \multirow{3}{*}{$2001-03$} & PageRank & 32,6 & & \\
\cline { 2 - 5 } & ReCoP & 26,9 & 68,9 & \\
\cline { 2 - 5 } & LeaderRank & 13,9 & 17,9 & \\
\hline \hline \multirow{3}{*}{$2001-08$} & PageRank & 32,4 & & 12,9 \\
\cline { 2 - 5 } & ReCoP & 23,4 & 68,6 & \\
\cline { 2 - 5 } & LeaderRank & 19,8 & 19,0 & \\
\hline
\end{tabular}

Tabela 7.1: Valor de correlação de Kendall com os subconjuntos de dados 2001-01, 2001-03 e 2001-08.

\subsection{Estudo comparativo de cenários}

Esse procedimento simula cenários específicos com usuários teste, a fim de estimar o grau de acerto nas classificações de tais usuários, obtidos a partir dos algoritmos implementados. Os usuários teste são os seguintes:

- Usuário muito bom: esse usuário colabora muito, tem avaliações recebidas muito boas (de confiança e de conteúdo).

- Usuário muito ruim: esse usuário colabora com conteúdo, mas esse conteúdo é avaliado com valores muito ruins, e tem avaliações de não confiança.

- Usuário médio: esse usuário realiza uma quantidade média de interações no sistema, recebe algumas avaliações de conteúdo e de confiança.

Para essa finalidade foram criados dados falsos que foram alocados aos usuários teste. As especificações para tais dados, segundo o tipo de usuário, é indicado a seguir:

- Usuário muito bom: O usuário bom tem que ter mais avaliações positivas e criação de conteúdo que qualquer outro usuário da comunidade.

- Usuário médio: O usuário médio tem que ter a quantidade média de avaliações em relação aos outros usuários da rede.

- Usuário muito ruim: O usuário ruim tem que ter mais avaliações de pouco valor que qualquer outro usuário da comunidade. 
Com essas especificações, foram gerados os dados apresentados nas Tabelas 7.2, 7.3 e 7.4. A Tabela 7.2 apresenta os índices dos documentos criados para cada tipo de usuário por mês. Os índices designados não existem no conjunto de dados original e a quantidade foi calculada mediante consultas no conjunto de dados. Por exemplo, a quantidade designada para o usuário bom por mês, foi calculada do seguinte jeito: encontrando o usuário com maior quantidade de documentos criados por mês, a essa quantidade foi acrescentada uma unidade para ter um número maior. Esse valor é designado ao respectivo usuário.

\begin{tabular}{|l|c|c|c|c|c|c|}
\hline $\begin{array}{l}\text { Subconjunto } \\
\text { de dados }\end{array}$ & \multicolumn{2}{|c|}{ Bom Usuário } & \multicolumn{2}{c|}{ Mau Usuário } & \multicolumn{2}{c|}{ Usuário Médio } \\
\cline { 2 - 7 } Inicia & Termina & Inicia & Termina & Inicia & Termina \\
\hline \hline $2001-01$ & 11000 & 11129 & 21000 & 21129 & 31000 & 31004 \\
\hline $2001-02$ & 12000 & 12156 & 22000 & 22156 & 32000 & 32003 \\
\hline $2001-03$ & 13000 & 13147 & 23000 & 23147 & 33000 & 33004 \\
\hline $2001-04$ & 14000 & 14199 & 24000 & 24199 & 34000 & 34003 \\
\hline $2001-05$ & 15000 & 15094 & 25000 & 25094 & 35000 & 35003 \\
\hline $2001-06$ & 16000 & 16210 & 26000 & 26210 & 36000 & 36003 \\
\hline $2001-07$ & 17000 & 17129 & 27000 & 27129 & 37000 & 37003 \\
\hline $2001-08$ & 18000 & 18173 & 28000 & 28173 & 38000 & 38003 \\
\hline $2001-09$ & 19000 & 19101 & 29000 & 29101 & 39000 & 39003 \\
\hline $2001-10$ & 100 & 176 & 200 & 276 & 300 & 303 \\
\hline $2001-11$ & 1100 & 1152 & 2100 & 2152 & 3100 & 3103 \\
\hline
\end{tabular}

Tabela 7.2: Índices dos documentos falsos criados de acordo ao tipo de usuário teste.

Na Tabela 7.3 é apresentado o resumo das quantidades de avaliações criadas para cada tipo de usuário. A coluna "Realiza" refere-se à quantidade de avaliações falsas que o usuário teste faz ao conteúdo de outros usuários. A coluna "Recebe" indica a quantidade de avaliações recebidas de outros usuários ao conteúdo do usuário teste. A quantidade de avaliações foi calculada mediante consulta ao conjunto de dados original.

\begin{tabular}{|l|c|c|c|c|c|c|}
\hline \multirow{2}{*}{$\begin{array}{l}\text { Subconjunto } \\
\text { de dados }\end{array}$} & \multicolumn{2}{|c|}{ Bom Usuário } & \multicolumn{2}{c|}{ Mau Usuário } & \multicolumn{2}{c|}{ Usuário Médio } \\
\cline { 2 - 7 } & Realiza & Recebe & Realiza & Recebe & Realiza & Recebe \\
\hline \hline $2001-01$ & 12.905 & 5.365 & 2 & 5.365 & 31 & 40 \\
\hline $2001-02$ & 9.892 & 3.780 & 2 & 3.780 & 29 & 38 \\
\hline $2001-03$ & 15.803 & 4.530 & 2 & 4.530 & 32 & 38 \\
\hline $2001-04$ & 10.154 & 5.634 & 2 & 5.634 & 29 & 35 \\
\hline $2001-05$ & 8.797 & 5.632 & 2 & 5.632 & 26 & 33 \\
\hline $2001-06$ & 10.217 & 6.090 & 2 & 6.090 & 26 & 32 \\
\hline $2001-07$ & 7.627 & 4.440 & 2 & 4.440 & 24 & 29 \\
\hline $2001-08$ & 20.840 & 6.718 & 2 & 6.718 & 35 & 42 \\
\hline $2001-09$ & 11.226 & 4.562 & 2 & 4.562 & 29 & 35 \\
\hline $2001-10$ & 12.704 & 4.458 & 2 & 4.458 & 29 & 36 \\
\hline $2001-11$ & 7943 & 2.738 & 2 & 2.738 & 19 & 26 \\
\hline
\end{tabular}

Tabela 7.3: Avaliações falsas criadas para os usuários: Bom, mau e médio.

Na Tabela 7.4 é apresentado o resumo das quantidades de avaliações de confiança criadas para cada tipo de usuário. A coluna "Realiza" refere-se à quantidade de avaliações de confiança falsas que realiza o usuário teste a outros usuários. A coluna "Recebe" indica a quantidade de avaliações de confiança recebidas pelo usuário teste a partir das avaliações de outros usuários. A quantidade de avaliações de confiança foi calculada mediante consulta ao banco de dados original. 


\begin{tabular}{|l|c|c|c|c|c|c|}
\hline \multirow{2}{*}{$\begin{array}{l}\text { Subconjunto } \\
\text { de dados }\end{array}$} & \multicolumn{2}{|c|}{ Bom Usuário } & \multicolumn{2}{c|}{ Mau Usuário } & \multicolumn{2}{c|}{ Usuário Médio } \\
\cline { 2 - 7 } & Realiza & Recebe & Realiza & Recebe & Realiza & Recebe \\
\hline \hline $2001-01$ & 2.819 & 2.071 & 308 & 679 & 10 & 10 \\
\hline $2001-02$ & 68 & 192 & 51 & 63 & 4 & 5 \\
\hline $2001-03$ & 100 & 755 & 67 & 56 & 6 & 5 \\
\hline $2001-04$ & 190 & 522 & 82 & 161 & 4 & 5 \\
\hline $2001-05$ & 107 & 178 & 106 & 166 & 5 & 5 \\
\hline $2001-06$ & 133 & 615 & 114 & 236 & 4 & 5 \\
\hline $2001-07$ & 100 & 203 & 74 & 202 & 4 & 5 \\
\hline $2001-08$ & 95 & 363 & 94 & 81 & 5 & 5 \\
\hline $2001-09$ & 129 & 290 & 116 & 53 & 4 & 5 \\
\hline $2001-10$ & 70 & 370 & 59 & 239 & 4 & 5 \\
\hline $2001-11$ & 134 & 1.993 & 131 & 83 & 4 & 6 \\
\hline
\end{tabular}

Tabela 7.4: Avaliações de confiança falsas criadas para os usuários: Bom, mau e médio.

Com esses dados, na Figura 7.2 são mostrados os resultados do desempenho na identificação dos usuários teste por cada um dos algoritmos. Os resultados indicam a porcentagem de acerto da resposta obtida por cada algoritmo e a resposta prevista da posição dos três tipos de usuários. Neste trabalho, a posição de cada tipo de usuário numa classificação correta é definida do seguinte jeito:

- Usuário muito bom: deve estar classificado na posição "1" (como usuário de maior e melhor contribuição).

- Usuário médio: deve estar classificado dentro da faixa $\left\lceil\frac{N}{3}\right\rceil$ e $\left\lfloor\frac{2 N}{3}\right\rfloor$. Em que, $N$ representa o número total de usuários classificados pelo algoritmo.

- Usuário muito ruim: deve estar localizado na posição $N$ da classificação (como usuário de menor e pior contribuição).

Para uniformizar os dados, foi usada a escala de porcentagem de $0-100$. Dadas essas premissas e segundo os resultados das classificações dos modelos, podemos inferir:

- Na classificação do usuário muito bom, o modelo Collaborative Reputation obteve $100 \%$ de acerto, classificando ao usuário na posição 1 nos três subconjuntos. Um detalhe importante de ressaltar a respeito dos resultados obtidos, é que quase todos os algoritmos, nos três subconjuntos de dados, identificaram a posição correta do usuário muito bom em 100\%. O algoritmo LeaderRank obteve 99,986\% e 99,973\% de acerto nos subconjuntos $2001-03$ e $2001-08$ respectivamente.

- Na classificação do usuário muito ruim, o pior algoritmo em classificar esse tipo de usuário foi o PageRank, com menos de $0,12 \%$ de acerto em média para os três subconjuntos. Uma das principais observações no PageRank é a não aceitação de valores negativos para realizar a classificação dos usuários, o que origina um cálculo baseado só em dados positivos, sem considerar punições por colaborações classificadas como não úteis. Assim, o usuário muito ruim obteve avaliações falsas negativas que não foram consideradas pelo algoritmo. Portanto, a sua classificação não foi prejudicada. Os melhores algoritmos em classificar esse tipo de usuário foram o ReCoP e o LeaderRank com 100\% de acerto, seguido pelo modelo Collaborative Reputation que obteve um 100\%, 99, 998\% e 99, 996\% para os subconjuntos $2001-01,2001-03$ e 2001 - 08 respectivamente. 
- Na classificação do usuário médio, o algoritmo que mostrou melhor desempenho foi o ReCoP, seguido pelo LeaderRank. PageRank segue em desempenho com aproximadamente 32,6\% de acerto em promédio na classificação desse tipo de usuário. O pior modelo nesse experimento para o usuário médio foi o Collaborative Reputation que obteve menos de $9,2 \%$ de acerto nos três subconjuntos.

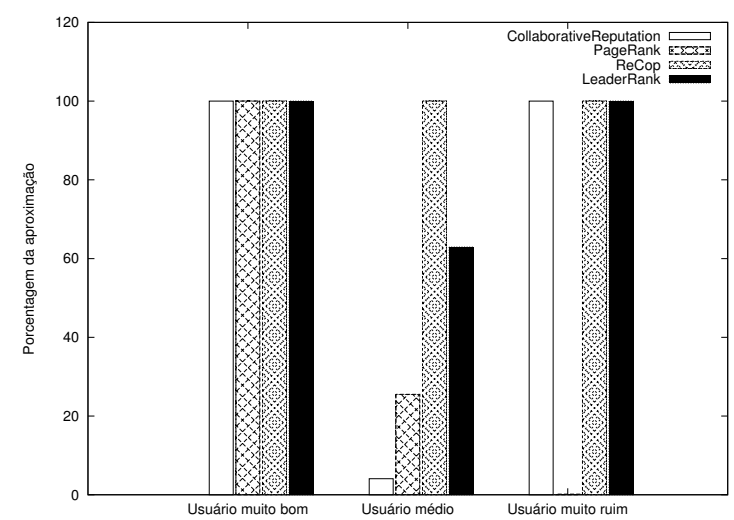

(a)

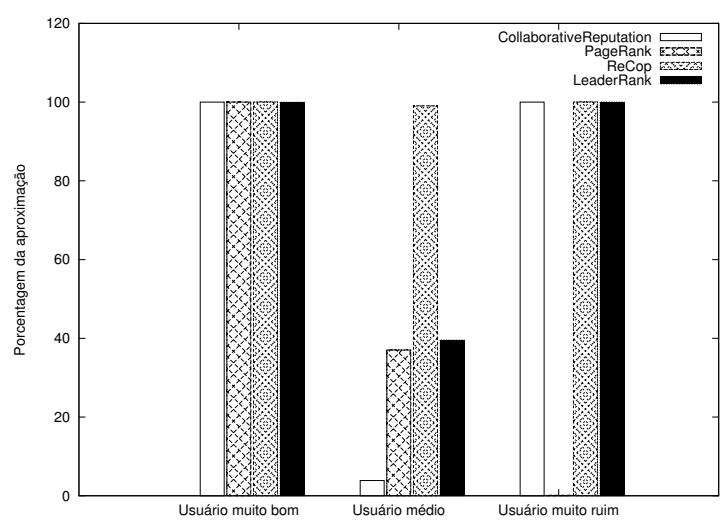

(b)

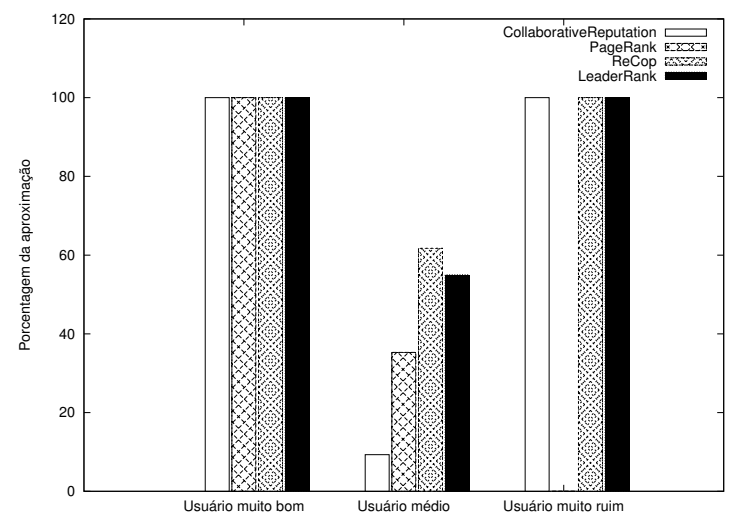

(c)

Figura 7.2: Resultados do estudo comparativo de cenários na classificação dos usuários teste: muito bom, médio e muito ruim. Cenários a) $2001-01$, b) $2001-03$, c) $2001-08$

\subsection{Tolerância a ruídos}

Para examinar a tolerância dos algoritmos a ruídos, foram medidas as mudanças na pontuação e na ordenação quando adicionadas ou removidas avaliações aleatoriamente. Essas avaliações correspondem a avaliações falsas ou perdidas.

Os valores obtidos a partir do grafo modificado são comparados com os do grafo original, medindo o impacto $I_{S}$ na pontuação e o impacto $I_{R}$ na classificação. Os impactos são dados pelas seguintes equações:

$$
I_{S}=\frac{\sum_{i=1}^{n}\left|S_{i}^{\prime}-S_{i}\right|}{\sum_{i=1}^{n} S_{i}} * 100
$$




$$
I_{R}=1-\kappa\left(R, R^{\prime}\right)
$$

No qual, $I_{S}$ representa o impacto na pontuação (score), $S$ e $S^{\prime}$ correspondem às pontuações obtidas a partir do grafo original e o modificado. $I_{R}$ representa o impacto na ordenação dos usuários (classificação), $R$ e $R^{\prime}$ correspondem à classificação (ranking) obtida a partir do grafo original e o modificado. Nesse caso, o valor do impacto na ordenação é determinado pelo grau de similaridade estre as listas ordenadas, para tal, é usado o coeficiente de correlação de Kendall definido em 7.2.

Com esses critérios, foram calculados os impactos, na pontuação e classificação, quando adicionadas ou excluídas 100, 200, 400, 600, 800, 1000 avaliações ao conteúdo e quando adicionadas ou excluídas avaliações de confiança aos usuários.

\subsubsection{Estudos com avaliações de conteúdo}

Nas Figuras 7.3 e 7.4, apresentam-se os resultados do impacto quando adicionadas ou excluídas avaliações ao conteúdo. Os resultados obtidos para o algoritmo LeaderRank não sofre impacto com esse tipo de dados (por não usar avaliações ao conteúdo), assim o impacto obtido tanto em pontuação quanto em classificação para LeaderRank foi 0.

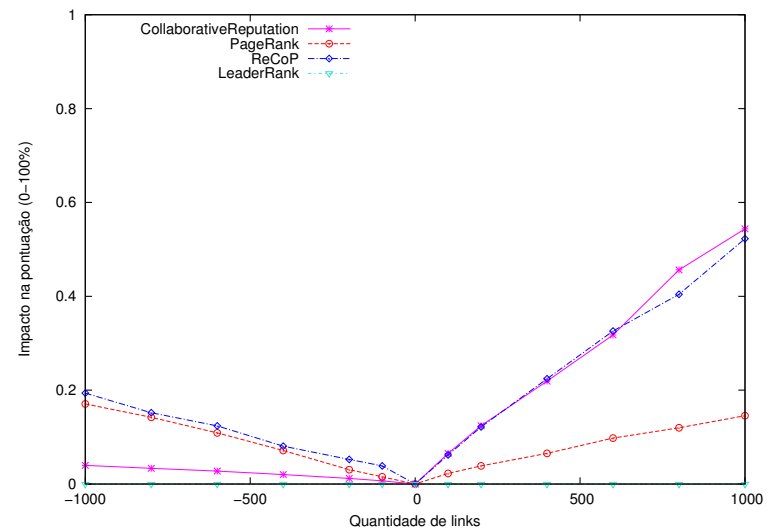

(a)

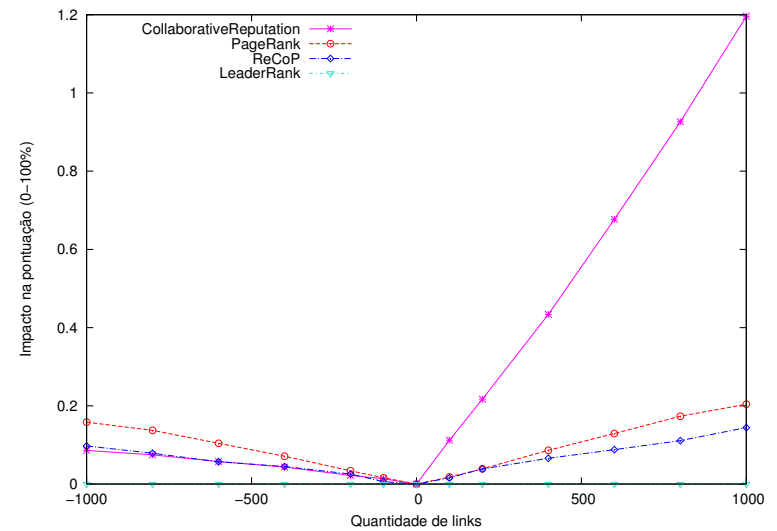

(b)

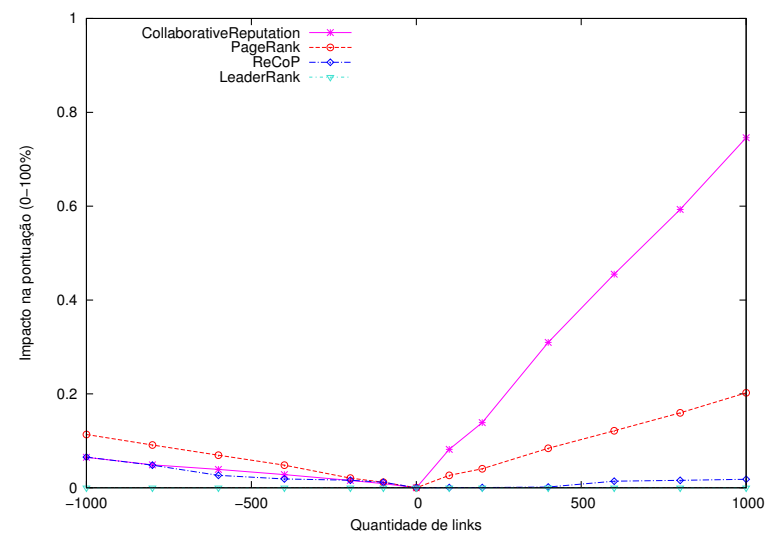

(c)

Figura 7.3: Impacto na pontuação por adição/exclusão de avaliações ao conteúdo. Cenários a) 2001 - 01, b) $2001-03$, c) $2001-08$ 


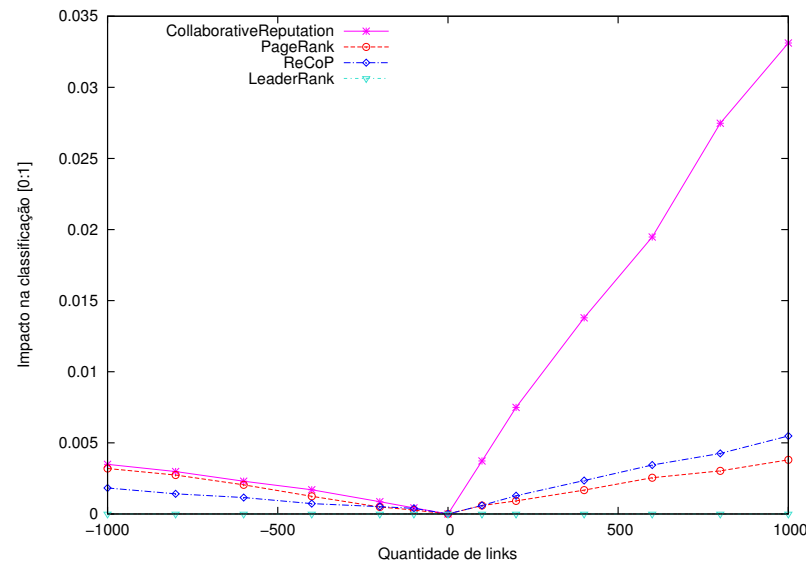

(a)

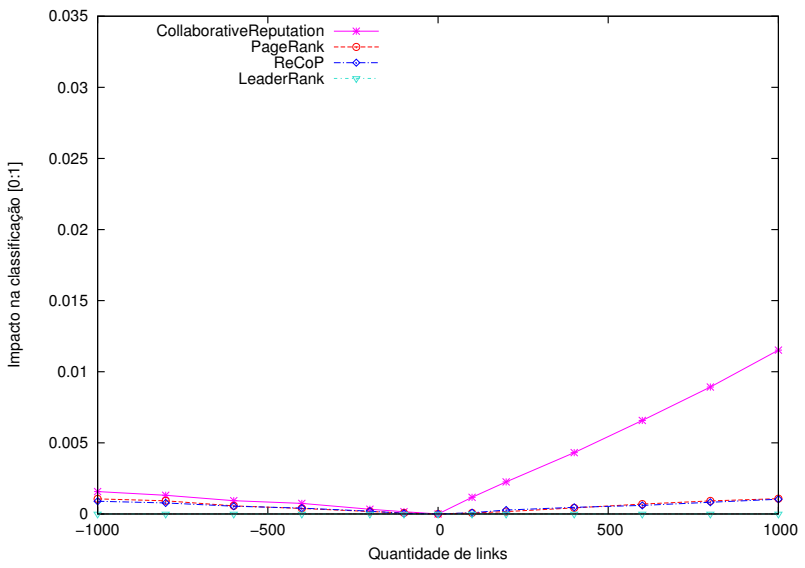

(b)

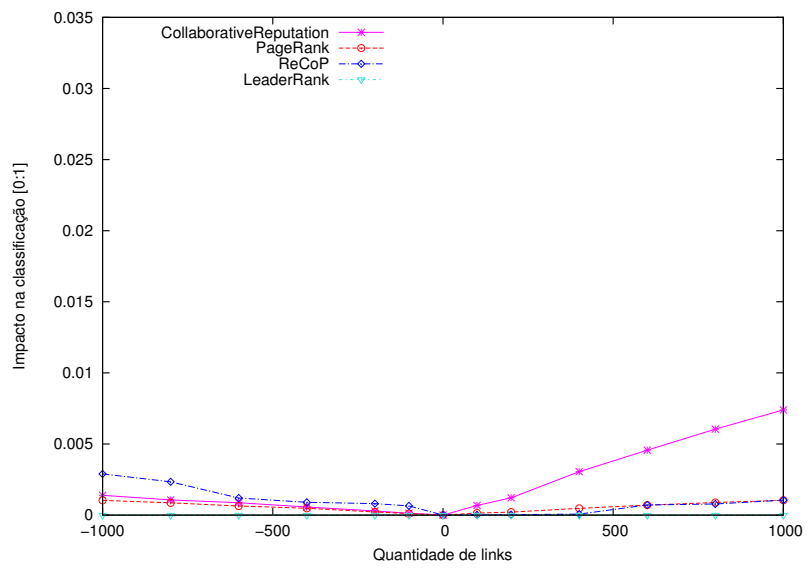

(c)

Figura 7.4: Impacto na classificação por adição/exclusão de avaliações ao conteúdo. Cenários a) 2001-01, b) $2001-03$, c) $2001-08$

- No subconjunto 2001 - 01, considera-se os resultados obtidos pelo algoritmo PageRank, em impacto $I_{S}$ e $I_{R}$, como os mais estáveis, quando adicionadas avaliações, e o Collaborative Reputation como o de pior desempenho no mesmo caso. Quando eliminadas avaliações nesse subconjunto, o CR obteve o melhor desempenho no impacto na pontuação $\left(I_{S}\right)$ e o $\operatorname{ReCoP}$ no impacto na classificação $\left(I_{R}\right)$.

- Nos subconjuntos 2001 - 03 e 2001 - 08, a diferença entre o $I_{S}$ e $I_{R}$ de ReCoP e PageRank é pequena. Mesmo assim, esses resultados são melhores do que os resultados dos impactos obtidos por Collaborative Reputation, quando adicionadas avaliações ao conteúdo. Quando eliminadas avaliações, o modelo Collaborative Reputation fica muito próximo aos resultados obtidos com PageRank e ReCoP.

\subsubsection{Estudos com avaliações de confiança}

Nas Figuras 7.5 e 7.6, apresentam-se os resultados do impacto quando adicionadas ou excluídas avaliações de confiança. Nesse cenário, os resultados obtidos para o modelo ReCoP não sofrem impacto, pois não usa avaliações de confiança no cálculo de reputação, e o impacto obtido tanto em pontuação quanto em classificação é 0 . 


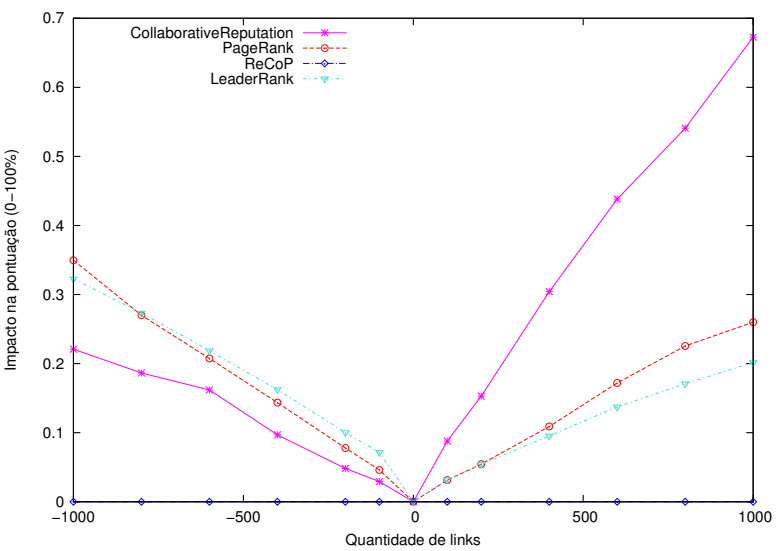

(a)

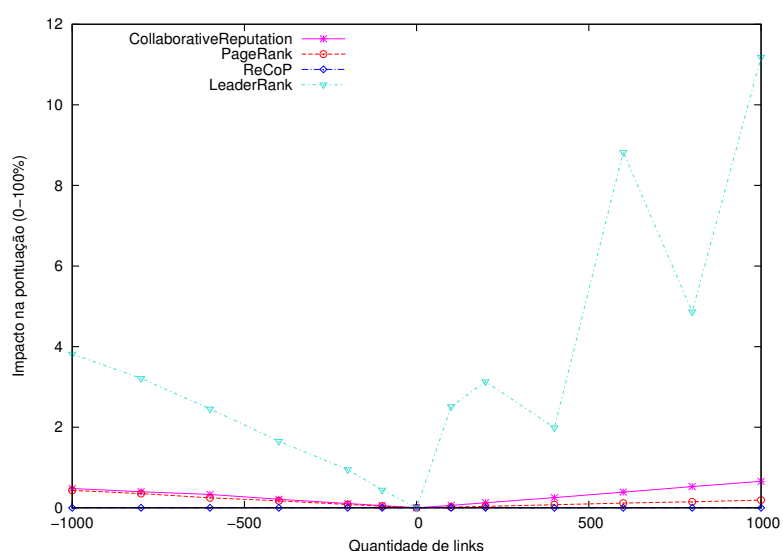

(b)

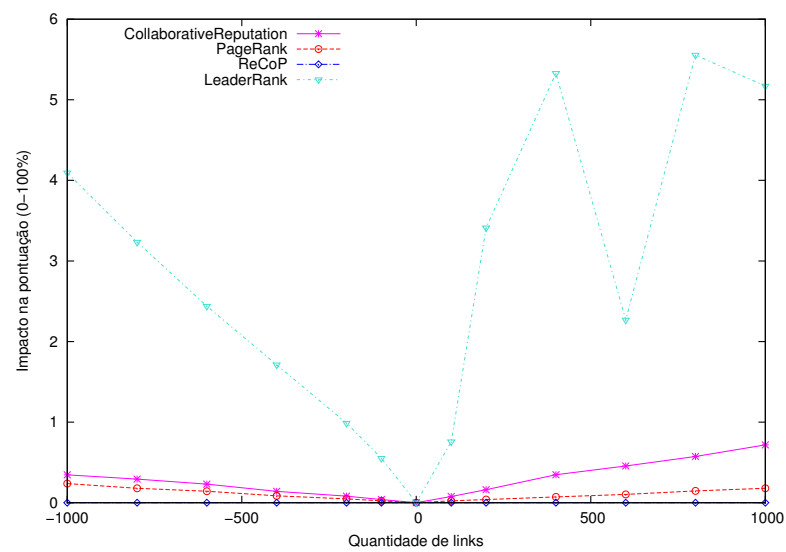

(c)

Figura 7.5: Impacto na pontuação por adição/exclusão de avaliações de confiança. Cenários a) 2001 - 01 , b) $2001-03$, c) $2001-08$

- O modelo Collaborative Reputation, no subconjunto 2001-01, para o impacto $I_{S}$, apresenta o pior desempenho na adição de avaliações falsas de confiança, mas é o melhor quando excluídas avaliações. O LeaderRank, no impacto $I_{S}$, apresentou o melhor resultado quando incluídas avaliações, mas o pior quando excluídas. Para o impacto $I_{R}$, em 2001 - 01, o LeaderRank apresenta o pior desempenho, quando adicionadas ou excluída avaliações de confiança. Com esse mesmo subconjunto, o modelo que apresentou melhores resultados foi o PageRank com 99, 8\% de similaridade, porém, a diferença com o Collaborative Reputation foi quase desprezível, o qual obteve uma porcentagem de $97,7 \%$ de similaridade.

- Nos subconjuntos 2001 - 03 e 2001 - 08, a diferença entre os impactos $I_{S}$ e $I_{R}$ entre Collaborative Reputation e PageRank é pequena $\left(I_{S}: 2001-03 \rightarrow C R=96,4 \%\right.$ e $P R=98,1 \%$, $2001-08 \rightarrow C R=96,5 \%$ e $P R=98,7 \%, I_{R}: 2001-03 \rightarrow C R=99,7 \%$ e $P R=99,8 \%$, 2001-08 $\rightarrow C R=99,8 \%$ e $P R=99,9 \%$, porém, o PageRank melhora os resultados do Collaborative Reputation quando adicionadas avaliações. O de pior desempenho foi o LeaderRank, pois ao basear seu cálculo inteiramente nos valores de confiança, o modelo é mais sensível que os outros a esse tipo de interação. 


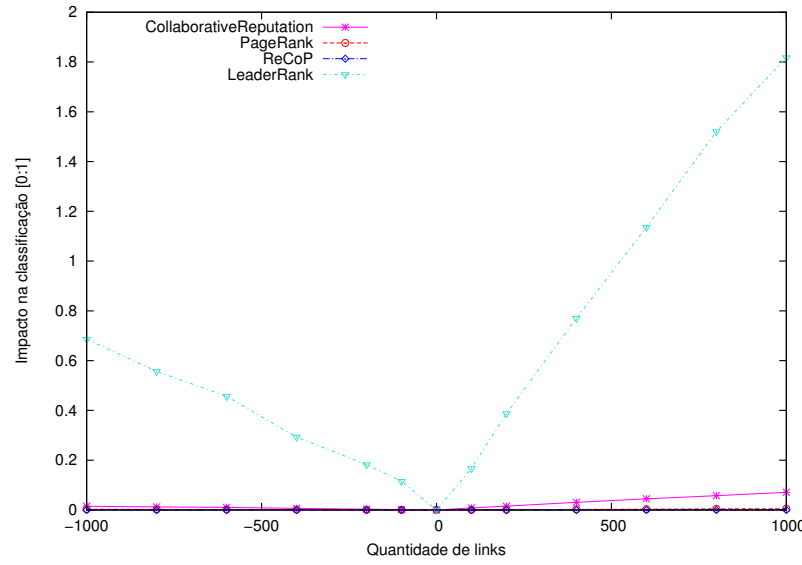

(a)

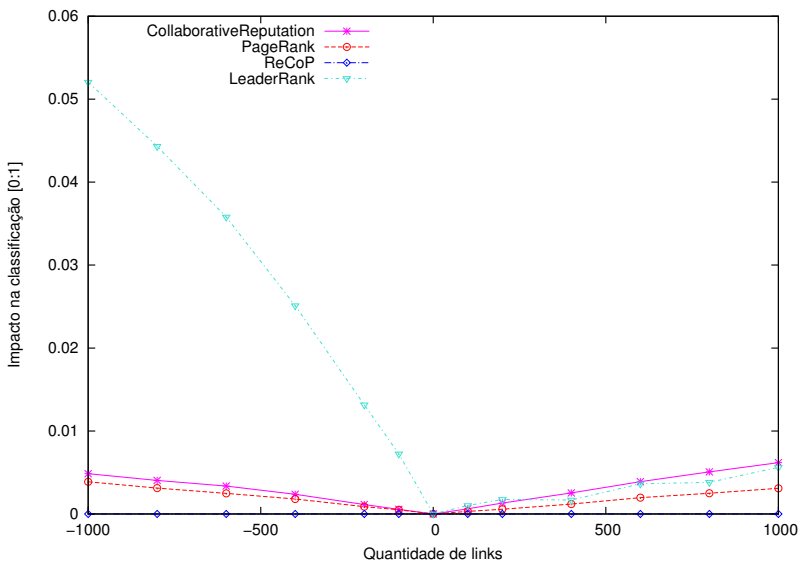

(b)

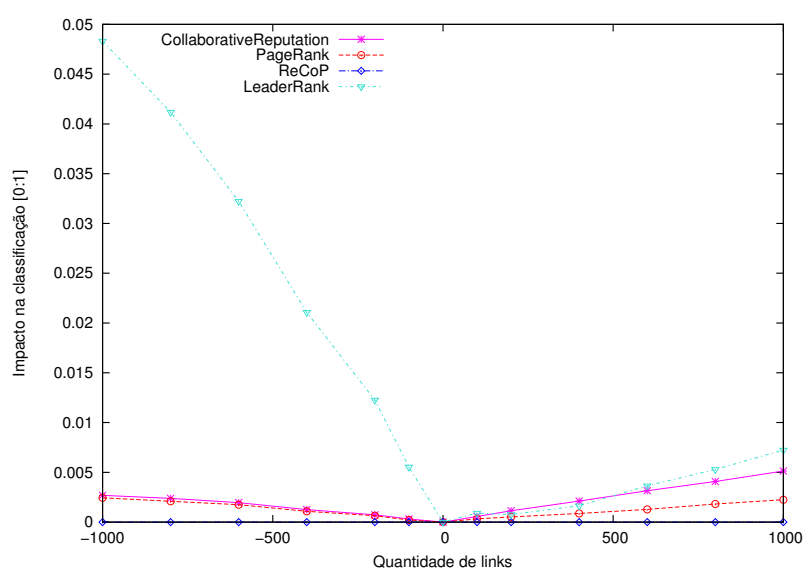

(c)

Figura 7.6: Impacto na classificação por adição/exclusão de avaliações de confiança. Cenários a) 2001-01, b) $2001-03$, c) $2001-08$

\subsubsection{Conclusões}

- Os resultados obtidos com Collaborative Reputation mostram que o modelo proposto é mais sensível às interações dos usuários que os outros algoritmos, podendo variar as pontuações e classificações dos usuário com base nas interações consideradas válidas. As interações são consideradas válidas quando elas são admitidas para o cálculo de reputação, depois de passar pelo filtro de informação do próprio modelo.

- Collaborative Reputation é muito mais sensível a informação falsa, depende do tipo de fonte de dados atingido e a quantidade de dados que a fonte representa.

- A fonte de dados predominante afeta diretamente no impacto tanto na pontuação quanto na classificação quando adicionadas avaliações falsas.

- No caso do subconjunto 2001 - 01, a fonte de dados dominante é das avaliações ao conteúdo com 59, $7 \%$ (rate), enquanto que a fonte de dados das avaliações de confiança fica em 40,3\% (trust). A Tabela 6.2 apresenta os dados dos subconjuntos. Quando adicionadas avaliações ao conteúdo, o modelo Collaborative Reputation foi muito mais sensível, tanto na pontuação quanto na classificação, devido à porcentagem da fonte de dados rate. Na adição de avaliações 
de confiança, pela porcentagem da fonte de dados trust, o modelo foi sensível na pontuação dos usuários, mas não tanto na classificação.

- Nos subconjuntos 2001 - 03 e 2001 - 08, a porcentagem da fonte rate está acima de $98 \%$ enquanto que trust tem em média 1,4\%, o que sugere que o modelo é mais susceptível a avaliações de conteúdo do que a avaliações de confiança. Isso devido à presença dos pesos $\alpha$ e $\beta$ nas fontes de dados.

\subsection{Robustez contra ataques Sybil}

As atividades maliciosas são comuns nas redes sociais, em particular quando os usuários manipulam os dados para ganhar reputação [Masum e Zhang, 2004]. Um exemplo de manipulação é chamado de Sybil Attack [Douceur, 2002] ou ataque Sybil. Nesse tipo de ataque, alguns usuários deliberadamente criam entidades falsas dentro de um domínio de confiança e reputação para fornecer múltiplas avaliações sobre o mesmo objeto.

Para lidar com esse problema, foi simulada uma situação em que um usuário cria $n$ identidades falsas e realiza um conjunto de avaliações, depois foram comparados os valores de reputação dos modelos.

Dentre os tipos de cenários possíveis, foram identificados basicamente dois:

1. Usuários com identidades falsas avaliam conteúdo e

2. Usuários com identidades falsas avaliam um mesmo usuário

Foi realizado o experimento de Robustez contra ataque Sybil adicionando 10, 50 e 100 usuários falsos para cada cenário descrito. Os $v$ usuários falsos adicionaram avaliações falsas, ao conteúdo e de confiança, a um usuário específico. A escolha do usuário foi feita seguindo os seguintes critérios:

- Foram selecionados os usuários classificados na metade inferior das listas ordenadas dos modelos implementados. Isso com o intuito de analisar a similaridade das listas ordenadas com e sem ataque Sybil de um usuário de baixa reputação.

- Foi realizada uma escolha aleatória dentre os possíveis usuários selecionados.

A eficiência nos resultados obtidos foi medida usando o coeficiente de concordância de Kendall, no qual, $R$ e $R^{\prime}$ representam a ordenação sem e com ataque Sybil:

$$
S=1-\kappa\left(R, R^{\prime}\right)
$$

Os valores das Tabelas 7.5, 7.6 e 7.7 representam a porcentagem de variação entre os resultados obtidos com os dados originais e os resultados obtidos na inclusão de $v$ usuários falsos. Adicionar avaliações em "Trust" indica que foram incorporados avaliações de confiança falsas à rede de relacionamento e adicionar avaliações em "Rating" indica que foram adicionadas avaliações falsas ao conteúdo. 


\begin{tabular}{|c|l|c|c|c|c|}
\hline \multirow{2}{*}{$\begin{array}{l}\text { Quantidade } \\
\text { de usuários } \\
(v)\end{array}$} & $\begin{array}{l}\text { Collaborative } \\
\text { Reputation }\end{array}$ & PageRank & ReCoP & LeaderRank \\
\hline \hline \multirow{3}{*}{ Trust } & 10 & 0 & 0,0000209 & 0 & 0,0131233 \\
\cline { 2 - 6 } & 50 & 0 & 0,0000836 & 0 & 0,0340236 \\
\cline { 2 - 6 } Rating & 100 & 0 & 0,0001482 & 0 & 0,0540709 \\
\cline { 2 - 6 } & 50 & 0 & 0,000029 & 0,0000496 & 0 \\
\cline { 2 - 6 } & 100 & 0 & 0,0001188 & 0,0000517 & 0 \\
\hline
\end{tabular}

Tabela 7.5: Resultados obtidos com a simulação do ataque Sybil no subconjunto 2001 - 01.

\begin{tabular}{|c|l|c|c|c|c|}
\hline \multirow{2}{*}{$\begin{array}{l}\text { Quantidade } \\
\text { de usuários } \\
(v)\end{array}$} & $\begin{array}{l}\text { Collaborative } \\
\text { Reputation }\end{array}$ & PageRank & ReCoP & LeaderRank \\
\hline \hline \multirow{3}{*}{ Trust } & 10 & 0 & 0,0000304 & 0 & 0,0012109 \\
\cline { 2 - 6 } & 50 & 0 & 0,0000729 & 0 & 0,0005748 \\
\cline { 2 - 6 } Rating & 100 & 0 & 0,0001012 & 0 & 0,0005831 \\
\cline { 2 - 6 } & 50 & 0 & 0,0000346 & 0,000046 & 0 \\
\cline { 2 - 6 } & 100 & 0 & 0,0000783 & 0,000046 & 0 \\
\hline \multirow{2}{*}{}
\end{tabular}

Tabela 7.6: Resultados obtidos com a simulação do ataque Sybil no subconjunto 2001 - 03.

\begin{tabular}{|c|l|c|c|c|c|}
\hline & $\begin{array}{l}\text { Quantidade } \\
\text { de usuários } \\
(v)\end{array}$ & $\begin{array}{l}\text { Collaborative } \\
\text { Reputation }\end{array}$ & PageRank & ReCoP & LeaderRank \\
\hline \hline \multirow{3}{*}{ Trust } & 10 & 0 & 0,0000536 & 0 & 0,0005589 \\
\cline { 2 - 6 } & 50 & 0 & 0,0000819 & 0 & 0,0006634 \\
\cline { 2 - 6 } & 100 & 0 & 0,0001083 & 0 & 0,0014746 \\
\hline \multirow{3}{*}{ Rating } & 10 & 0 & 0,0000529 & 0,0001894 & 0 \\
\cline { 2 - 6 } & 50 & 0 & 0,0000898 & 0,0002127 & 0 \\
\cline { 2 - 6 } & 100 & 0 & 0,0001153 & 0,0002191 & 0 \\
\hline
\end{tabular}

Tabela 7.7: Resultados obtidos com a simulação do ataque Sybil no subconjunto 2001 - 08.

Os impactos obtidos nos três subconjuntos com os algoritmos apresentados, não são muito relevantes. Por tanto, uma análise mais aprofundada não foi realizada.

\subsection{Ameaças à validade}

\subsubsection{Validade de construção}

"A validade de construção considera os relacionamentos entre a teoria e a observação, ou seja, se o tratamento reflete a causa bem e o resultado reflete o efeito bem" [Travassos et al., 2002]. Nosso trabalho temos as seguintes:

- Métodos selecionados: os procedimentos usados na validação do modelo, foram selecionados por conveniência, usando como base alguns dos trabalhos relacionados a esta pesquisa.

- Seleção do conjunto de dados: a falta de disponibilidade de dados reais na web, com as características para validar o modelo, fez o escopo de datasets pequeno. O uso do dataset de Epinions.com atendeu às necessidades desta pesquisa.

- Estudos com subconjunto de dados: os estudos para avaliar o modelo proposto foram realizados usando subconjuntos de dados distintos, uma vez que a pesquisa tenta validar o modelo em 
situações diferentes. Os subconjuntos podem não representar adequadamente todo o conjunto de dados.

\subsubsection{Validade interna}

"A validade interna define se o relacionamento observado entre o tratamento e o resultado é causal, e não é o resultado da influência de outro fator que não é controlado ou mesmo não foi medido" [Travassos et al., 2002]. Presentes no trabalho temos:

- Autenticidade dos dados: como dito no capítulo anterior, os dados foram coletados e disponibilizados na web por Massa e Avesani [2009]. Isso pode significar, que o método usado na coleta pode discriminar alguns dados de acordo as necessidades do coletor.

- Influência do pesquisador na coleta de dados: os dados que constituem o conjunto de dados usado no experimento, conforme explicado no Capítulo 6, está disponibilizado na Web. Portanto, o pesquisador não influenciou na coleta de dados.

\subsubsection{Validade externa}

"A validade externa define as condições que limitam a habilidade de generalizar os resultados de um experimento para a prática industrial" Travassos et al. [2002].

- Generalização para outras comunidades: os resultados obtidos apresentaram como o modelo proposto funciona no dataset usado. A validade para outros dados não foi avaliada. Portanto, os resultados obtidos nesta pesquisa não podem ser diretamente generalizados para outros contextos.

\subsubsection{Validade de conclusão}

"A validade de conclusão é relacionada à habilidade de chegar a uma conclusão correta a respeito dos relacionamentos entre o tratamento e o resultado do experimento" [Travassos et al., 2002]. Neste trabalho temos:

- Resultados obtidos: o objetivo geral da pesquisa é verificada através dos diferentes experimentos presentes na fase de experimentação. O modelo proposto pode ser usado para calcular o valor de reputação de usuários de uma rede social a partir de sua participação. No entanto, o modelo atente só a algumas das vulnerabilidades presentes em sistemas de reputação.

- Testes estatísticos: Não foram feitos testes estatísticos para verificar a significância dos resultados obtidos. 


\section{Capítulo 8}

\section{Conclusões}

"El hombre encuentra a Dios detrás de cada puerta que la ciencia logra abrir." Albert Einstein

Neste capítulo são apresentadas as considerações finais do trabalho, um resumo da pesquisa, as principais contribuições e um compêndio de sugestões para trabalhos futuros.

\subsection{Principais considerações}

Atualmente há diversas técnicas que ajudam na identificação de usuários relevantes em de uma comunidade. Os sistemas de confiança e reputação dão suporte a esse processo, identificando os usuários cuja colaboração é de maior relevância para a comunidade. Assim, esses sistemas possibilitam que os participantes de uma comunidade se relacionem mais uns com outros, fortalecendo laços na comunidade e encorajando os usuários a interagir mais. Nesse sentido, os sistemas de confiança e reputação assumem a função de catalizadores no crescimento da comunidade e com isso as entidades não precisam interagir várias vezes com uma mesma entidade para saber se é de confiança ou não.

Uma análise de domínio foi realizada para a identificação dos principais mecanismos que participam no cálculo de reputação em sistemas de reputação na Web 2.0. Essa análise foi usada na definição de um modelo que objetiva melhorar os resultados de outros modelos usados para encontrar as entidades mais relevantes de uma rede.

Nesta dissertação propomos um modelo de reputação de usuários considerando dados quantitativos e qualitativos e que faz uso das seguintes fontes de dados: a contribuição dos participantes de uma comunidade (contribution), as avaliações ao conteúdo criado pelos usuários (rate) e as avaliações de confiança designadas entre usuários de uma mesma rede de relacionamento (trust). O modelo proposto tem como base fundamental o algoritmo PageRank e foi usado para realizar a classificação de usuários em de uma comunidade. A proposta faz uso das variáveis $\alpha$ e $\beta$, que determinam o grau de relevância (peso) das fontes de dados trust e rate e são calculadas a partir dos dados das interações dos participantes da comunidade, dependendo diretamente da quantidade dos dados e dos valores das reputações dos usuários. No entanto, esses valores podem não refletir os objetivos da comunidade em que o modelo é implantado e não ajudar na classificação de usuários 
segundo esses objetivos. Nesse caso, a especificação dos valores para cada variável pode ser definido previamente por um usuário administrador do sistema.

A avaliação do modelo foi realizada usando como base o conjunto de dados Epinions.com. Esse conjunto de dados proporciona centenas de registros de informação sobre os usuários e suas interações no site Epinions.com.

O modelo proposto é um modelo para o cálculo de reputação em sistemas centralizados e baseados no usuário. Os resultados mostram que o modelo Collaborative Reputation é muito mais sensível a variações nas avaliações das entidades na comunidade. Nesse sentido, a classificação obtida com o modelo proposto não é muito tolerante a perda/inclusão de informação.

Embora o modelo tenha se mostrado eficiente em alguns dos procedimentos diante dos outros modelos avaliados, existem diversas modificações que poderiam ser feitas para melhorar os resultados. Atualmente o modelo calcula a reputação com base em toda a informação fornecida do conjunto de dados, mas precisa de procedimentos de filtragem de dados antes do processo de cálculo, assim, poderia ser desconsiderada informação de baixa qualidade. As avaliações entre usuários e de usuários a conteúdo são realizadas em uma única escala, sem considerar possíveis relações de conhecimento entre o avaliador e a entidade avaliada, por exemplo, as avaliações de usuários com maior experiência em algumas áreas tem que ser mais valoradas do que avaliações de usuários com pouco ou escasso conhecimento da entidade avaliada. Procedimentos de sistemas de recomendação poderiam ser usados para esse tipo de melhora. A inclusão de um sistema de punições para usuários que colaboram negativamente deve ser discutido. Os sistemas colaborativos se caracterizam por promover a interação e colaboração dos usuários e esse tipo de mecanismo poderia inibir o uso do sistema em que o modelo é implementado.

\subsection{Limitações e pesquisas futuras}

É preciso frisar que as conclusões apresentadas neste estudo são específicas ao conjunto de dados Epinions.com, dataset coletado por Massa [2005]. Portanto, os resultados não podem ser generalizados diretamente para outros cenários e pode ser vulnerável em outras comunidades.

As principais dificuldades encontradas na realização dos experimentos são indicadas a seguir:

- Disponibilidade de datasets com dados reais de uso livre para a realização dos experimentos. Atualmente são encontrados alguns dataset em http://snap.stanford.edu/data/, mas nem todos os conjuntos de dados possuem a diversidade suficiente de dados para avaliar a nossa proposta nas suas três características: trust, rate e contribution.

- Uniformização dos resultados quantitativos da classificação de usuários de todos os modelos, para a realização dos experimentos. A estandardização de resultados originou perda de informação na análise dos resultados. 
Para dar continuidade ao trabalho apresentado, o modelo pode ser avaliado usando como estudo de caso os dados reais do projeto Arquigrafia [Workbench, 2011a] desenvolvido no contexto do Groupware Workbench [Workbench, 2011b]. O ambiente Arquigrafia propõe a construção coletiva e colaborativa de um acervo digital de imagens e informação da arquitetura brasileira, possibilitando a interação e o compartilhamento de informação de pessoas interessadas em arquitetura. $\mathrm{O}$ Arquigrafia é desenvolvido com o Groupware Workbench, um ferramental baseado em componentes para a construção de sistemas colaborativos na Web 2.0.

Para disponibilizar o modelo de forma reusável para outros contextos, é prevista a implementação da proposta em forma de componente e incluí-lo no kit de componentes do projeto Groupware Workbench.

Levando em consideração as principais deficiências encontradas na fase de avaliação do modelo, o passo seguinte é melhorar a proposta para o cálculo de reputação dos participantes de uma rede social. Os gráficos obtidos a partir dos resultados do modelo proposto apresentam uma perda de informação (parte da informação é filtrada pelos mecanismos de imunidade do modelo), o que indica que devem ser encontrados métodos mais sofisticados para lidar com mais vulnerabilidades dos sistemas de reputação, a fim de considerar para o cálculo de reputação a melhor e maior quantidade de informação disponível.

O uso de subconjuntos de dados para a realização dos experimentos foi uma tentativa para analisar o comportamento do modelo com cada tipo de fonte de dados, mas a geração e análise de resultados com o íntegro de dados pode ser considerado para melhorar as conclusões.

Com os resultados obtidos usando um modelo melhorado da proposta, realizar uma classificação dos usuários, a fim de dar um reconhecimento ao esforço deles, delegando responsabilidades de acordo com o grau de reputação. Um sistema de punição e premiação à colaboração poderia ser incluído para melhorar a qualidade do conteúdo compartilhado. 
CONCLUSÕES 


\section{Referências Bibliográficas}

Alag(2008) S. Alag. Collective Intelligence in Action. Manning Publications, primeira edição. ISBN 1933988312. Citado na pág. 5

Brin e Page(1998) S. Brin e L. Page. The anatomy of a large-scale hypertextual web search engine. Computer Networks and ISDN Systems, 30(1-7):107-117. Citado na pág. 1, 21, 46, 47

Budd(2005) A. Budd. What is web 2.0?. clearleft ltd. http://www.andybudd.com/presentations/ dcontruct05/, Novembro 2005. Último acesso em 04/08/2011. Citado na pág. xv, 5, 6

Cheng e Friedman(2005) A. Cheng e E. Friedman. Sybilproof reputation mechanisms. Em P2PECON '05: Proceedings of the 2005 ACM SIGCOMM workshop on Economics of peer-topeer systems, páginas 128-132, New York, NY, USA. ACM. Citado na pág. 1

Costa(2005) R. Costa. Por um novo conceito de comunidade: redes sociais, comunidades pessoais, inteligência coletiva. Revista Interface - Comunicação, Saúde, Educação, 17. Citado na pág. 7

Cruz(2008) C. C. P. Cruz. Recop: Um modelo para reputação em comunidades de prática. Dissertação de Mestrado, Programa de Pós-Graduação em Informática, Universidade Federal do Rio de Janeiro, Brasil. Citado na pág. 11, 19, 46

Cruz et al.(2007) C. C. P. Cruz, M. T. A. Gouvêa, C. L. R. Motta e F. M. Santoro. A proposal for recognizing reputation within communities of practice. Em CSCWD (Selected Papers)'07, páginas 443-454. Citado na pág. 1, 10, 15, 19, 20

Dellarocas(2004) C. Dellarocas. Building trust online: The design of robust reputation reporting mechanisms for online trading communities, 2004. Citado na pág. 15

Deutsch(1962) M. Deutsch. Cooperation and trust. some theoretical notes, 1962. Citado na pág. 8

Douceur(2002) J. R. Douceur. The sybil attack. Em Revised Papers from the First International Workshop on Peer-to-Peer Systems, IPTPS '01, páginas 251-260, London, UK. Springer-Verlag. Citado na pág. 47, 61

Ellis et al.(1991) C. A. Ellis, S. J. Gibbs e G. Rein. Groupware: some issues and experiences. Commun. ACM, (1):39-58. ISSN 0001-0782. doi: 10.1145/99977.99987. Citado na pág. 6

Fuks et al.(2005) H. Fuks, A. B. Raposo, M. A. Gerosa e C. J. P. Lucena. Applying the 3c model to groupware development. International Journal of Cooperative Information Systems(IJCIS). World Scientific, 14(2-3):299-328. Citado na pág. xv, 6, 7

Fukuyama(1995) F. Fukuyama. Trust: The Social Virtues and the Creation of Prosperity. Free Press, New York, primeira edição. Citado na pág. 7

Gal-Oz et al.(2008) N. Gal-Oz, E. Gudes e D. Hendler. A Robust and Knot-Aware TrustBased Reputation Model. Proceedings of IFIPTM. URL http://www.springerlink.com/index/ c57434x3q187k250.pdf. Citado na pág. 24 
Gerosa(2006) M. A. Gerosa. Desenvolvimento de Groupware Componentizado com Base no Modelo $3 C$ de Colaboração. Tese de Doutorado, Departamento de Informática, Pontifícia Universidade Católica do Rio de Janeiro, Brasil. Citado na pág. 7

Golbeck(2005) J. Golbeck. Computing and Applying Trust in Web-based Social Networks. Tese de Doutorado, Department of Computer Science, University of Maryland, USA. Citado na pág. xv, $5,7,8,9,10,17,18$

Golbeck e Hendler(2006) J. Golbeck e J. Hendler. Inferring trust relationships in web-based social networks. ACM Transactions on Internet Technology, 6. Citado na pág. 8, 15

Gomes(2009) E. A. Gomes. Segurança em aplicações p2p através de reputação inferida de redes sociais. http://edeyson.com.br/Arquivos/Doutorado/Redes\%20Sociais\%20e\%20Aplicacoes\% 20Ubiquas.pdf, 2009. Último acesso em 02/02/2011. Citado na pág. 1, 6, 10, 15

Grudin(1994) J. Grudin. Computer-supported cooperative work: History and focus. IEEE Computer, 27(5):19-26. Citado na pág. 6

Guedes(2007) J. Guedes. Um framework para o cálculo de reputações de agentes de software baseado em testemunhos. Dissertação de Mestrado, Departmento de Informática, Pontifícia Universidade Católica do Rio de Janeiro, Brasil. Citado na pág. 12, 13, 20

IEEE(1990) IEEE. IEEE 90: IEEE Standard Glossary of Software Engineering Terminology. Institute of Electrical and Electronics Engineers, New York. Citado na pág. 13

Jøsang(2010) A. Jøsang. Trust management in online communities. Workshop on New Forms of Collaborative Production and Innovation:Economic, Social, Legal and Technical Characteristics and Conditions-SOFI. Citado na pág. 13

Jøsang e Golbeck(2009) A. Jøsang e J. Golbeck. Challenges for robust of trust and reputation systems, Setembro 2009. Citado na pág. 8, 11, 13

Jøsang et al.(2007) A. Jøsang, R. Ismail e C. Boyd. A survey of trust and reputation systems for online service provision, 2007. Citado na pág. xv, 11, 12

Kamvar et al.(2003) S. D. Kamvar, M. T. Schlosser e H. G. Molina. The eigentrust algorithm for reputation management in $\mathrm{P} 2 \mathrm{P}$ networks. Em Proceedings of the 12th international conference on World Wide Web, WWW '03, páginas 640-651, New York, NY, USA. ACM. ISBN 1-58113-680-3. URL http://dx.doi.org/10.1145/775152.775242. Citado na pág. 22

Kang et al.(1990) K. C. Kang, S. G. Cohen, J. A. Hess, W. E. Novak e A. S. Peterson. FeatureOriented Domain Analysis (FODA) Feasibility Study. Citado na pág. 27

Kazienko et al.(2009) P. Kazienko, K. Musiał e A. Zgrzywa. Evaluation of node position based on email communication. Em Control and Cybernetics, páginas 67-86. Citado na pág. xv, xvii, 23, $34,38,39,51$

Kendall(1948) M. G. Kendall. Rank correlation methods. Griffin, London. Citado na pág. 52

Ludwig et al.(2009) S. A. Ludwig, V. Pulimi e A. Hnativ. Fuzzy approach for the evaluation of trust and reputation of services. FUZZ-IEEE, páginas 20-24. Citado na pág. 38

Lü et al.(2011) L. Lü, Y. Zhang, Ch. H. Yeung e T. Zhou. Leaders in social networks, the delicious case, 2011. Citado na pág. $21,46,51$

Mármol e Pérez(2009) F. G. Mármol e G. M. Pérez. Security threats scenarios in trust and reputation models for distributed systems. Elsevier Computers $\&$ Security, 28(7):545-556. Citado na pág. 22 
Marsh(1994) S. P. Marsh. Formalising Trust as a Computational Concept. Tese de Doutorado, University of Stirling. Citado na pág. xvii, 35, 36

Massa(2005) P. Massa. Page-rerank: using trusted links to re-rank authority. Citado na pág. 34, 66

Massa e Avesani(2004) P. Massa e P. Avesani. Trust-aware collaborative filtering for recommender systems. Em Robert Meersman e Zahir Tari, editors, On the Move to Meaningful Internet Systems 2004: CoopIS, DOA, and ODBASE, volume 3290 of Lecture Notes in Computer Science, páginas 492-508. Springer Berlin Heidelberg. ISBN 978-3-540-23663-4. doi: 10.1007/978-3-540-30468-5_31. URL http://dx.doi.org/10.1007/978-3-540-30468-5_31. Citado na pág. 43

Massa e Avesani(2009) P. Massa e P. Avesani. Trust Metrics in Recommender Systems. Em Jennifer Golbeck, editor, Computing with Social Trust, Human?Computer Interaction Series, chapter 10, páginas 259-285. Springer London, London. ISBN 978-1-84800-355-2. doi: 10.1007/978-1-84800-356-9_10. URL http://dx.doi.org/10.1007/978-1-84800-356-9_10. Citado na pág. 2,63

Masum e Zhang(2004) H. Masum e Y. Zhang. Manifesto for the Reputation Society. First Monday, 9(7). URL http://www.firstmonday.org/issues/issue9_7/masum/index.html. Citado na pág. 61

Michalsky et al.(2010) S. Michalsky, E. Z. S. Mamani e M. A. Gerosa. A inteligência coletiva na web: Uma análise de domínio para o jornalismo online. Simpósio Brasileiro de Sistemas Multimídia e Web (WebMedia 2010), 2:45-48. Citado na pág. 28

Mui e Mohtashemi(2002) L. Mui e M. Mohtashemi. A computational model of trust and reputation. Em In Proceedings of the 35th Hawaii International Conference on System Science (HICSS. Citado na pág. 11

Mui et al.(2002) L. Mui, A. H. e M. Mohtashemi. Notions of reputation in multi-agent systems: A review. Em Proceedings of AAMAS'02, páginas 280-287, Bologna, Italy. ACM. ISBN 1-58113480-0/02/0007. Citado na pág. 11

Musiał et al.(2009) K. Musiał, P. Kazienko e P. Bródka. User position measures in social networks. Em SNA-KDD '09: Proceedings of the 3rd Workshop on Social Network Mining and Analysis, páginas 1-9, New York, NY, USA. ACM Press. Citado na pág. 23, 34, 38

Nguyen et al.(2010) H. T. Nguyen, W. Zhao e J. Yang. A Trust and Reputation Model Based on Bayesian Network for Web Services. IEEE International Conference on Web Services, páginas 251-258. Citado na pág. 38

Nielsen(2009) Nielsen. Global Faces and Networked Placed. disponível online em:, Março 2009. URL http://blog.nielsen.com/nielsenwire/wp discretionary $\{-\}\{\}\{\{$ content/uploads/2009/ 03/nielsen_globalfaces_mar09.pdf. Citado na pág. 1

Oliveira(2010) L. Oliveira. Funcionalidades colaborativas no compartilhamento de conteúdo em redes sociais na web 2.0: Uma engenharia de domínio baseada no modelo 3c de colaboração. Dissertação de Mestrado, Instituto de Matemática e Estatística, Universidade de São Paulo, Brasil. Citado na pág. 27

Oliveira e Gerosa(2010) L. Oliveira e M. Gerosa. Uma engenharia de domínio baseada em padrões de interação e no modelo 3c de colaboração para redes sociais de compartilhamento na web 2.0. Simpósio Brasileiro de Sistemas Multimídia e Web (WebMedia 2010), 2:49-52. Citado na pág. 28

O'Reilly(2005) Tim O'Reilly. O'Reilly Network: What Is Web 2.0, Setembro 2005. URL http: //www.oreillynet.com/lpt/a/6228. Citado na pág. 5 
Pimentel e Fuks(2011) M. Pimentel e H. Fuks. Sistemas Colaborativos. Elsevier Editora Ltda., Rio de Janeiro, primeira edição. Citado na pág. 2, 6

Prieto-Díaz e Arango(1991) R. Prieto-Díaz e G. Arango. Domain analysis concepts and research directions. Domain Analysis and Software Systems Modeling. Citado na pág. 27

Primo(2006) A. Primo. O aspecto relacional das interações na Web 2.0, 2006. URL http://www6. ufrgs.br/limc/PDFs/web2.pdf. Citado na pág. 5

Recuero(2005) R. C. Recuero. Um estudo do capital social gerado a partir das redes sociais no orkut e nos weblogs. Revista FAMECOS, 28. Citado na pág. 6

Resnick et al.(2000) P. Resnick, R. Zeckhauser, E. Friedman e K. Kuwabara. Reputation Systems: Facilitating Trust in Internet Interactions. Communications of the ACM, 43(12). Citado na pág. 11

Segaran(2007) T. Segaran. Programming Collective Intelligence: Building Smart Web 2.0 Applications. O’Reilly, Beijing, primeira edição. ISBN 978-0-596-52932-1. Citado na pág. 5

Shapiro(1987) S. P. Shapiro. The social control of impersonal trust. The American Journal of Sociology, 93:623-658. Citado na pág. 8

Silva et al.(2012) E. M. Silva, D. O. Rodrigues, J. G. de Souza, A. C. Salgado e S. R. Lemos. T-sweets: an alternative to the stimulus collaboration from trust inference in social networks. Anais do IX Simpósio Brasileiro de Sistemas Colaborativos (SBSC) (SBSC'12). Citado na pág. 18, 19

Travassos et al.(2002) G. H. Travassos, D. Gurov e E. A. G. do Amaral. Introdução à engenharia de software experimental. Relatório técnico, Programa de Engenharia de Sistemas e Computação COPPE / UFRJ, São Leopoldo, RS. Citado na pág. 62, 63

Wang e Vassileva(2007) Y. Wang e J. Vassileva. A review on trust and reputation for web service selection. Distributed Computing Systems Workshops, International Conference on, 0:25. ISSN 1545-0678. doi: http://doi.ieeecomputersociety.org/10.1109/ICDCSW.2007.16. Citado na pág. 11,13

Workbench(2011a) Groupware Workbench. Arquigrafia. http://www.arquigrafia.org.br/, 2011a. Citado na pág. 67

Workbench(2011b) Groupware Workbench. Groupware workbench. http://www. groupwareworkbench.org.br/, 2011b. Último acesso em 19/05/2011. Citado na pág. 67

Zhou e Hwang(2007) R. Zhou e K. Hwang. Powertrust: A robust and scalable reputation system for trusted Peer-to-Peer computing. IEEE Transactions on Parallel and Distributed Systems, 18 (4):460-473. ISSN 1045-9219. doi: 10.1109/TPDS.2007.1015. URL http://dx.doi.org/10.1109/ TPDS.2007.1015. Citado na pág. 22 


\section{Índice Remissivo}

análise de domínio, 25, 26

assimetria, 10

cenário de avaliação, 41

composição, 9

conclusões, 63

confiança

definição, 8

propriedades, 8

considerações finais algoritmos, 24, 47

análise de domínio, 30

confiança e reputação, 15

proposta, 39

dataset, 41

distintivos, 27

EigenTrust, 22

estimativa de reputação, 32

estudos, 49

FODA, 25

Groupware Workbench, 65

impacto, 54

interações

de avaliação, 35

de contribuição, 34

karma, 27

Kendall, 50

LeaderRank, 21

modelo 3c

comunicação, 7

cooperação, 7

coordenação, 7

moderação, 27

moderador, 30

NodePosition, 22

PageRank algoritmos baseados em, 21

personalização, 10

proposta, 31

contribuições, 2

mecanismos

de imunidade, 38

objetivos, 2

organização do trabalho, 3

rasultados

robustez contra ataques, 59

ReCoP, 19

redes sociais, 5

REPORT* 20

reputaçao, 10

resource, 13

resultados, 49

comparação da ordenação, 50

diversidade, 49

experimento controlado, 51

tolerância

a ruidos, 54

sistema de confiança, 33

sistema de interação, 34

sistemas colaborativos, 6

sybil attack, 59

T-SWEETS, 18

TidalTrust, 17

trabalhos relacionados, 17

transitividade, 8

TrustExpert, 23

vulnerabilidades

sistemas de reputação, 13

WBSN, 5

Web 2.0, 5 